\title{
Experiments on Sorption Hysteresis of Desiccant Materials
}

\author{
A. Pesaran \\ F. Zangrando
}

August 1984

Prepared under Task No. 1600:22

FTP No. 443

Solar Energy Research Institute

A Division of Midwest Research institute

1617 Cole Boulevard

Golden, Colorado 80401

Prepared for the

U.S. Department of Energy

Contract No. DE-AC02-83CH10093 
Printed in the United States of America Available from:

National Technical Information Service

U.S. Department of Commerce

5285 Port Royal Road

Springfield, VA 22161

Price:

Microfiche A01

Printed Copy A07

\section{NOTICE}

This report was prepared as an account of work sponsored by the United States Government. Neither the United States nor the United States Department of Energy, nor any of their employees, nor any of their contractors, subcontractors, or their employees, makes any warranty, express or implied, or assumes any legal liability or responsibility for the accuracy, completeness or usefulness of any information, apparatus, product or process disclosed, or represents that its use would not infringe privately owned rights. 


\section{PREFACE}

This report documents the test facility, experimental procedure, and experimental results on sorption properties of promising desiccant materials to be used in solar desiccant cooling systems. This research was performed under task 1600.22 of the Solar Desiccant Cooling Program at Solar Energy Research Institute for the U.S. Department of Energy. The authors would like to acknowledge the contribution of Harry Poh1, the laboratory technician, who wi ed the instrumentation and ran the experiments; review comments by Terry Penney, Ken Schultz, and Al Czanderna of SERI, Kirk Crllier of Collier Engineering, and especially Anthony Fraioli of Argonne National Laboratory are appreciated.

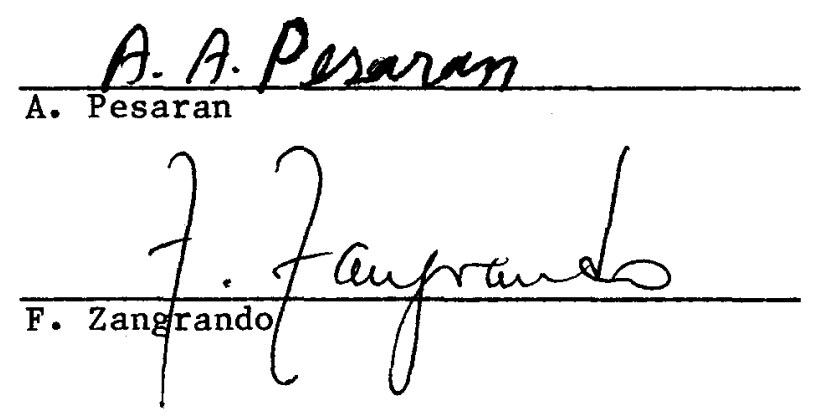

Approved for

SOLAR ENERGY RESEARCH INSTITUTE

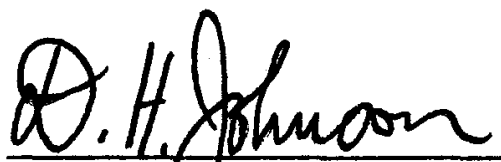

D. Johngor, Acting Chief

Thermal Research Branch

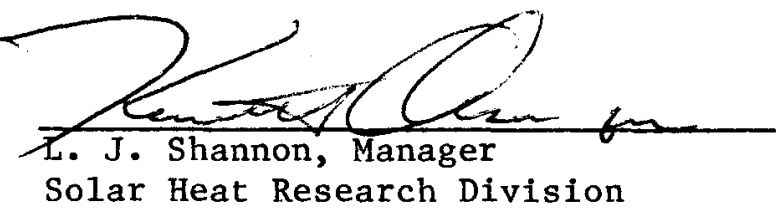




\section{SUMMARY}

\section{Objective}

To develop a test facility to measure the sorption properties of candidate solid desiccant materials under dynamic conditions as well as equilibrium conditions, under different geometrical configurations, and under a broad range of process air stream conditions characteristic of desiccant dehumidifier operation.

\section{Discussion}

The report summarizes the theory of perturbation chromatography and its application to determining sorption properties; describes the test facility, the instrumentation, and its capabilities; describes the test cells used to evaluate the effect of dehumidifier geometry (packed bed and parallel passage) on dynamic performance; and details the methodology used for the dynamic and equilibrium experiments conducted on silica gel.

\section{Conclusions}

The results of experiments conducted on silica gel in various geometries of dehumidifiers for solar cooling are displayed graphically and discussed in terms of dimensionless parameters, which facilitate comparison of the various tests. The dependence of the sorption processes on air velocity and test cell aspect ratio was identified. It was found that with an increase in air velocity and aspect ratio, the rotational speed of a parallel passage dehumidifier wheel should increase. The dynamic hysteresis between adsorption and desorption processes was also identified. The dynamic hysteresis showed fundamental differences between the adsorption/desorption process which has to be accounted for in the modeling to accurately predict dehumidifier performance in solar cooling applications. The experiments provide data on the dynamic performance of silica gel in a parallel-passage configuration, which is under preparation for tests in a rotary dehumidifier that will be conducted at SERI in late FY 1984. The experimental results of the equilibrium tests were in discrepancy with the published data. The possible reasons for this discrepancy were attributed to invalidity of one of the basic assumptions in the theory of isotopic perturbation chromatography for silica ge1-water vapor systems under the experimental conditions of this study. 


\section{TABLE OF CONTENTS}

$\underline{\text { Page }}$

1.0 Introduction $\ldots \ldots \ldots \ldots \ldots \ldots \ldots \ldots \ldots \ldots \ldots \ldots \ldots \ldots \ldots \ldots \ldots \ldots \ldots \ldots \ldots$

1.1 Background...................................... 1

1.2 Purpose of this Study.............................. 3

2.0 Application of Chromatography to Sorption................... 4

2.1 Background...................................... 4

2.2 Perturbation Chromatography......................... 4

2.3 Theory of Perturbation Chromatography.................. 5

3.0 Description of the Experimental Set-Up.................... 8

3.1 Introduction.................................... 8

3.2 Chromatograph Loop................................. 8

3.3 Subsystems.................................... 10

3.4 Instrumentation.................................. 14

4.0 Description of Test Cells............................. 16

4.1 Introduction. ...................................... 16

4.2 Material.......................................... 16

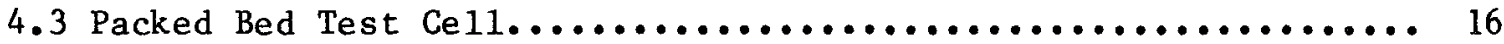

4.4 Parallel Passage Test Cell............................. 16

5.0 Experimental Procedure.............................. 2.1

5.1 Set-Up of Chromatograph Loop......................... 21

5.2 Monitoring of Experiments.......................... 21

6.0 Results and Discussion................................ 23

7.0 Conclusions and Recommendations......................... 42

7.1 Conclusions...................................... 42

7.2 Recommendations and Future Plans...................... 42

8.0 References.......................................... 44

Appendix A - Data Reduction................................ 46

A.1 Equilibrium Data................................ 46

A.2 Breakthrough Data................................ 50

Appendix B - Preparation of Test Cells......................... 57

B.1 Packed Bed Test Ce11.............................. 57

B.2 Para1le1 Passage Test Cel1........................... 57 
TABLE OF CONTENTS (Concluded)

Page

Appendix C - Detailed Operating Procedure....................... 59

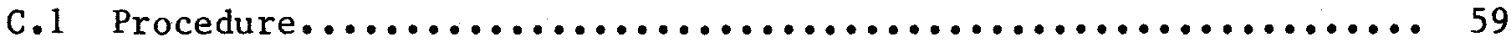

C.2 Preliminary Set-Up............................... 62

C.3 Isothermal Bath for the Gas Bubbler.................... 63

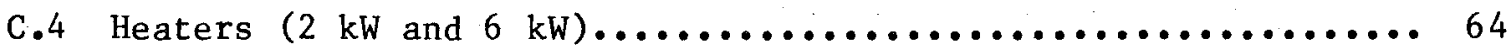

C.5 Thermal Conductivity Power Unit Start-Up................. 65

C.6 Operation of Ultra High Vacuum System................... 66

C.7 Overall Shut-Down Instructions...................... 67

Appendix D - Raw Data.................................... 68

D.1 Samples of Data from Residual Gas Analyzer and Thermal Conductivity Detector.............................. 68

D.2 Breakthrough Data for Each Experiment.................. 68 


\section{LIST OF FIGURES}

Page

1-1 Equilibrium Data for Regular Density Silica Ge1................ 1

3-1 Schematic Diagram of the Improved Experimental Set-Up as Originally Designed................................. 9

3-2 Schematic Diagram of the Chromatograph Loop................... 10

3-3 Schematic Diagram of the Residual Gas Analyzer................. 11

3-4 Schematic Diagram of the Humidifier System.................. 13

3-5 Schematic Diagram of the Injection Subsystem................. 14

4-1 Schematic of the Packed Bed Test Ce11...................... 17

4-2 Schematic of the Parallel Passage Test Ce11................... 18

4-3 Para1le1 Passage Test Ce11s................................ 19

6-1 Typical Breakthrough Data for Adsorption of Water Vapor on Silica Gel in a Paralle1 Passage Geometry (Experiment No 43)............ 25

6-2 Typical Breakthrough Data for Desorption of Water Vapor from Silica Gel in a Parallel Passage Geometry (Experiment No. 44)...... 29

6-3 Repeatability of Breakthrough Data for Experiment Nos. 40 and 42.... 30

6-4 Repeatability of Breakthrough Data for Experiment Nos. 1 and 1R.... 31

6-5 Comparison of Breakthrough Response for Four Humidity Ratio Ranges........................................ 32

6-6 Comparison of Breakthrough Response for Two Humidity Ratio Ranges... 33

6-7 Dependence of Breakthrough Response on Air Velocity for Experiment Nos. 36, 38 and Nos. 37, 39.................... 35

6-8 Dependence of Breakthrough Response on Air Velocity for Experiment Nos. 13R, 21 and Experiment Nos. 11R, 19............ 36

6-9 Dependence of Breakthrough Response on Aspect Ratio............. 37

6-10 Dependence of Breakthrough Response on Isotherma1 Bath Temperature........................................ 39 
LIST OF FIGURES (Concluded)

Page

A-1 Dependence of Thermal Conductivity Detector Output Voltage on Air Humi dity Ratio........................................ 51

A-2 Relation between Output Voltage of Therma1 Conductivity Detector and Air Humidity Ratio............................... 53

D-1 Output of DATAQUAD for the Composition of Inlet Air to the Test Cell before the Breakthrough Part............................... 69

D-2 Output of DATAQUAD after Helium Gas is Injected to the Test Ce11... 70

D-3 Output of DATAQUAD after Injection of $\mathrm{D}_{2} \mathrm{O}$ to the Bypass Column..... 70

D-4 Output of Thermal Conductivity Detector after Start of the Breakthrough Part.................................. 71 


\section{LIST OF TABLES}

Page

1-1 Desiccant Properties and Dehumidifier Efficiency.............. 2

4-1 Test Ce11 Parameters.................................... 20

6-1 Summary of Experimental Parameters........................ 24

6-2 Comparison of Breakthrough Times of Adsorption and Desorption

Experiments....................................... 27

6-3 Summary of Results of Equilibrium Experiments................ 40 


\section{NOMENCLATURE}

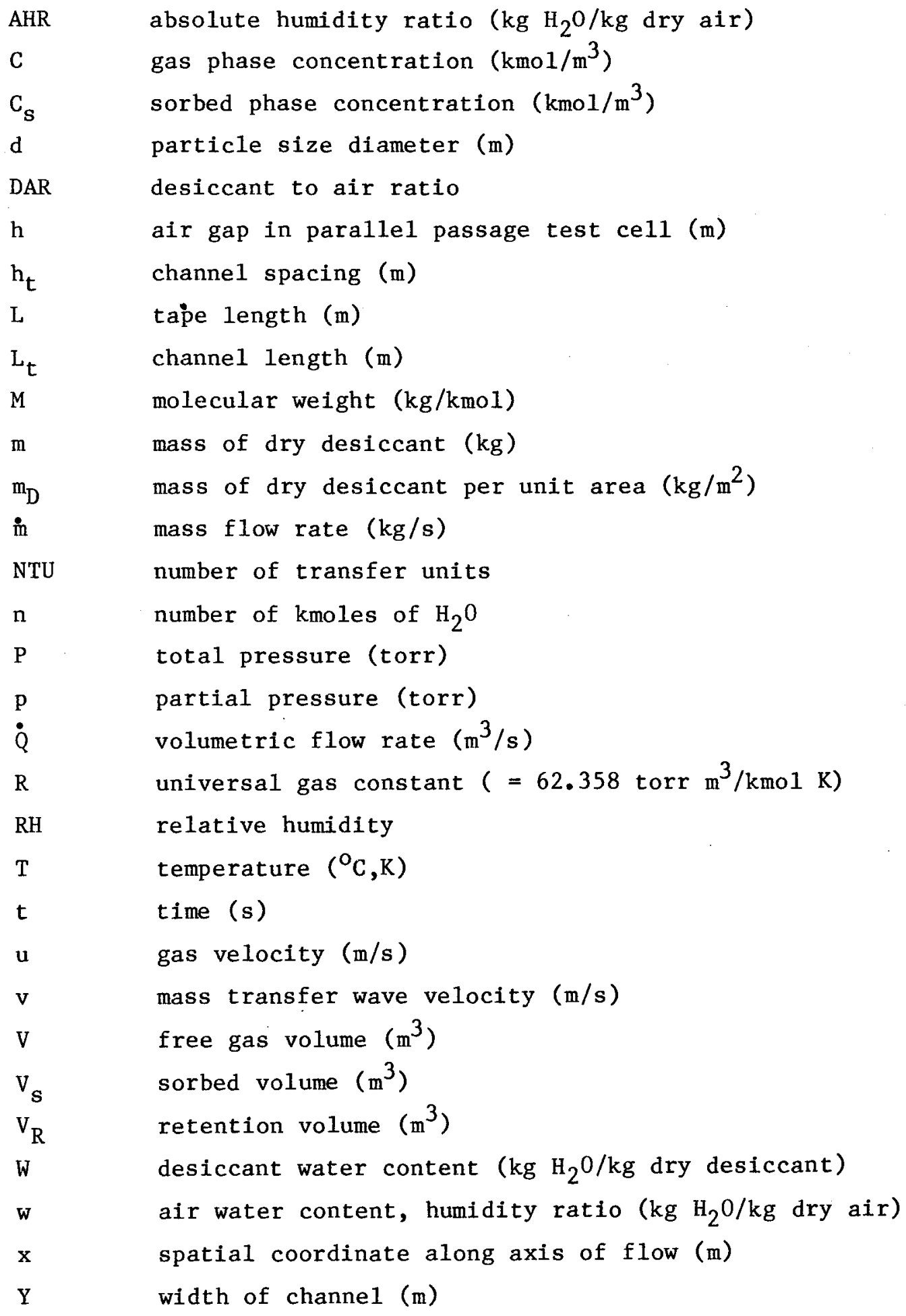




\section{GREEK SYMBOLS}

$\Delta \quad$ difference between two quantities

$\rho$ density $\left(\mathrm{kg} / \mathrm{m}^{3}\right)$

SUPERSCRIPTS

* isotopic tracer $\left(\mathrm{D}_{2} \mathrm{O}\right)$

He helium

SUBSCRIPTS

$\begin{array}{ll}\text { a, air } & \text { air } \\ \text { bp } & \text { bypass } \\ \text { dew } & \text { dew point } \\ f & \text { final value } \\ \text { R } & \text { retention } \\ \text { reading } & \text { flow controller reading } \\ \text { o } & \text { initial value } \\ \text { tc } & \text { test cell } \\ \text { sat } & \text { saturation } \\ \text { total } & \text { total } \\ \text { w, water } & \text { water }\end{array}$




\section{SEPI絭}


SECTION 1.0

\section{INTRODUCTION}

\subsection{BACRGROUND}

Solid desiccant cooling systems, which can take advantage of solar energy, have received considerable attention as an alternative to standard vapor compression systems for air conditioning. The system process involves drying an air stream by passage through a desiccant bed and subsequent evaporative cooling to provide the air conditioning. The desiccant in the dehumidifier is regenerated with hot air provided by energy obtained from either a gas burner or solar collectors $[1,2]$. The thermal performance of the system depends on the efficiency of each component. The technology of all the components except dehumidifiers is reasonably advanced and components with fairly high effectiveness (between 0.9 and 0.95 ) are available; thus the greatest potential for improving system performance lies in the development of advanced, highly effective dehumidifiers. The performance of the dehumidifier is 1imited by the sorption desiccant capacity, sorption properties, and long-term stability under cyclic operation conditions. The sorption processes in the desiccant bed are the passage of a thermal and a mass transfer wave with different diffusivities. Until recently, most of the research on solid desiccants was motivated by industrial adsorption applications involving thick packed beds operating near equilibrium conditions. This resulted in the compilation of physical property data for the most common industrial desiccant materials under equilibrium conditions, yet considerable scatter exists in the equilibrium isotherms in the literature; e.g., $\pm 15 \%$ scatter for silica gel (see Figure 1.1). The much thinner desiccant cooling system dehumidifiers and

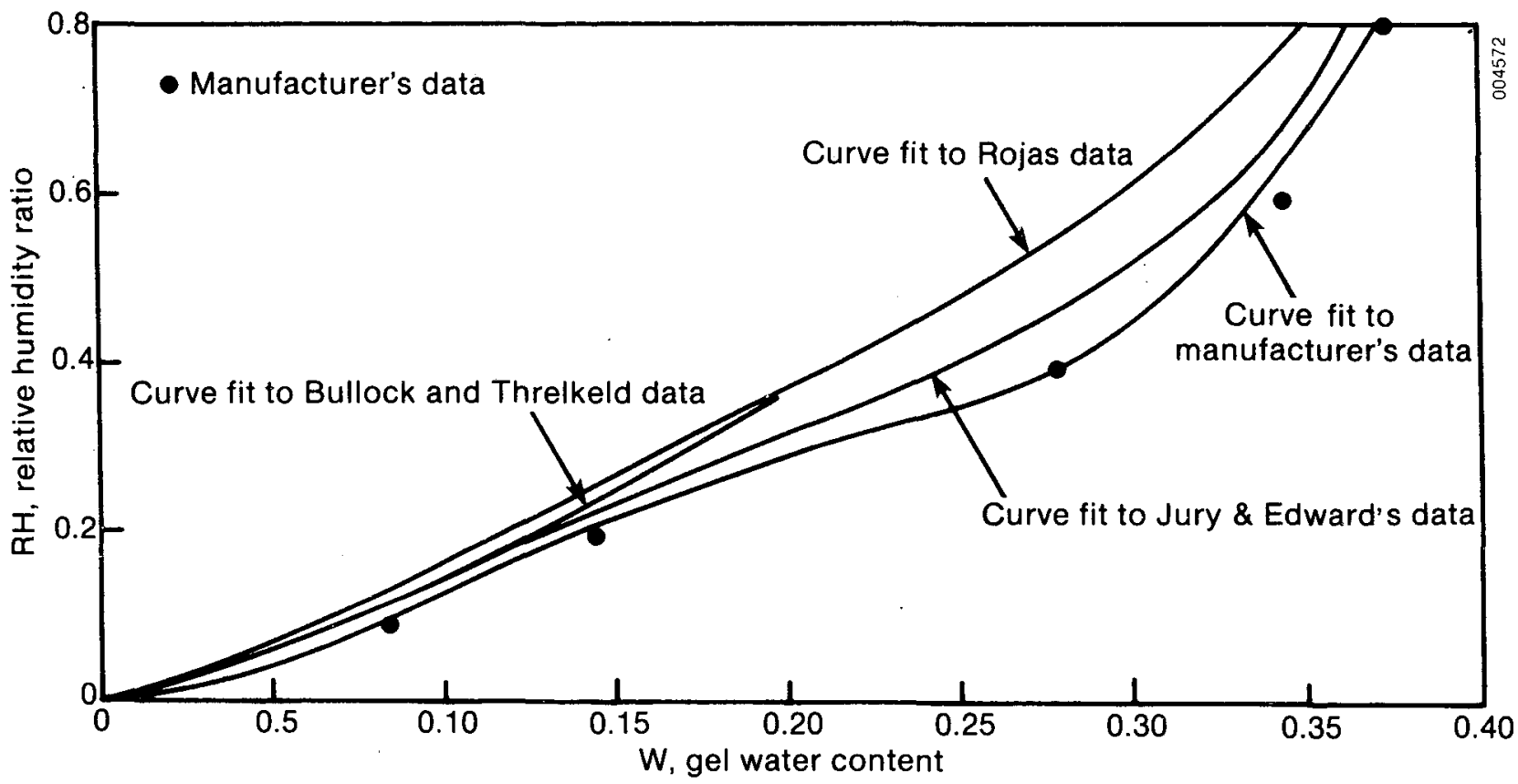

Figure 1-1. Equilibrium Data for Regular Density Silica Ge1 [3] 
the advanced dehumidifier geometries proposed imply that the bed will not operate at equilibrium because only a portion of the mass transfer wave will be contained in the bed.

Two computer models have been developed to predict the performance of dehumidifiers. Barlow [2] developed a pseudo-steady-state model for coupled heat and mass transfer in desiccant dehumidifiers based on heat exchanger effectiveness equations. This model uses lumped gas-side heat and mass transfer coefficient correlations and is based on published equilibrium data of desiccant properties. The model showed good agreement with single-blow adsorption tests, while the agreement was poor for desorption tests, even when different effective transfer coefficients were used for the two processes. Pesaran [3] developed a model at the University of California, Los Angeles, for the Solar Energy Research Institute (SERI) that includes solid-side mass transfer resistance and showed that in packed beds the solid-side resistance controls the transfer process. This model showed an improvement in predicting the adsorption process but an equal discrepancy in predicting the desorption process. These models have shown that performance predictions for thin beds, characteristic of desiccant cooling dehumidifiers, are very sensitive to variations in physical properties and effective transfer coefficients. For example, Table 1-1, adapted from Herzenberg et a1. [4], shows the effect of various silica gel properties on the performance of a dehumidifier. It can be seen that heat of adsorption, isotherm shape, and hysteresis can have a strong

Table 1-1. Desiccant Properties and Dehumidifier Efficiency

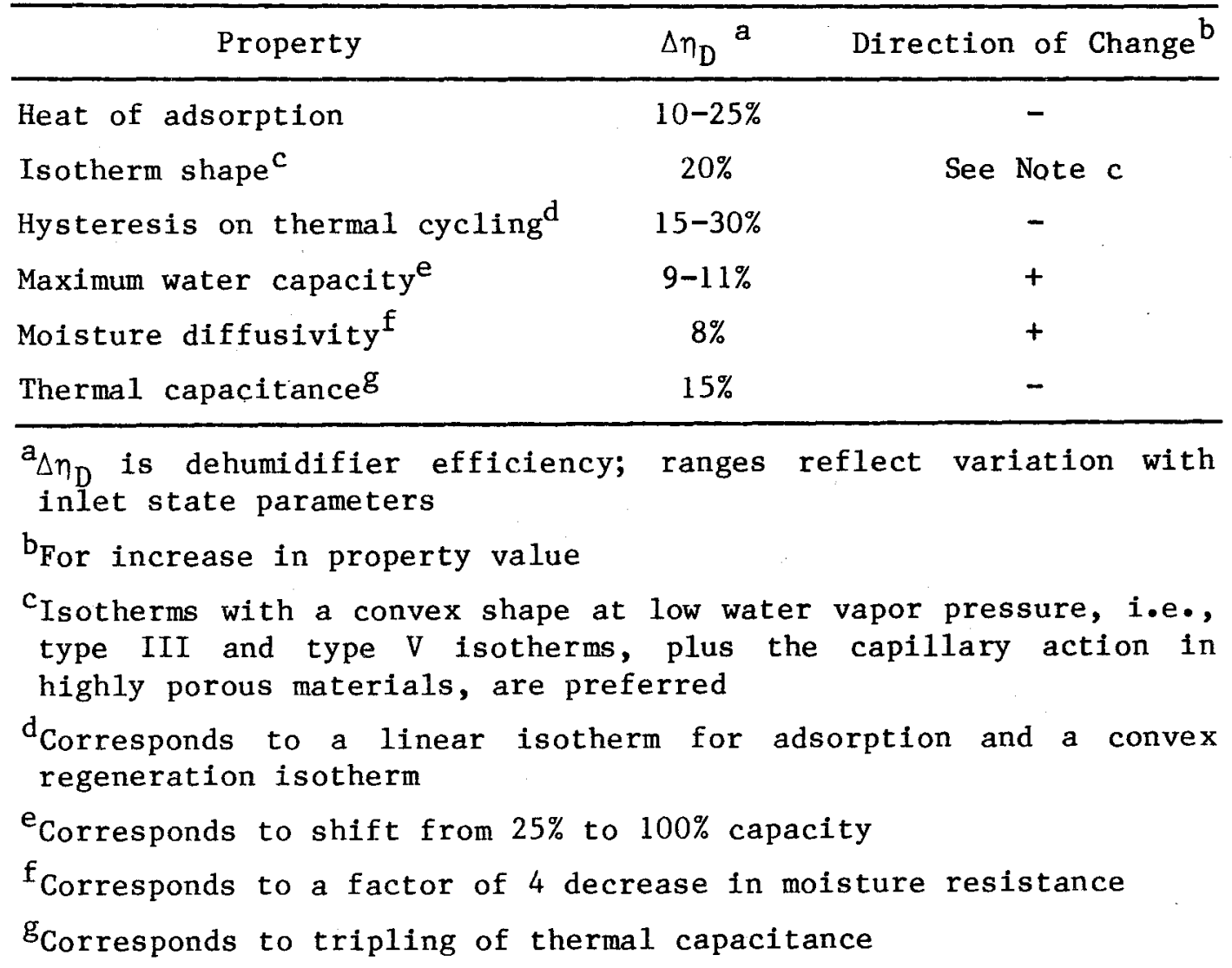


impact on performance. This impact shows the need for accurate knowledge of the sorption properties of the desiccant and to correlate them to dynamic operating conditions in the various geometries being considered for the advanced dehumidifier design [6]. The difference between adsorption and desorption processes as noted by Barlow [2] and Pesaran [3] needs to be investigated under more controlled conditions.

\subsection{PURPOSE OF THIS STUDY}

Our objective has been to develop a versatile test facility to measure the sorption properties of candidate solid desiccant materia1s under dynamic as well as equilibrium conditions and under different geometrical configurations. The chromatograph test facility assembled at SERI allows us to measure dynamic adsorption/desorption characteristics of any promising advanced desiccant material under a broad range of process air stream conditions characteristic of desiccant dehumidifier operation. It also allows us to analyze the effect of various dehumidifier geometries on the dynamic performance of the desiccant. Experimental data obtained will permit us to improve theoretical models of heat and mass transfer processes and dehumidifier performance models.

The first tests conducted in the sorption hysteresis test facility evaluated the dynamic sorption characteristics of silica gel under isothermal conditions and the effect of dehumidifier geometry on the mass transfer process. These tests provide data for a silica gel, parallel-passage dehumidifier that will be tested at SERI in FY 1984 [6]. Future tests will concentrate on characterizing other promising desiccant materials as we11 as on producing basic data on sorption properties at near-adiabatic (instead of isotherma1) conditions, which simulates the operation of actual desiccant dehumidifiers more closely.

The following sections summarize the theory of perturbation chromatography and its application to determining sorption properties; describe the SERI test facility, instrumentation, and capabilities; describe the test cells used to evaluate the effect of dehumidifier geometry on dynamic performance; detail the methods used for the dynamic and equilibrium experiments; discuss the experimental results obtained in the first set of tests conducted in this facility; and summarize future test plans. The methods for data reduction are described in Appendix $A$, the preparation of the test cells is described in Appendix $B$, the detailed operating procedure is described in Appendix $C$, and Appendix D contains the raw data collected at this test facility. 


\section{SECTION 2.0 \\ APPLICATION OF CHROMATOGRAPHY TO SORPTION}

\subsection{BACKGROUND}

Two methods to measure desiccant sorption properties under controlled process air stream conditions of temperature, pressure, and water vapor concentration are the following:

- Gravimetry, whereby a small sample of desiccant is suspended from a microbalance in a chamber and exposed to the process air; direct measurement of the sample mass gives desiccant water content as a function of time.

- Perturbation chromatography, whereby the process air stream flows into a test cell that contains the desiccant material, the air stream interacts with the desiccant, and the concentration of the outlet air stream is monitored as a function of time; the water content of the sample is then calculated from the retention time of an isotopic tracer injected into the test cell.

While gravimetric techniques have very high accuracy, they cannot simulate dehumidifier geometry. Use of these techniques would require correlation with data obtained in tests that can reproduce dehumidifier geometry. Chromatographic techniques are not as direct as gravimetric techniques, require more data reduction, and are generally not as accurate to determine equilibrium conditions, but the test cell can be built to simulate a section of the dehumidifier; therefore, parametric studies can evaluate the effect of dehumidifier geometry and desiccant bonding methods on the dynamic sorption properties, which is why we chose a chromatograph loop for these tests.

\subsection{PERTURBATION CHROMATOGRAPHY}

In a chromatograph loop, a stream of dry process air can either flow directly into the test cell or it can first be humidified to a controlled water vapor concentration. The thermal conductivities of the inlet and outlet streams are compared in a two-chamber thermal conductivity detector. In the adsorption process humid air is introduced into the initially dry test cell, the water is sorbed by the dry desiccant, the air is dried, and the thermal conductivity detector shows a large deviation. As the desiccant becomes loaded with water, the outlet water vapor concentration rises and the deviation decreases. At equilibrium, the inlet and outlet water vapor concentrations match once again and the thermal conductivity detector shows no deviation. The reverse occurs for a desorption process. Therefore, the output of the thermal conductivity cell provides breakthrough data (effluent concentration as a function of time) for the sorption processes, giving sorption rate information. The actual concentration of the outlet stream can be determined from inlet conditions and thermal conductivity correlations, or it can be measured directly, as is discussed in Section 3.0. Once equilibrium is reached in the test ce11, the water content of the desiccant sample can be calculated after measuring the 
retention time of isotopically labeled water vapor injected into the process air stream. This retention time can be obtained by observing the variation in thermal conductivity as the isotope peak passes through the thermal conductivity detector. The water content of the desiccant can be expressed as a function of process stream conditions and retention times. This dependence is derived in Section 2.3 .

\subsection{THEORY OF PERTURBATION CHROMATOGRAPHY}

The following derivation is adapted from Pitts and Czanderna [7]. Consider a gas at water concentration $C(x, t)$ eluting through a test cell containing a desiccant of dry mass $m$ and water content $w(x, t)$. By continuity, the change in water concentration in a section of the test cell is given by the net flux into that section, or

$$
\frac{\partial n}{\partial t}+v \frac{\partial(\mathrm{Cu})}{\partial x}=0
$$

where $\mathrm{n}$ is the total number of moles of $\mathrm{H}_{2} \mathrm{O}$ molecules in the section. Because $\mathrm{n}=\mathrm{C}_{\mathrm{s}} \mathrm{V}_{\mathrm{s}}+\mathrm{CV}$, then by substitution in $\mathrm{Eq} \cdot 2-1$ we have

$$
v_{s} \frac{\partial C}{\partial C} \frac{\partial C}{\partial t}+v \frac{\partial C}{\partial t}+C v \frac{\partial u}{\partial x}+u v \frac{\partial C}{\partial x}=0
$$

Assuming that the process stream velocity in the test cel1, $u$, is constant, then $\partial \mathrm{u} / \partial \mathrm{x}=0$ and $\mathrm{Eq} \cdot 2-2$ can be written as

$$
\frac{\partial C}{\partial t}+\frac{u}{1+\frac{V}{V} \frac{\partial C}{\partial C}} \frac{\partial C}{\partial x}=0 .
$$

Since $C$ is a conserved quantity, the Lagrangian derivative is zero, so we can write the velocity of a perturbation in $\mathrm{C}$ as

$$
\frac{d x}{d t}=\frac{u}{1+\frac{v_{s}}{v} \frac{\partial C}{\partial C}} .
$$

The retention time can be defined as

$$
t_{R}=\frac{V}{\frac{d x}{d t} A}=\frac{v_{R}}{u A},
$$

then

$$
\frac{\mathrm{u}}{\frac{\mathrm{dx}}{\mathrm{dt}}}=1+\frac{\mathrm{V}_{\mathrm{s}}}{\mathrm{V}} \frac{\partial \mathrm{C}_{\mathrm{s}}}{\partial \mathrm{C}}=\frac{\mathrm{V}_{\mathrm{R}}}{\mathrm{V}} .
$$


Rearranging Eq. 2-3 gives

$$
V_{R}=v+V_{S} \frac{\partial C_{s}}{\partial C}
$$

If an isotopic perturbation is introduced into the test cell and its related variables are labeled with an asterisk, then Eq. 2-4 becomes

$$
\mathrm{V}_{\mathrm{R}}^{*}=\mathrm{V}+\frac{\partial \mathrm{C}_{\mathrm{s}}^{*}}{\partial \mathrm{C}^{*}}
$$

Assuming that the sorption process does not distinguish between the labeled and unlabeled water molecules, then

$$
C_{S}^{*}=\frac{C_{s} C^{*}}{C} \text { and } \frac{\partial C_{s}^{*}}{\partial C^{*}}=\frac{C_{s}}{C} \text {. }
$$

Substituting this into Eq. 2-5 yields

$$
\mathrm{V}_{\mathrm{R}}{ }^{*}=\mathrm{V}+\frac{\mathrm{C}_{\mathrm{S}}}{\mathrm{C}}
$$

Substituting the desiccant water content $\left(W=V_{S} C_{s} M_{W} / m\right)$ in the above equation gives

$$
\mathrm{V}_{\mathrm{R}}=\mathrm{V}+\frac{\mathrm{m}}{\mathrm{M}_{\mathrm{W}}} \frac{\mathrm{W}}{\mathrm{C}}
$$

and finally,

$$
\mathrm{W}=\left(\mathrm{V}_{\mathrm{R}}^{*}-\mathrm{V}\right) \frac{\mathrm{M}_{\mathrm{W}} \mathrm{C}}{\mathrm{m}}
$$

In a real experiment, $\mathrm{V}_{\mathrm{R}}{ }^{*}$ cannot be measured directly because there is dead volume, or volume between the test cell and detectors that is not packed. The chromatograph described here uses the bypass method to correct for the dead volume.

The bypass (a short length of empty tubing) and the test cell are attached to a six-port switching valve. The retention volume can be determined by measuring the time it takes the perturbation to propagate through the test cell and through the bypass:

$$
\mathrm{v}_{\mathrm{R}}^{*}=\mathrm{v}_{\mathrm{R}, \mathrm{tc}}^{*}-\mathrm{v}_{\mathrm{R}, \mathrm{bp}}^{*}=\dot{\mathrm{Q}}_{\mathrm{tc}} \mathrm{t}_{\mathrm{tc}}^{*}-\dot{\mathrm{Q}}_{\mathrm{bp}} \mathrm{t}_{\mathrm{bp}}^{*},
$$


therefore

$$
W=\left[\left(\dot{Q}_{t c} t_{t c}^{*}-\dot{Q}_{b p} t_{b p}^{*}\right)-v\right] \frac{M_{w} c}{m} .
$$

The free gas volume, $V$, can be measured by passing a nonreactive gas, such as helium, through the test cell and bypass, thus

$$
\mathrm{V}=\dot{\mathrm{Q}}_{\mathrm{tc}} \mathrm{t}_{\mathrm{tc}}^{\mathrm{He}}-\dot{\mathrm{Q}}_{\mathrm{bp}} \mathrm{t}_{\mathrm{bp}}^{\mathrm{He}} \text {; }
$$

therefore, the desiccant water content becomes

$$
W=\left[\dot{Q}_{t c}\left(t_{t c}^{*}-t_{t c}^{H e}\right)-\dot{Q}_{b p}\left(t_{b p}^{*}-t_{b p}^{H e}\right)\right] \frac{M_{w} C}{m} .
$$

The flow rates and concentration in $\mathrm{Eq} \cdot 2-8$ can be expressed in terms of the equilibrium conditions of the process air prior to injection into the test ce11/bypass section; the derivation of these relations for the SERI chromatograph loop is given in detail in Appendix A.

The measurement of retention time at one temperature and concentration yields one point on a sorption isotherm and is equivalent to measuring the mass gained by a fixed sample of desiccant suspended from a microbalance and exposed to the same air stream conditions.

An isotherm is constructed from retention time data taken at different concentrations; a set of isotherms taken in this manner yields heat of adsorption information, as would be obtained gravimetrically. However, the use of chromatography allows us to evaluate the effect of test cel1 geometry and desiccant bonding techniques on the dynamic and equilibrium properties of the desiccant. 
SECTION 3.0

\section{DESCRIPTION OF THE EXPERIMENTAL SET-UP}

\subsection{INTRODUCTION}

A gas chromatographic sorption apparatus to characterize the sorption properties of desiccants was designed and constructed at the end of 1979 by SERI [7]. The apparatus was modified substantially for the present study. The experimental set-up consists of a chromatograph, support subsystems, and instrumentation. A schematic diagram of the modified experimental set-up is given in Figure 3-1.

The gas reservoir consists of one or more cylinders of compressed, "bone-dry" air (less than 3-ppm water content). The air passes through a two-stage pressure regulator (manufactured by Union Carbide, Linde) and enters a manifold of two mass flow controllers (manufactured by Tylan). These control the air mass flow rate over a wide range and feed the gas into a humidifier to obtain the desired level of water vapor concentration in the process stream. The detail of the humidifier is explained in Section 3.3.3.

The humidified air then passes to a dew point hygrometer sensor (manufactured by General Eastern), which measures and monitors the dew point temperature. The absolute pressure is monitored by a pressure transducer (manufactured by MKS Instrument, Inc.) at this point, and the gas stream is fed into the chromatograph, which is immersed in a constant-temperature bath. Samples of isotopic tracer $\left(\mathrm{D}_{2} \mathrm{O}\right)$ plus air as well as nonadsorbing gas (helium) can be injected into the desiccant test cell via a 10-port switching valve V2 (Figures 3-2 and 3-5). The details of the chromatograph and support subsystems are described in this section.

\subsection{CHROMATOGRAPH LOOP}

The chromatograph, shown in detail in Figure 3-2, consists of a thermal conductivity detector (D), three switching valves (V1, V2, V3), two sample loops $(\mathrm{S} 1, \mathrm{~S} 2)$, a bypass loop (bp), and the test cell (tc) containing a desiccant. The flow first enters a six-port switching valve (V1), which provides either the process stream, i.e., air and water vapor ( $V l$ in primary position), or bone-dry air ( $\mathrm{Vl}$ in secondary position). The flow enters the first loop of a thermal conductivity detector, then goes to a 10-port switching valve containing 2 sample loops for the injection of isotopic tracer (heavy water, $\mathrm{D}_{2} 0$ ) or a nonadsorbing gas (helium). Next, the flow passes through another sixport switching valve, which contains the desiccant test cell and the bypass loop. The stream emerges from the test cell (V3 in primary position) or bypass (V3 in secondary position) and passes through the second loop of the thermal conductivity detector. At this point, the pressure drop across the chromatograph 10op is measured using a differential pressure transducer (manufactured by MKS Instrument, Inc.). Then the process stream passes through an exhaust manifold where needle valves control the pressure maintained in the line at any given flow rate. A small portion of the process stream is then injected into the vacuum chamber of the residual gas analyzer for analysis. 


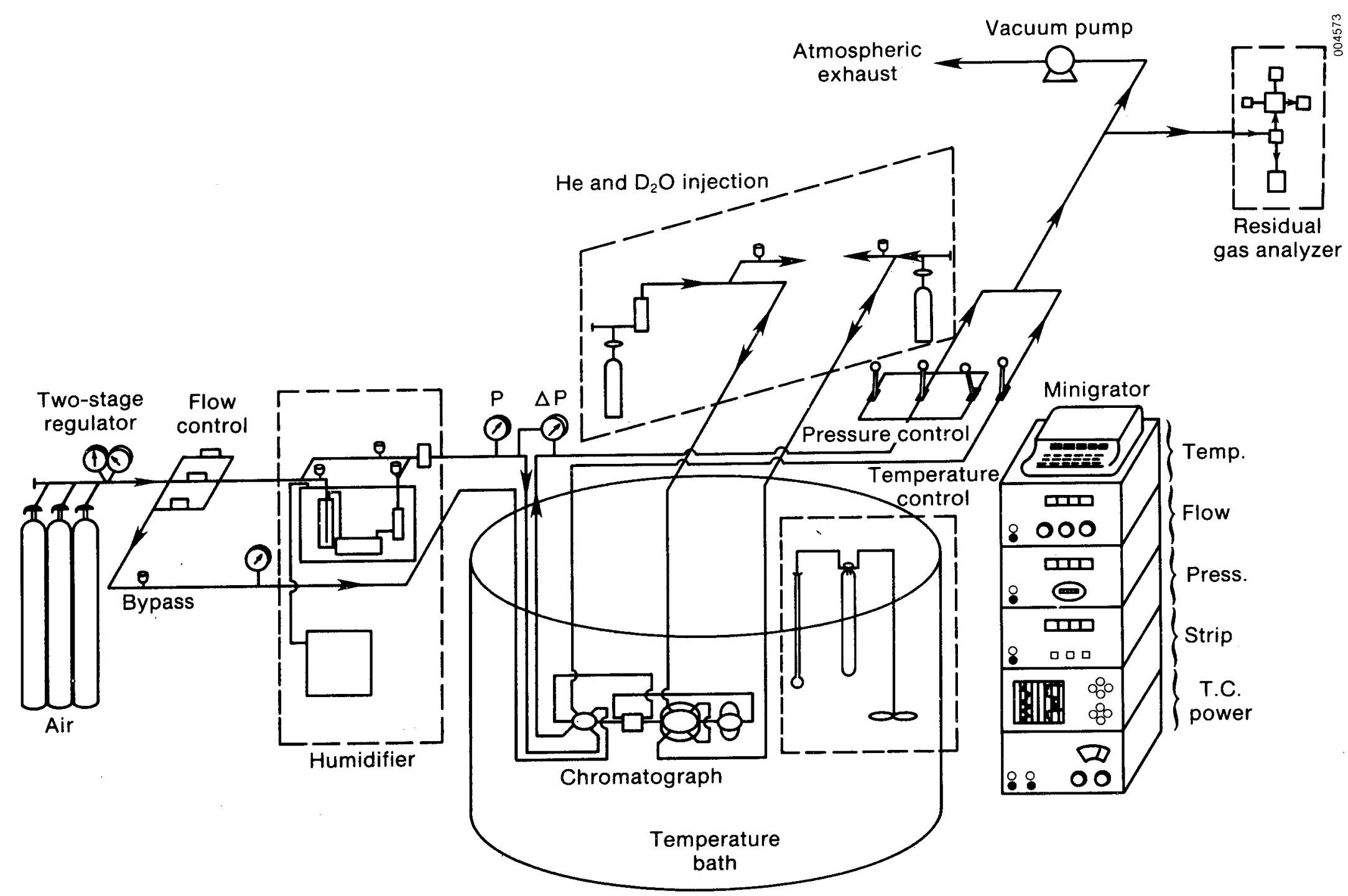

Figure 3-1. Schematic Diagram of the Improved Experimental Set up as Originally Designed [7] 


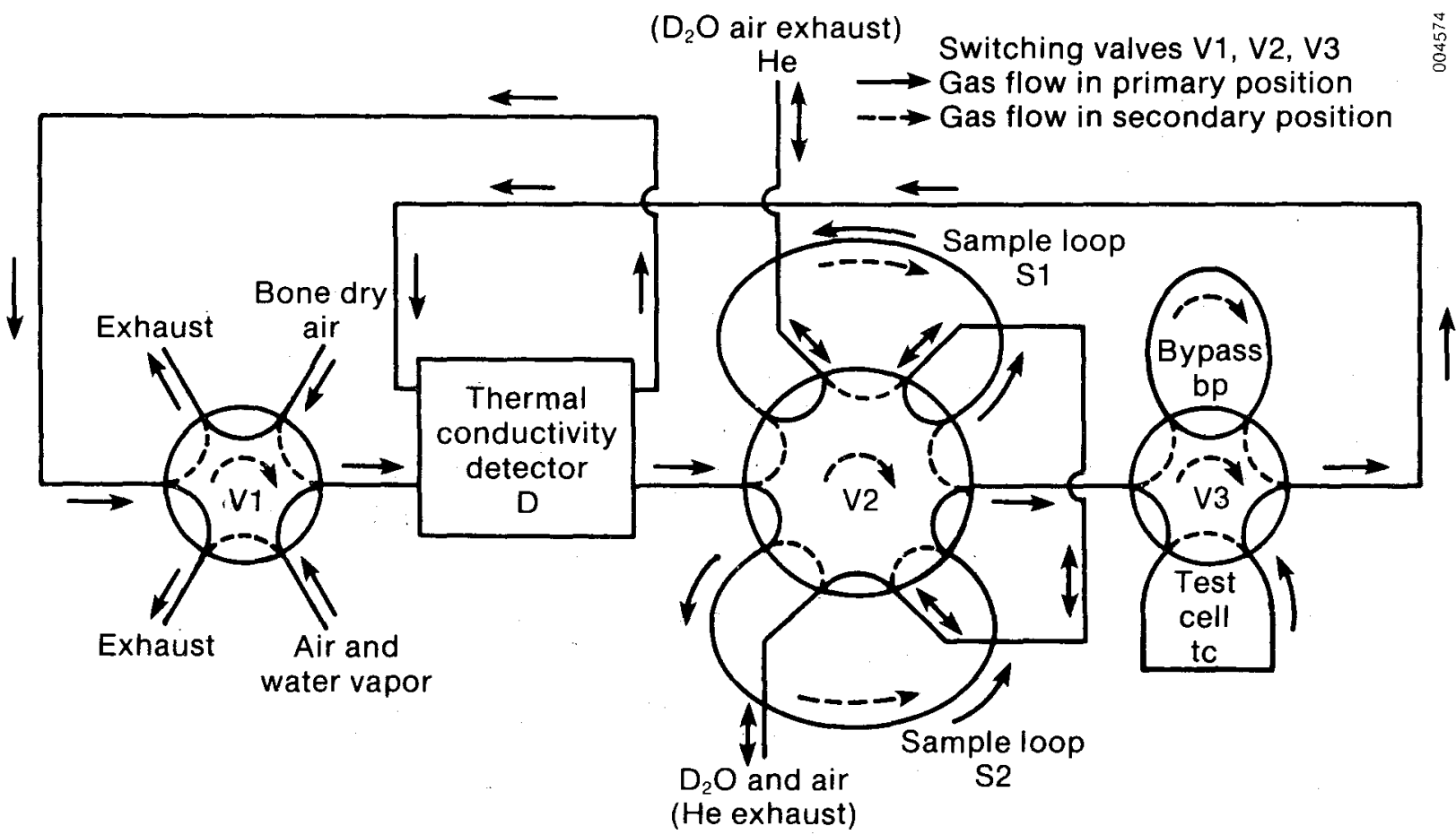

Figure 3-2. Schematic Diagram of the Chromatograph Loop

Finally, the stream passes to a vacuum pump, through an atmospheric exhaust, and then outside the building.

\subsection{SUBSYSTEMS}

\subsubsection{Constant-Temperature Bath}

This subsystem consists of a 40-gal stainless steel tank filled with deionized water, a $2-\mathrm{kW}(110-\mathrm{V})$ heater, three $6-\mathrm{kW}(480-\mathrm{V})$ heaters, two temperature controllers, a compressed air driven mixer (manufactured by Mixing Equipment Co.), and a hydraulic scissor jack (manufactured by American Manufacturing Co.). The heaters are supported on a platform that also will act as a cover for the tank when it is raised by the jack. The $6-\mathrm{kW}$ heaters act as boost heaters to speed up the process of raising the water temperature. When the temperature of the bath reaches within $1^{\circ}$ to $2^{\circ} \mathrm{C}$ of the final desired bath temperature, the temperature controller (manufactured by White-Rodgers) turns off the heaters. Through a thermistor-operated proportional temperature controller (manufactured by Yellow Springs Instruments), the 2-kW heater provides the required power to compensate for the heat losses from the tank to maintain a stable bath temperature. For temperatures below ambient, a recirculating cooler (manufactured by Neslab) is used.

\subsubsection{Residual Gas Analyzer}

This subsystem consists of an ultra high vacuum chamber, a pumping unit, a gas inlet valve, a forepump, and a capillary tube (all manufactured by Balzers), 
several heating tapes, a quadrupole mass analyzer (manufactured by Spectrum Scientific Limited), and an associated mass spectrometer (DATAQUAD, manufactured by Spectrum Scientific Limited). The pumping unit consists of a turbomolecular pump to obtain ultra high vacuum, a rotary vane pump for backing, and the control electronics. The vacuum in the chamber is measured by a vacuum gauge controller $\left(10^{-9}\right.$ to $10^{-4}$ torr) and a convection vacuum gauge ( $10^{-4}$ to $10^{3}$ torr) (manufactured by Granville-Phillips). A schematic set-up of this subsystem is given in Figure 3-3.

The pumping unit removes the air and other gases from the vacuum chamber. The surface of the chamber is kept at $80^{\circ}$ to $100^{\circ} \mathrm{C}$ to prevent adsorption of molecules to the interior surface and to have a lower vacuum. The pumping unit reduces the vacuum in the closed chamber to $10^{-9}$ to $10^{-8}$ torr. The quadrupole mass analyzer emits electrons, which ionize the molecules and atoms in the chamber. The ionized gases in the chamber move toward the quadrupole, which measures the intensity (proportional partial pressure) of each ionized molecule based on its mass to charge ratio. The mass spectrometer (DATAQUAD) shows the results of the quadrupole analysis. DATAQUAD controls the range of mass to charge ratio and the analysis rate of the quadrupole.

When the vacuum reaches its lower limit of $10^{-9}$ to $10^{-8}$ torr, DATAQUAD is set to analyze the gas in the chamber, which of ten is referred to as BACKGROUND. A small portion of the process gas is sampled through the heated capillary into the vacuum chamber by opening the gas inlet valve. A forepump draws the sample into the vacuum chamber at a fast rate $(0,28 \mathrm{~L} / \mathrm{s})$. The operating vacuum for analysis of a sample is usually from $10^{-7}$ to $10^{-5}$ torr. The process gas is analyzed and the background analysis is subtracted from this analysis to find the true partial pressure of each mass to charge ratio.

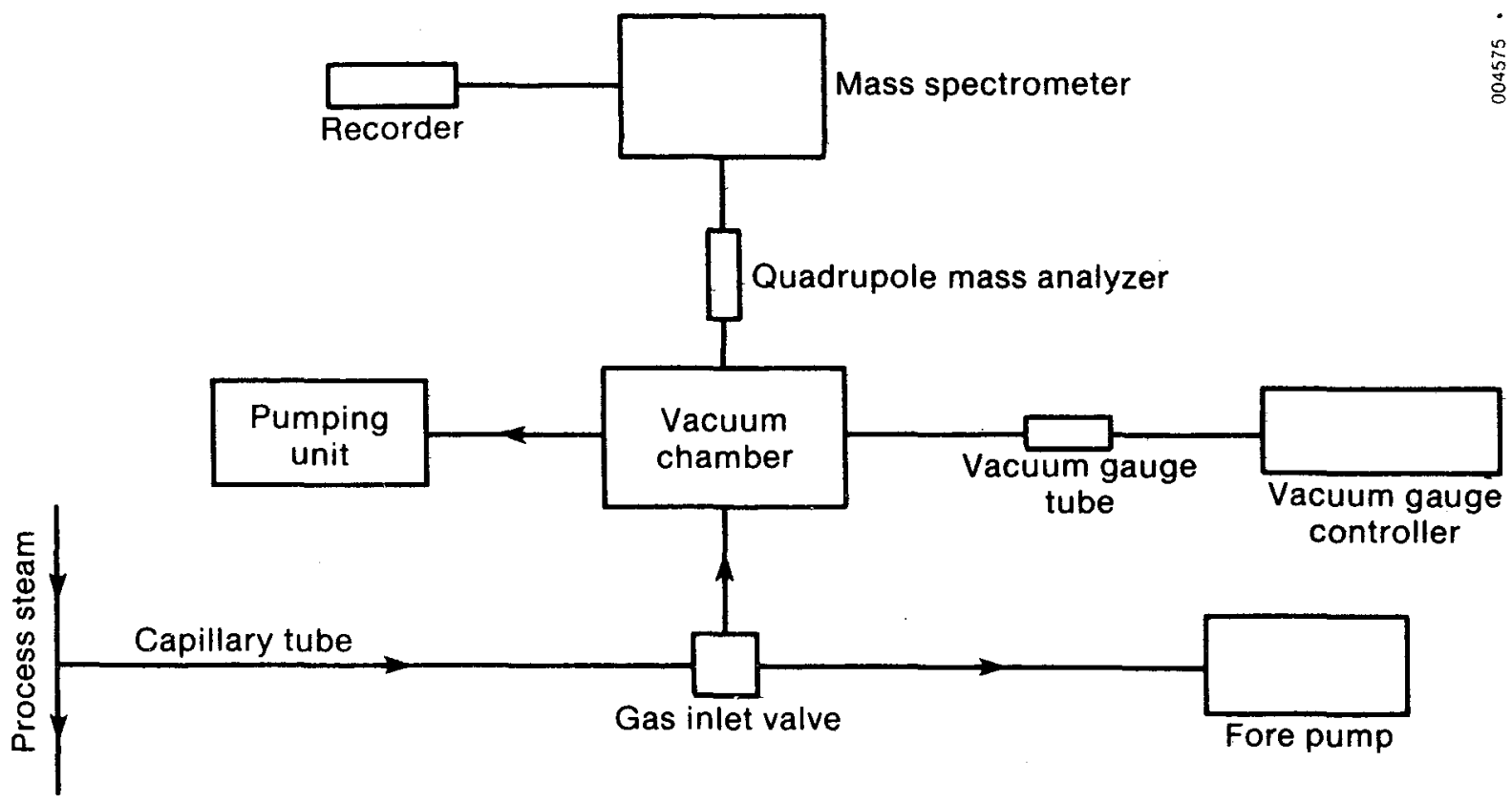

Figure 3-3. Schematic Diagram of the Residual Gas Analyzer 
DATAQUAD also can monitor the partial pressure of one specific mass to charge ratio continuously (when in TREND ANALYSIS mode), which is a desirable feature for transient experiments.

\subsubsection{Humidifier}

The humidifier is used to provide different, but uniform, humidity ratios to the chromatograph loop. This subsystem consists of a 12-gal isothermal bath (manufactured by Tamson), a recirculating cooler (manufactured by Neslab), a gas bubbler, a trap, and a mist eliminator. A schematic of the humidifier is given in Figure 3-4. Bone-dry air flows through the bubbler, which is a closed stainless steel cylinder $(0.15-\mathrm{m}$ height and $0.04-\mathrm{m}$ diameter), where the air comes into contact with deionized water. The air becomes saturated with water vapor at a desired temperature when leaving the bubbler. A large mass transfer surface area is required to accomplish this task, therefore a $(10-\mu)$ sparger (porous meta1) is used in the bubbler to break the air into fine bubbles ( $1-\mathrm{mm}$ diameter). The saturated air then goes into the trap where any carry-over water is separated from the air and then enters into the mist eliminator where very fine droplets of water are captured. The trap is an empty, closed Plexiglass ${ }^{R}$ cylinder $(0.30 \mathrm{~m}$ length and $0.07 \mathrm{~m}$ diameter). The mist eliminator is a stainless steel cylinder $(0.1 \mathrm{~m}$ length and $0.02 \mathrm{~m}$ diameter) filled with micron-size stainless screen for capturing the fine droplets. The saturated air, which does not have any entrained droplets, goes to the chromatograph loop through a dew point sensor and an absolute pressure transducer. The humidity ratio of the inlet air to the chromatograph loop can be calculated at this point (see Appendix A). The isothermal bath provides a uniform temperature environment for the bubbler, trap, and mist eliminator; the recirculating cooler provides a stable temperature in the isothermal bath for temperatures below ambient temperature. Note that the parameters that control the inlet humidity ratio to the chromatograph are this isothermal bath temperature and the pressure in the system. Different inlet humidity ratios can thus be obtained for different experiments by setting both the pressure and the isothermal bath temperature at desired values.

\subsubsection{Isotope and Helium Injection Subsystem}

This subsystem consists of helium (He) and bone-dry air cylinders, a small chamber for mixing air and isotopic water vapor $\left(D_{2} 0\right)$, a 10-port switching valve (V2) with two sample loops ( $1, S 2)$, and several valves for purging and cutting off. The schematic diagram of the injection subsystem is given in Figure $3-5$.

When the process air is passing through one sample loop, the other loop can be loaded with He or $\mathrm{D}_{2} \mathrm{O}$ and air. Helium can be loaded by opening valves LV3 and LV5 while the other valves are closed. $\mathrm{D}_{2} \mathrm{O}$ and air can be loaded by opening valves LV1, LV2, and LV4. The sequence of opening and closing of these valves is explained in detail in Section 5.0. For injection of the $\mathrm{D}_{2} \mathrm{O}$ (or He) we switch the position of 10-port valve (V2) after loading of $\mathrm{D}_{2}{ }^{\mathrm{O}}$ (or $\mathrm{He}$ ) is completed. 


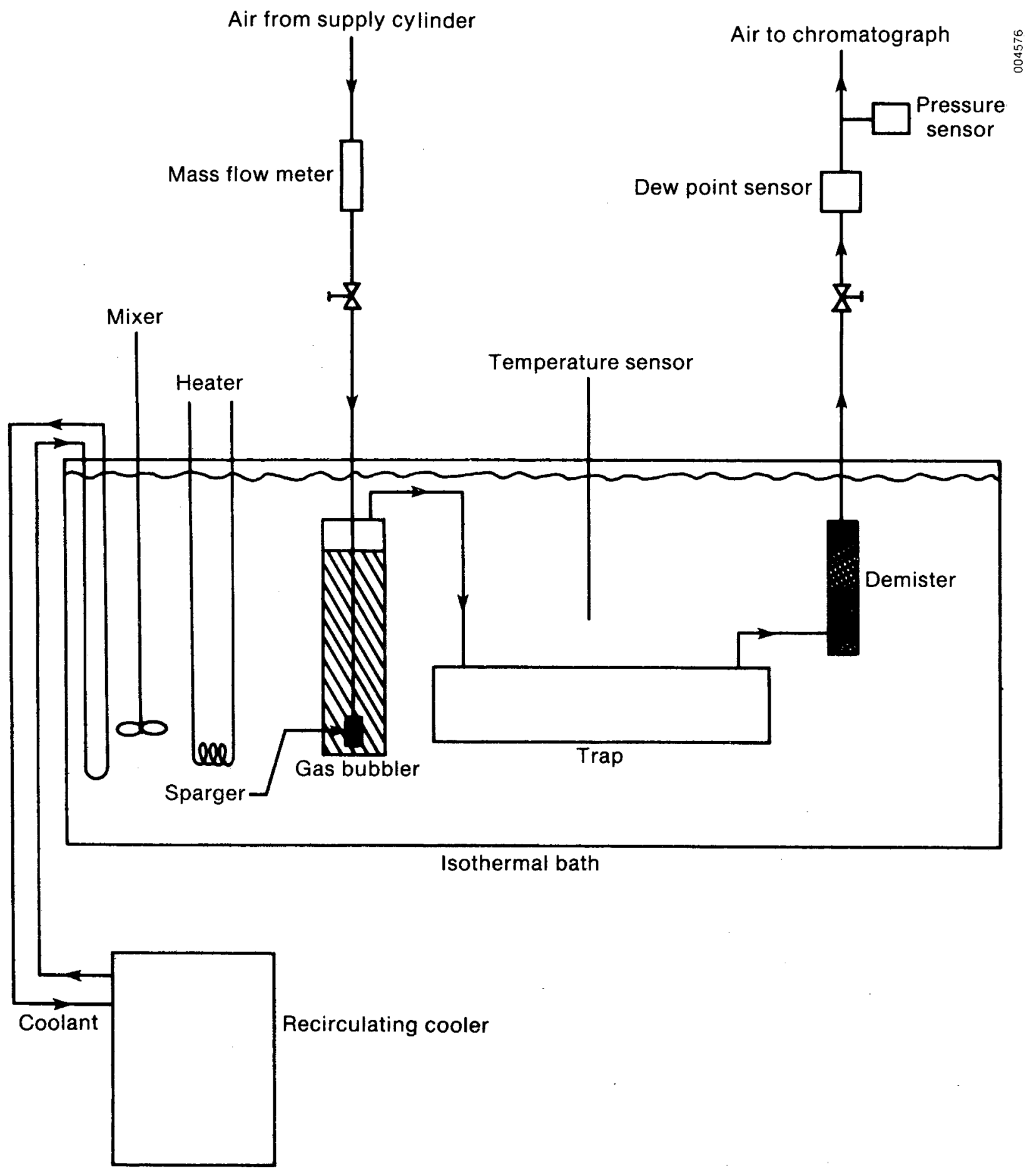

Figure 3-4. Schematic Diagram of the Humidifier System 


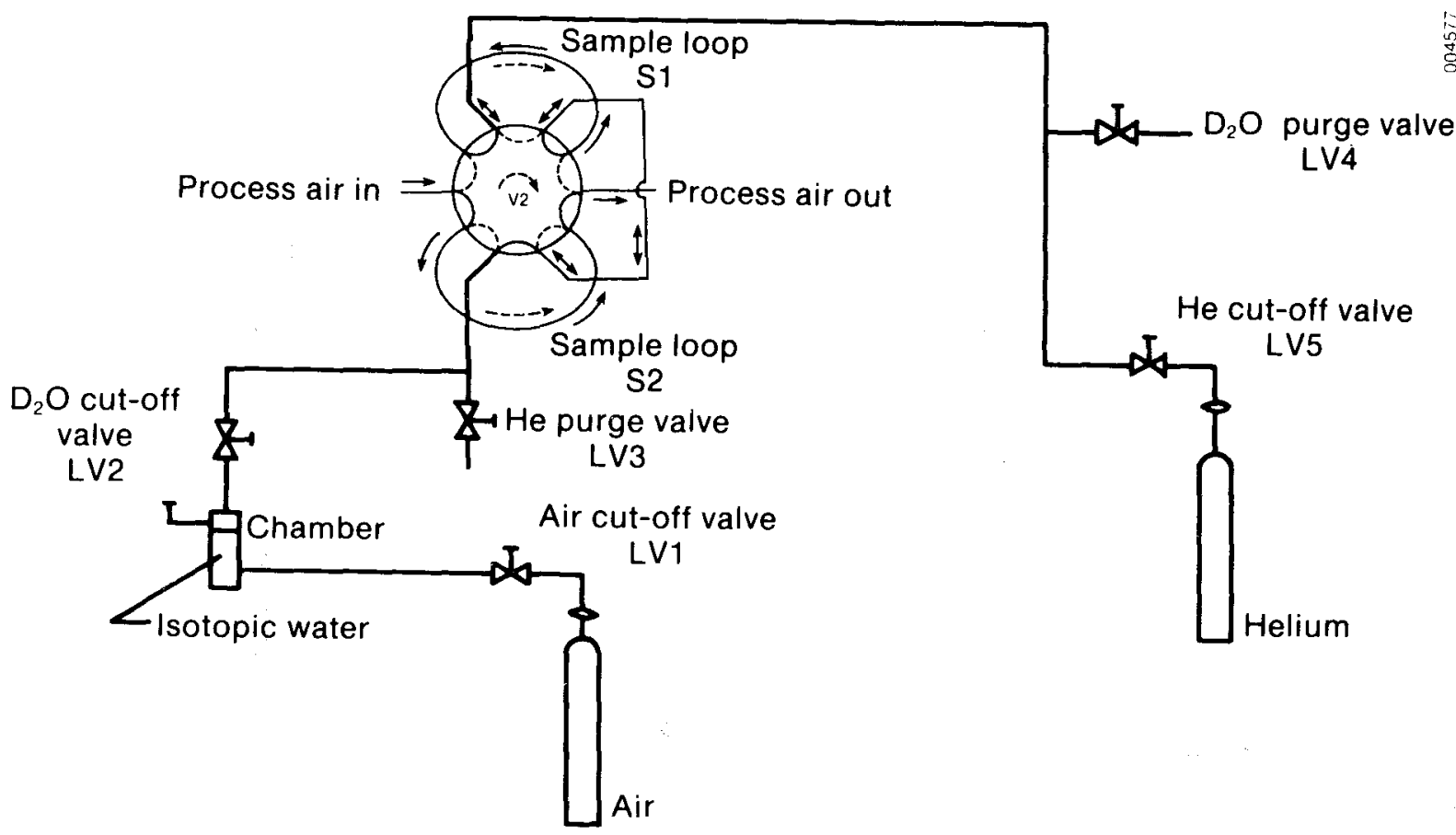

Figure 3-5. Schematic Diagram of the Injection Subsystem

\subsection{INSTRUMENTATION}

The mass flow rate of air through the system is measured by two Tylan mass flow controllers of different range $\left(10-500 \mathrm{~cm}^{3} / \mathrm{min}\right.$ and $\left.400-20,000 \mathrm{~cm}^{3} / \mathrm{min}\right)$. The reading of the mass flow controller is the volumetric flow rate at standard conditions $\left(1 \mathrm{~atm}, 0^{\circ} \mathrm{C}\right)$, Qreading. The absolute pressure and pressure drop across the test cell are measured by an MKS absolute pressure transducer (0-1000 torr) and an MKS differential pressure transducer (0-1000 torr), respectively. Al1 temperatures are measured using a copper-constantan (type T) thermocouple. The humidity ratio (or water vapor concentration) of process air upstream of the test cell is measured by a General Eastern optical condensation dew point hygrometer. The composition of process air downstream of the test cell is measured by a residual gas analyzer. However, because of a long dead volume between the test cell and the vacuum chamber of the gas analyzer, the response of the analyzer is not fast enough for breakthrough experiments. The residual gas analyzer measures accurately the composition of process air at the start of the breakthrough experiment and when the breakthrough is finished (when the test cell has reached its equilibrium state). For breakthrough tests, GOW-MAC thermal conductivity detectors measure the relative conductivity of effluent air stream to inlet process stream.

A thermal conductivity detector is made of a block of metal with two cavities and two electrical resistances (filaments) in the cavities. The process air first passes through one of the cavities and then to the test cell. After exchange of water vapor in the test cell, the air passes through the other cavity. The filaments are electrically heated, and heat transfers from the filaments to the process air. The rate of heat transfer and thus the 
temperature of the filaments depend on flow rates, temperature, pressure, and thermal conductivity of the process air. The resistance of the filament strongly depends on its temperature. When the same process air (pressure, temperature, flow rate, and thermal conductivity) passes through both cavities of the thermal conductivity detector, the resistances of the filaments are equal and the thermal conductivity detector is "balanced." The thermal conductivity of process air depends on its composition (water vapor concentration). When process air of different composition passes through the two cavities of the detector, the resistances of the filaments are not equal, and thus the detector is not balanced. The degree of deflection from balance is a measure of the difference between the compositions of process air going through the two cavities. Knowing one composition, the deflection from balance, and calibration curve, one can measure the other composition. Usually, the deflection is measured in volts, which are linearly proportional to concentration (see Ref. 8 and Appendix A).

Injection of $\mathrm{D}_{2} \mathrm{O}$ (or He) through the test cell (or bypass) changes the thermal conductivity detector of air and thus the deflection of the therma 1 conductivity detector, so thermal conductivity can be used for perturbation studies. The residual gas analyzer is also used for detection of $\mathrm{D}_{2} \mathrm{O}$ (or He) for perturbation studies.

The output signals of all sensors, i.e., thermocouples, pressure transducers, dew point hygrometers, and thermal conductivity detector, are collected by an interface data acquisition system (HP-3497A) and a desk computer (HP-85) at a preprogrammed time interva1. The data are then recorded by a printer (EPSONMX80) or stored on a cartridge. The output signal of the thermal conductivity detector is also recorded on a strip chart recorder (Gould-110) for visual observation. 
SECTION 4.0

\section{DESCRIPTION OF TEST CELLS}

\subsection{INTRODUCTION}

Two different configurations of test cells were designed and constructed for the sorption hysteresis studies: packed bed and parallel passage. The packed bed test cell was used to obtain equilibrium data of the desiccant materials and to compare the data with published values. The packed bed experimental data were also used as a reference base for results obtained with the parallel passage geometry to find the effect of adhesive and filling materials on adsorption capacity. The parallel passage test cell simulates one of the channels of the SERI parallel passage dehumidifier, which has the largest heat transfer to pressure drop ratio among the available dehumidifier geometries. Both packed bed and parallel passage test cells are described in detail in this section. Preparation of the desiccant material selected for experimentation is also described.

\subsection{MATERIAL}

The desiccant material used in this study is silica gel (Davison, Grade 40), since silica gel has been recommended in solar desiccant cooling applications $[1,9]$ because of its high moisture recycling capacity in the temperature range available from solar collectors. The size of this gel as provided by the manufacturer is mesh 6-12 (1.4-3.4-mm particle diameter), but finer particles (0.1-0.5 mm) were used in the SERI parallel passage dehumidifier to have minimal diffusional resistance in the particles. The larger gel was ground and sieved to produce two batches of finer particles with a narrower range of distribution: mesh 45-60 (0.3- $\mathrm{mm}$ average particle diameter) and mesh 60-80 $(0.2-\mathrm{mm}$ average particle diameter). No significant changes in sorption capacity of silica gel are expected from the grinding, since the internal pore volume of the gel that primarily determines the sorption capacity has not changed.

\subsection{PACKED BED TEST CELL}

The packed bed test cell is made of $3.2-\mathrm{mm}\left(1 / 8-\mathrm{in}_{\bullet}\right) 0 . \mathrm{D}$. stainless tubing with $0.5-\mathrm{mm}\left(0.02-i \mathrm{n}_{\text {. }}\right)$ wall thickness and packed with small particles of desiccant material (e.g., mesh 45-60, Davison Grade 40 silica ge1). The packing length is about $0.1 \mathrm{~m}$ ( $4 \mathrm{in}$ ), and glass wool plugs are used to support the particles. A schematic of the packed bed test cell is shown in Figure 4-1. The masses of the dry empty test cell and dry packed test cell are measured to obtain the mass of dry desiccant used in the test cells. See Appendix $\mathrm{B}$ for the details for preparing packed bed test cel1s.

\subsection{ParalleL PASSAGe TEST CELL}

The SERI parallel passage dehumidifier is composed of parallel channels of double-sided $\operatorname{Mylar}^{\mathrm{R}}$ (polyester) tapes on which fine particles of silica gel 


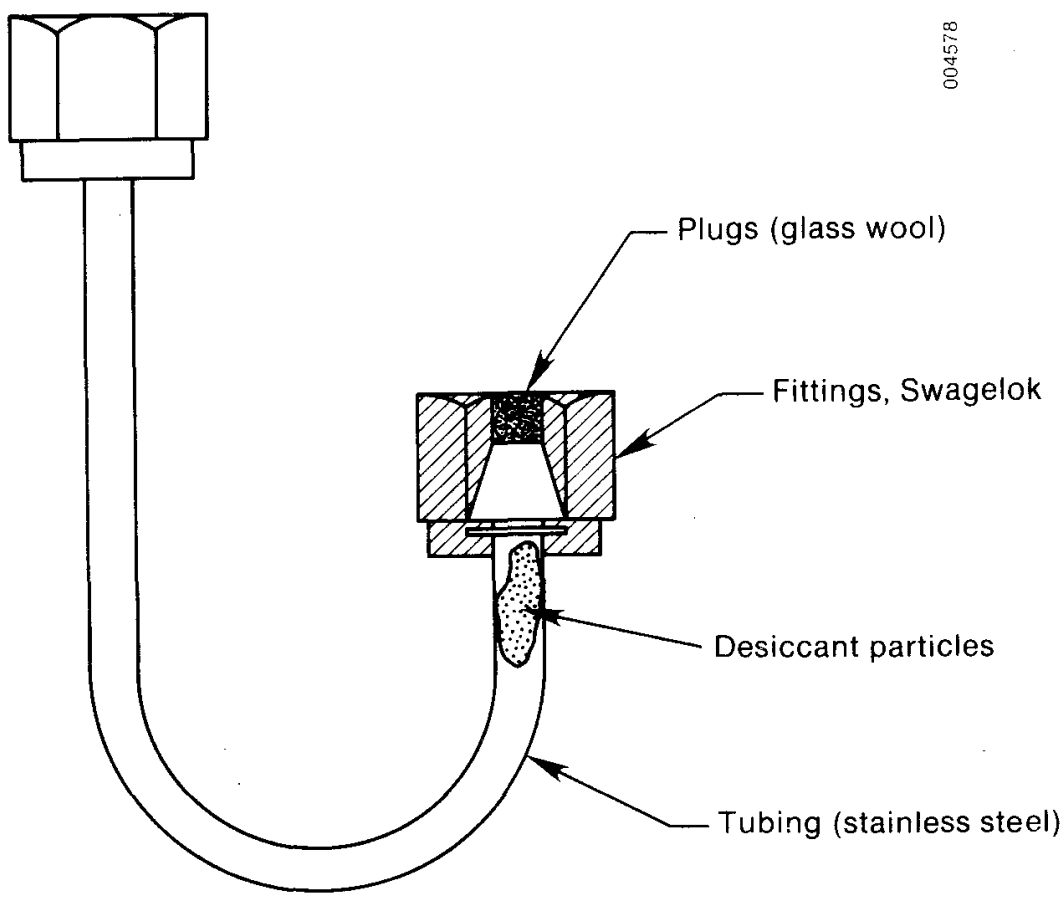

Figure 4-1. Schematic of the Packed Bed Test Ce11

are impregnated. To simulate this configuration in the chromatograph loop, two test cells were designed and then constructed at the SERI machine shop. Each test cell was fabricated from two Lexan ${ }^{R}$ (polycarbonate) sheets machined so that when they are fastened together a parallel passage is formed as shown in Figure 4-2. Lexan ${ }^{R}$ was chosen for its good thermal and physical properties and ease of fabrication. Appropriate sizes of double-sided Mylar ${ }^{\mathrm{R}}$ tape were glued to the walls of the passage. Fine particles of silica gel were sprinkled on the Mylar ${ }^{\mathrm{R}}$ tape to form one layer of silica gel particles. The weight of dry silica gel used in the test cell was calculated by weighing the dry test cell with and without silica gel. See Appendix B for details of these measurements and preparation of the parallel passage test cell for experiments. The width $(\mathrm{Y})$ of the passage is $0.02 \mathrm{~m}$. The total length $\left(\mathrm{L}_{\mathrm{t}}\right)$ of the channel is $0.2 \mathrm{~m}$. The length of the tapes (L) can be varied so that different aspect ratios $(\mathrm{h} / \mathrm{L})$ can be obtained consistent with our test plan [5]. Two parallel passage test cells with two different channel spacing $\left(h_{t}=3\right.$ and $1.7 \mathrm{~mm}$ ) were constructed. The actual flow passage ( $h$ ) depends on $h_{t}$, the thickness of the Mylar ${ }^{R}$ tape ( $\delta$ ), and particle size (d), where $h=h_{t}-2 \delta-2 d$ (see Figure 4-2). By changing the thickness of the tapes, the particle size, and the length of the tape, the aspect ratio may be varied to obtain a range of $0.0025-0.075$.

The overall outside dimensions of the test cel1s are $0.016 \times 0.048 \times 0.353 \mathrm{~m}$ (see Figure 4-2). The exterior of the test cells was machined in such a way as to have small wall thickness near the silica gel coated tapes. This will enhance the heat transfer to and from the isothermal bath so that the test cells remain isothermal during the sorption process. Nitrile ${ }^{R}$ o-rings seal the test cell components. The Lexan ${ }^{\mathrm{R}}$ sheets were fastened together by Allen 


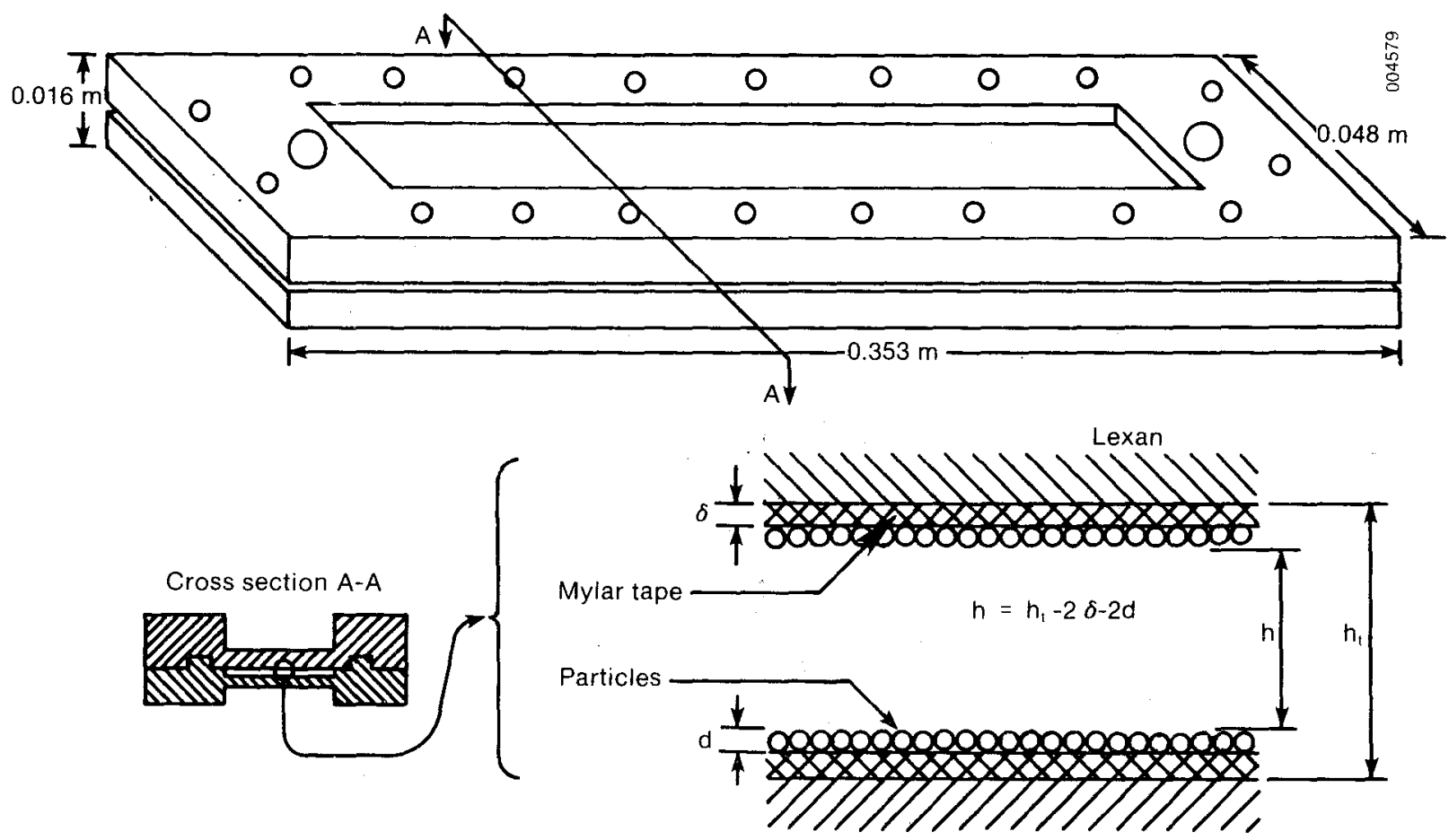

Figure 4-2. Schematic of the Parallel Passage Test Ce11

drive set screws. Figure 4-3 is a photograph of the two parallel passage cells. The upper cell is open to show the interior structure of the cell; the lower cell is assembled to show the outside configuration. The air-water vapor mixture enters through one of the Swagelok ${ }^{R}$ connectors at either end, passes through a flow straightener, and spreads horizontally across the air gap. The flow straightener is composed of glass wool fibers (the white material in Figure 4-3) and a rectangular metallic screen. The flow straighteners were set on both ends of the passage to minimize end effects. The air-water vapor mixture exchanges water with silica gel and exits from the other Swagelok ${ }^{\mathrm{R}}$ connector.

The relevant parameters for the test cells used in this study are summarized in Table $4-1$. 


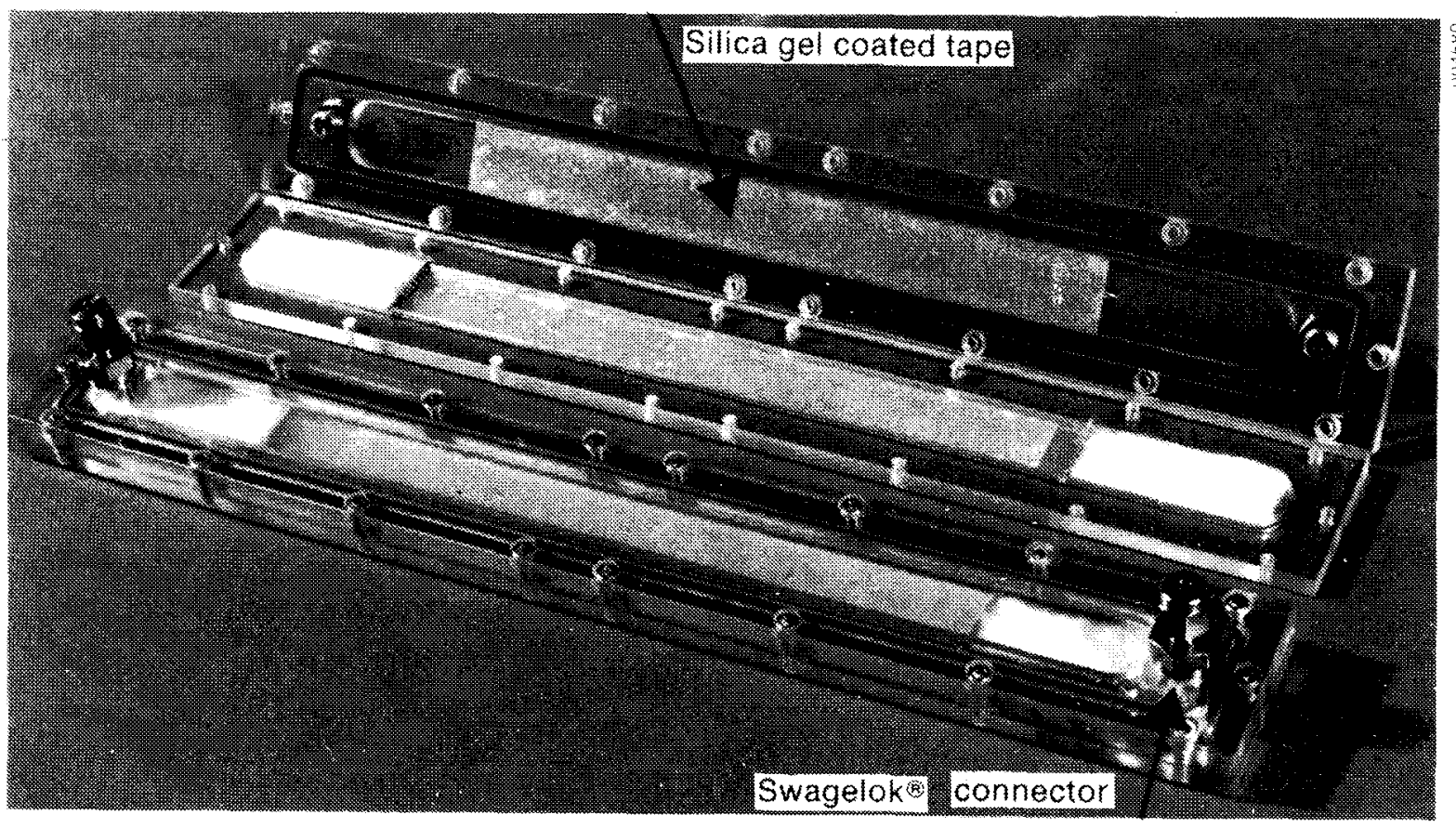

Figure 4-3. Parallel Passage Test Cells (open and closed) 
Table 4-1. Test Cel1 Parameters

\begin{tabular}{|c|c|c|c|c|}
\hline & \multirow{2}{*}{$\begin{array}{l}\text { Packed } \\
\text { Column } 0\end{array}$} & \multicolumn{3}{|c|}{ Parallel Passage } \\
\hline & & P1 & P2 & P3 \\
\hline Desiccant & \multicolumn{2}{|c|}{$\begin{array}{l}\text { Silica gel, Grade } 40 \\
45-60 \text { mesh }\end{array}$} & Davison, & ved to \\
\hline $\begin{array}{l}\text { Average particle } \\
\text { diameter }(\mathrm{cm})\end{array}$ & 0.03 & 0.03 & 0.03 & 0.03 \\
\hline Mass, dry desiccant ( $\mathrm{g})$ & 0.2334 & 0.6277 & 0.6277 & 0.3138 \\
\hline Internal diameter $(\mathrm{cm})$ & 0.267 & -- & -- & -- \\
\hline Flow height $(\mathrm{cm})$ & -- & 0.095 & 0.192 & 0.192 \\
\hline Width $(\mathrm{cm})$ & -- & 2.0 & 2.0 & 2.0 \\
\hline Length $(\mathrm{cm})$ & 10.78 & 10.0 & 10.0 & 5.0 \\
\hline Flow area $\left(\mathrm{cm}^{2}\right)$ & 0.018 & 0.190 & 0.384 & 0.384 \\
\hline Aspect ratio & -- & 0.0095 & 0.0192 & 0.0384 \\
\hline
\end{tabular}


SECTION 5.0

EXPERIMENTAL PROCEDURE

\subsection{SET-UP OF CHROMATOGRAPH LOOP}

The chromatograph loop was described in Section 3.0 and shown schematically in Figure 3-2; the test cells are described in Section 4.0 and shown in Figures 4-1 and 4-2. These test cells were prepared in advance and installed in the chromatograph loop. The configuration is such that process air stream conditions can be set up through the bypass loop, and once they have reached the desired operating values of temperature, pressure, flow rate, and relative humidity, the flow is switched into the test cell and the experiment begins.

Three units require long times to equilibrate: the two water baths that maintain the chromatograph loop and the humidifier at different isothermal conditions, and the vacuum chamber of the mass spectrometer. These units are generally brought to the desired conditions the evening before starting a test run.

Once these units are at the desired operating conditions, a monitoring program is loaded into the data acquisition system and the other units in the chromatograph loop are set as follows:

- The bone-dry air supply is turned on and adjusted through a coarse pressure regulator.

- The mass flow controllers are turned on and set at the desired flow rate.

- The pressure in the loop is set by regulating the pressure control valves downstream of the chromatograph loop and the coarse valve of the vacuum pump at the process air discharge point.

- The dew point hygrometer upstream of the test cell is turned on and balanced.

- The humidifier temperature and adjustment valves are set to obtain the desired humidity ratio by monitoring the dew point sensor.

- Once the flow parameters have reached equilibrium, the thermal conductivity detector is turned on and zeroed (balanced).

- The mass spectrometer inlet valve is opened and the process air stream is sampled to ensure that the process air is of uniform composition and to verify the operating conditions.

Once all operating parameters are set and have been equilibrated, the data acquisition and storage program is loaded into the HP computer, the process air stream is switched into the test cell, and the breakthrough part of the test begins.

\subsection{MONITORING OF EXPERIMENTS}

The data acquisition and storage program records all operating parameters at selected time intervals and stores the data on cartridge. Additionally, the 
outputs of the thermal conductivity detector and of the mass spectrometer are displayed graphically so that the trend in the process air stream concentration can be observed. The variation of these outputs as a function of time gives the breakthrough curve for the operating conditions. These outputs are monitored until no variation is observed in the process stream concentration, downstream of the test cell; this implies that the sorption process has reached equilibrium.

Determination of the desiccant water content requires measurement of retention times for a nonreactive gas (helium) and an isotopic tracer (deuterium dioxide), and the derivation is given in Section 2.0 and Appendix $A$. The retention times are measured as follows:

1. The inactive loop of the 10 -port valve is loaded with heavy water vapor $\left(D_{2} 0\right)$.

2. The thermal conductivity detector is zeroed again.

3. The process air stream is switched into the loop loaded with $\mathrm{D}_{2} \mathrm{O}$ vapor so that a small volume of tracer is carried into the test cell.

4. The pressure variation in the loop is small when the 10-port valve is switched, but it does affect the output of the thermal conductivity detector; this gives the initial time reference for the injection of the perturbation. A chronometer is started to obtain a redundant measurement with the mass spectrometer output.

5. The thermal conductivity detector is monitored until a variation in output is recorded; this gives the time at which the perturbation has reached the thermal conductivity detector after passing through the test cell and interacting with the desiccant. The same is monitored on the output of the mass spectrometer.

6. The same series of measurements are made in the bypass section to obtain a reference value for all the piping length outside the test ce11.

7. Steps 1 through 6 are repeated with the helium gas to obtain a measure of the free gas volume in the test cell.

Once these steps are completed, the test loop is reset to new operating parameters for the next test run.

The detailed operating procedure for the SERI sorption test facility can be found in Appendix $C$. 
SECTION 6.0

\section{RESULTS AND DISCUSSION}

In this section the results of breakthrough and equilibrium experiments for two silica gel bed configurations, packed and paralle1 passage, are presented. Breakthrough data were obtained after a step change in the inlet air humidity to a test cell and consist of effluent water vapor concentration versus time. Equilibrium data, silica gel water content versus air water vapor concentration, were obtained by isotope injection at the end of the breakthrough experiments. The operating procedures are summarized in Section 5.0 and detailed in Appendix C. Appendix A shows how the raw data can be converted to more meaningful values. Both adsorption and desorption tests were performed. A description of the test cells can be found in Section 4.0 and their relevant parameters are summarized in Table 4-1.

Table 6-1 summarizes the pertinent experimental parameters for the successful breakthrough tests conducted in this study. It is divided into sections depending on the type of test cell geometry used and on the isothermal bath temperature $\left(T_{t c}\right)$. Table $6-1$ shows:

- The experiment number, where R stands for "repeat" of an experiment

- Whether it was an adsorption or desorption process (AD/DE)

- The dew point temperature of an air stream in equilibrium with the desiccant before starting the test $\left(\mathrm{T}_{\mathrm{dew}, \mathrm{o}}\right)$

- The dew point temperature of the inlet air stream $\left(T_{\mathrm{dew}}, \mathrm{f}\right)$

- The pressure in the test cell ( $\left.P_{t c}\right)$

- The air velocity in the test cell (u)

- The absolute humidity ratios related to the dew point temperatures $\left(w_{O}\right.$, $\mathrm{w}_{\mathrm{f}}$ )

- The initial and final desiccant water content $\left(W_{o}, W_{f}\right)$ estimated from published data [10]

- The breakthrough time, defined as the time to reach $95 \%$ of the inlet humidity ratio.

For all tests conducted, we attempted to maintain the average pressure in the test cell $\left(\mathrm{P}_{t c}\right)$ near 760 torr and to operate between 5 humidity ratios (or dew point temperatures) that are approximately $0.0005\left(-25^{\circ} \mathrm{C}\right), 0.008\left(11^{\circ} \mathrm{C}\right), 0.012$ $\left(16^{\circ} \mathrm{C}\right), 0.015\left(20^{\circ} \mathrm{C}\right), 0.018\left(23^{\circ} \mathrm{C}\right)$. In this way, groups of experiments can be compared directly by normalizing the breakthrough response in the particular humidity ratio ranged selected, and to evaluate the effect of cell geometry and gas velocity on the dynamics of the sorption process. The data of each experiment are presented in Appendix D. In the remainder of this section the results of typical experimental runs are discussed. The dependence of sorption processes on air velocity, temperature, and test cell dimensions (aspect ratio for parallel) is discussed.

Figure 6-1 shows the adsorption results obtained in Experiment No. 43. During this experiment, the parallel passage test cell Pl was maintained at a 
Table 6-1. Summary of Experimental Parameters

\begin{tabular}{|c|c|c|c|c|c|c|c|c|c|c|}
\hline $\begin{array}{l}\text { Exp } \\
\text { no. }\end{array}$ & Process & ${ }_{\left({ }^{\circ} \mathrm{C}\right)}^{\mathrm{T}_{\mathrm{dew}}}$ & $\begin{array}{c}\mathrm{T}_{\mathrm{dew}, \mathrm{f}} \\
\left({ }^{\mathrm{o}} \mathrm{C}\right)\end{array}$ & $\begin{array}{c}P_{\text {tc }} \\
(\text { torr })\end{array}$ & $\begin{array}{c}\mathbf{u} \\
(\mathrm{m} / \mathrm{s})\end{array}$ & $\left(x 10^{3}\right)$ & $\left(\mathrm{w}_{\mathrm{f}} \mathrm{O}^{3}\right)$ & $w_{0}$ & $W_{f}$ & $\begin{array}{r}t_{95} \\
(\mathrm{~m} 1 \mathrm{n}\end{array}$ \\
\hline \multicolumn{11}{|c|}{ Packed Column $0, \mathrm{~T}_{\text {tc }}=30^{\circ} \mathrm{C}$} \\
\hline 1 & $\mathrm{AD}$ & -24.0 & 11.3 & 761 & 1.03 & 0.5 & 7.3 & 0.0174 & 0.1492 & 31 \\
\hline $1 R$ & $A D$ & -24.0 & 10.8 & 772 & 1.02 & 0.5 & 6.9 & 0.0176 & 0.1467 & 31 \\
\hline 2 & $\mathrm{AD}$ & 11.3 & 16.0 & 772 & 1.03 & 7.3 & 9.8 & 0.1492 & 0.1931 & 38 \\
\hline 3 & $A D$ & 16.0 & 21.0 & 760 & 1.05 & 9.8 & 13.6 & 0.1931 & 0.2498 & 34 \\
\hline 4 & $\mathrm{AD}$ & 21.0 & 23.4 & 760 & 1.05 & 13.6 & 15.8 & 0.2498 & 0.2806 & - \\
\hline 6 & $\mathrm{DE}$ & 20.5 & 16.2 & 743.0 & 1.07 & 15.3 & 11.8 & 0.2716 & 0.2181 & 15 \\
\hline 7 & $\mathrm{DE}$ & 16.2 & 11.2 & 742.0 & 1.06 & 11.8 & 8.5 & 0.2181 & 0.1662 & 49 \\
\hline 8 & $\mathrm{DE}$ & 11.2 & -25.0 & 734.0 & 1.07 & 8.5 & 0.5 & 0.1662 & 0.0182 & 45 \\
\hline
\end{tabular}

Parallel Passage P1, $\mathrm{T}_{\mathrm{tc}}=30^{\circ} \mathrm{C}$

$\begin{array}{lrrrrrrrrrr}11 & \mathrm{AD} & -10.0 & 10.9 & 713.4 & 0.36 & 1.8 & 8.5 & 0.0456 & 0.1604 & -- \\ 11 \mathrm{R} & \mathrm{AD} & -25.0 & 10.7 & 759.0 & 0.33 & 0.5 & 7.8 & 0.0179 & 0.1586 & 84 \\ 12 \mathrm{R} & \mathrm{AD} & 10.7 & 15.9 & 764.3 & 0.33 & 7.8 & 11.0 & 0.1586 & 0.2109 & 45 \\ 13 \mathrm{R} & \mathrm{AD} & 15.9 & 19.7 & 770.4 & 0.33 & 11.0 & 13.9 & 0.2108 & 0.2567 & 39 \\ 14 & \mathrm{AD} & 20.0 & 23.0 & 744.0 & 0.35 & 13.7 & 18.1 & 0.2650 & 0.3052 & 27 \\ 14 \mathrm{R} & \mathrm{AD} & 19.7 & 23.0 & 765.1 & 0.33 & 13.9 & 17.2 & 0.2567 & 0.3003 & - \\ 15 \mathrm{R} & \mathrm{DE} & 23.0 & 19.9 & 767.7 & 0.33 & 17.2 & 14.1 & 0.3003 & 0.2605 & -- \\ 17 & \mathrm{DE} & 15.9 & 10.9 & 767.2 & 0.33 & 10.9 & 7.8 & 0.2108 & 0.1601 & 79 \\ 18 & \mathrm{DE} & 10.9 & -13.0 & 766.2 & 0.33 & 7.8 & 1.3 & 0.1601 & 0.0370 & 58 \\ 19 & \mathrm{AD} & -25.0 & 10.8 & 762.0 & 0.17 & 0.5 & 8.0 & 0.0179 & 0.1611 & 85 \\ 20 & \mathrm{AD} & 10.9 & 15.9 & 765.1 & 0.17 & 8.0 & 11.1 & 0.1616 & 0.2128 & 101 \\ 21 & \mathrm{AD} & 15.9 & 20.5 & 765.1 & 0.17 & 11.1 & 14.9 & 0.2128 & 0.2694 & 62 \\ 22 & \mathrm{AD} & 20.4 & 23.0 & 768.6 & 0.17 & 14.7 & 17.4 & 0.2674 & 0.3029 & 31 \\ 23 & \mathrm{DE} & 23.1 & 20.4 & 765.2 & 0.17 & 17.4 & 14.8 & 0.3036 & 0.2681 & 21 \\ 24 & \mathrm{DE} & 20.4 & 16.2 & 767.4 & 0.17 & 14.8 & 11.2 & 0.2681 & 0.2157 & 46 \\ 25 & \mathrm{DE} & 16.2 & 11.0 & 762.1 & 0.17 & 11.3 & 8.1 & 0.2162 & 0.1629 & 150 \\ 26 & \mathrm{DE} & 11.0 & -25.0 & 765.2 & 0.16 & 8.1 & 0.5 & 0.1629 & 0.0180 & 118 \\ 33 & \mathrm{AD} & -25.0 & 10.8 & 1038.2 & 0.43 & 0.5 & 5.7 & 0.0180 & 0.1580 & -- \\ 35 & \mathrm{DE} & 23.1 & 11.0 & 763.1 & 0.33 & 17.4 & 7.9 & 0.3011 & 0.1611 & 77 \\ 36 & \mathrm{AD} & 11.0 & 23.0 & 761.7 & 0.44 & 7.9 & 17.2 & 0.1611 & 0.2984 & 20 \\ 37 & \mathrm{DE} & 23.0 & 10.9 & 762.7 & 0.44 & 17.2 & 7.8 & 0.2984 & 0.1594 & 56 \\ 38 & \mathrm{AD} & 10.9 & 23.3 & 762.2 & 0.17 & 7.8 & 17.8 & 0.1594 & 0.3063 & 45 \\ 39 & \mathrm{DE} & 23.3 & 11.0 & 771.6 & 0.16 & 17.8 & 8.0 & 0.3063 & 0.1630 & 141\end{array}$

Paralle1 Passage $\mathrm{P} 2, \mathrm{~T}_{\mathrm{tc}}=30^{\circ} \mathrm{C}$

$\begin{array}{rrrrrrrrrrr}40 & \mathrm{AD} & -24.0 & 11.0 & 759.6 & 0.17 & 0.5 & 8.0 & 0.0190 & 0.1615 & 62 \\ 41 & \mathrm{DE} & 11.0 & -9.7 & 760.3 & 0.17 & 8.0 & 1.8 & 0.1615 & 0.0458 & 75 \\ 42 & \mathrm{AD} & -9.7 & 11.0 & 761.7 & 0.17 & 1.8 & 8.0 & 0.0458 & 0.1616 & 58 \\ 43 & \mathrm{AD} & 11.0 & 23.2 & 759.3 & 0.17 & 8.0 & 17.5 & 0.1616 & 0.3025 & 37 \\ 44 & \mathrm{DE} & 23.2 & 11.1 & 760.2 & 0.17 & 17.5 & 8.1 & 0.3025 & 0.1625 & 125\end{array}$

Parallel Passage P2, $\mathrm{T}_{\text {tc }}=80^{\circ} \mathrm{C}$

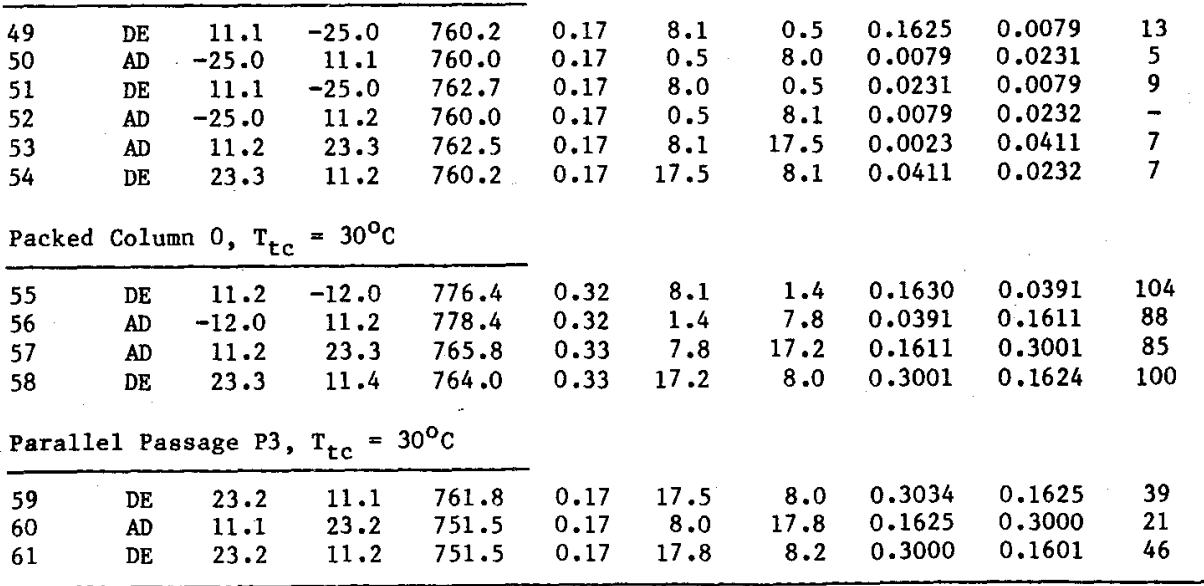



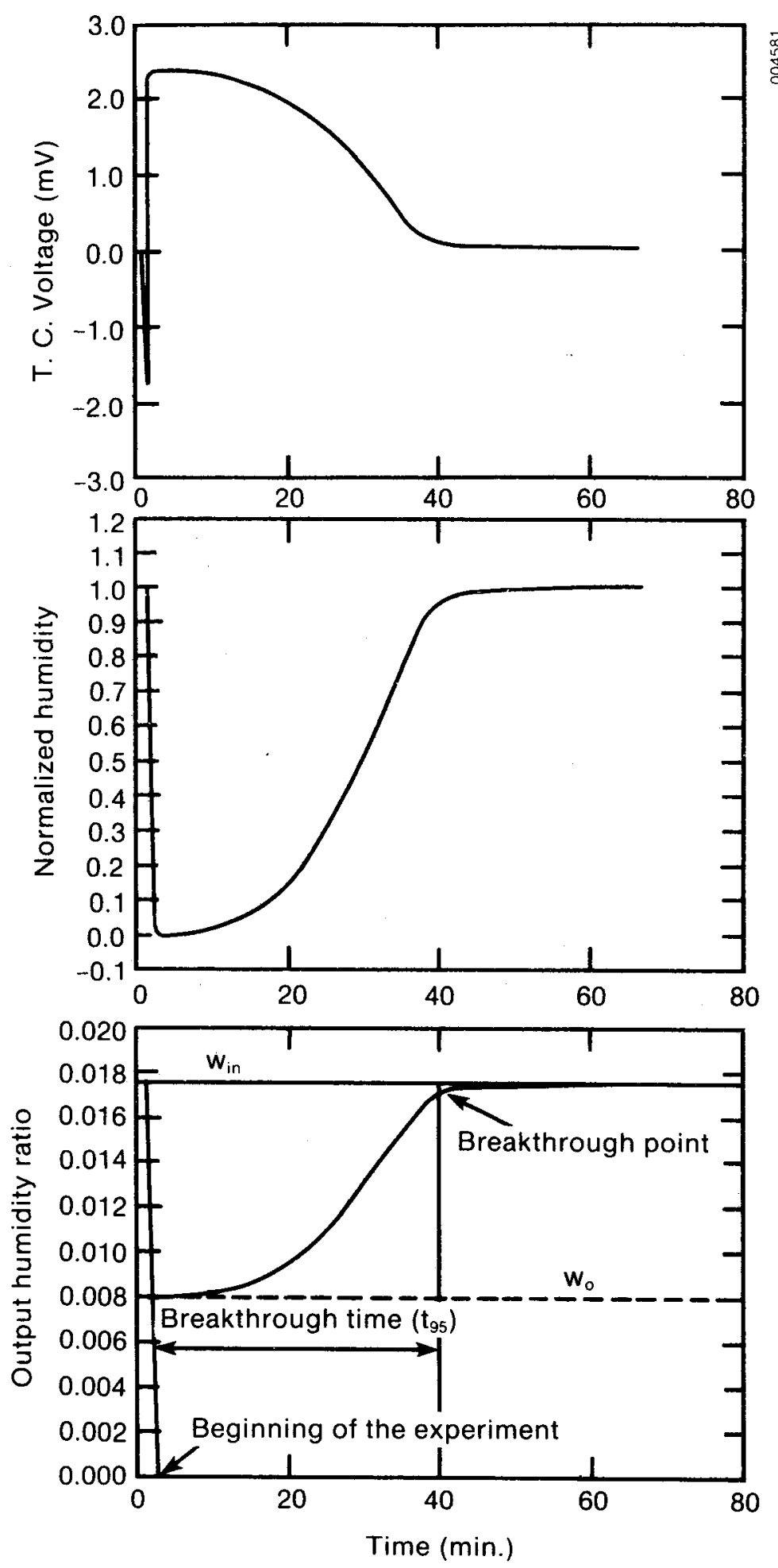

Figure 6-1. Typical Breakthrough Data for Adsorption of Water Vapor on Silica Gel in a Parallel Passage Geometry (Experiment No. 43) 
temperature $\mathrm{T}_{t c}=30^{\circ} \mathrm{C}$ and was initially at a desiccant water loading $W_{\mathrm{o}}=0.1616 \mathrm{~kg} \mathrm{H} \mathrm{H}_{2} \mathrm{O} / \mathrm{kg}$ dry desiccant, in equilibrium with an air stream of humidity ratio $w_{0}=0.008 \mathrm{~kg} \mathrm{H} \mathrm{H}_{2} / \mathrm{kg}$ dry air using Rojas [10] data. The experiment was conducted with an inlet air stream of humidity $w_{\text {in }}=0.0175 \mathrm{~kg}$ $\mathrm{H}_{2} \mathrm{O} / \mathrm{kg}$ dry air flowing through the test cell at velocity $\mathrm{u}=0.17 \mathrm{~m} / \mathrm{s}$. During the course of the experiment, the outlet humidity ratio changed from the initial value $w_{o}$ to the final value $w_{f}=w_{i n}$. At equilibrium, the desiccant water loading was estimated [10] to be $\mathrm{W}_{\mathrm{f}}=0.3025 \mathrm{~kg} \mathrm{\textrm {H } _ { 2 }} 0 / \mathrm{kg}$ dry desiccant.

The first graph of Figure 6-1 shows the experimentally measured voltage output of the thermal conductivity detector as a function of time. Initially, when the test cell is bypassed, the two cavities are exposed to air at the same humidity $\mathrm{w}_{\text {in }}$, therefore the output of the detector is zero. At the beginning of the experiment, the air stream is switched into the test ce11, one chamber of the detector is exposed to $w_{i n}$, and the other is exposed to the air that passed through the test cell, which is initially in equilibrium with $W_{0}$; $i . e$. $w_{0}$ - The sharp change of voltage output marks the beginning of the experiment. The outlet concentration stays at $w$ for a short period depending on inlet air conditions (air velocity, humidity, temperature). During this period the desiccant in the test cell has sufficient adsorption capacity to adsorb water vapor from $w_{i n}$ to $w_{0}$. For this period, output voltage of the thermal conductivity detector is at its maximum derivation as seen from first graph of Figure 6-1. As time passes the dessicant in the test cell loses its adsorption capacity and the outlet concentration starts to increase (third graph of Figure 6-1). Initially the slope of the increase in outlet concentration is steep, because of the large concentration driving force; however, the slope becomes smoother after the driving force becomes smaller. Finally, the desiccant in the test cell becomes saturated at the process conditions and does not adsorb any water; thus, the outlet concentration reaches the inlet concentration and remains constant as can be seen from third graph of Figure 6-1. After this point the output voltage of the thermal conductivity detector is at its minimum deviation. Ideally, we expect this deviation to be zero; however, because of pressure changes it is not zero in some of the experiments. The second graph shows the normalized humidity ratio as a function of time, displaying the shape of the breakthrough curve, normalized on the interval $w_{o}$ to $w_{f}$. The third graph shows the actual outlet humidity ratio as a function of time. Conversion between these data is discussed in Appendix A.

If we define the breakthrough time as the time for the humidity ratio to reach $95 \%$ of the inlet humidity after the beginning of the experiment, then the breakthrough time for Experiment No. 43 is 37 minutes. The breakthrough times defined in this manner are shown in Tables 6-1 and 6-2. The same type of data is shown in Figure 6-2, describing the results of Experiment No. 44, a desorption test between the same humidity and desiccant water content points as in Experiment No. 43. However, the breakthrough time in this case is 125 minutes and the shape of the breakthrough curve is different.

The response of the desiccant in the desorption case seems to be the reverse of adsorption; it can be explained in the same way as explained for adsorption. Table 6-2 compares breakthrough times of pairs of adsorption/ desorption experiments. It can be seen that in more than $75 \%$ of the experiments breakthrough time of adsorption is less than breakthrough time of 
Table 6-2. Comparison of Breakthrough Times of Adsorption and Desorption Experiments

\begin{tabular}{|c|c|c|c|c|}
\hline Exp. No. & Process & $w_{0} \times 10^{-3}$ & $w_{f} \times 10^{-3}$ & $\mathrm{t}_{95}(\min )$ \\
\hline \multicolumn{5}{|c|}{ Packed Column, $0, \mathrm{~T}_{\mathrm{tc}}=30^{\circ} \mathrm{C}$} \\
\hline $1 \mathrm{R}$ & $\mathrm{AD}$ & 0.5 & 6.9 & 31 \\
\hline 8 & $\mathrm{DE}$ & 8.5 & 0.5 & 45 \\
\hline 2 & $\mathrm{AD}$ & 7.3 & 9.8 & 38 \\
\hline 7 & $\mathrm{DE}$ & 11.8 & 8.5 & 49 \\
\hline 3 & $\mathrm{AD}$ & 9.8 & 13.6 & 34 \\
\hline 6 & $\mathrm{DE}$ & 15.3 & 11.8 & 15 \\
\hline \multicolumn{5}{|c|}{ Para11el Passage, $\mathrm{P} 1, \mathrm{~T}_{t c}=30^{\circ} \mathrm{C}$} \\
\hline $11 \mathrm{R}$ & $\mathrm{AD}$ & 0.5 & 7.8 & 84 \\
\hline 18 & $\mathrm{DE}$ & 7.8 & 0.5 & 58 \\
\hline $12 \mathrm{R}$ & $\mathrm{AD}$ & 7.8 & 11.0 & 45 \\
\hline 17 & $\mathrm{DE}$ & 10.9 & 7.8 & 79 \\
\hline 19 & $\mathrm{AD}$ & 0.5 & 8.0 & 85 \\
\hline 26 & $\mathrm{DE}$ & 8.1 & 0.5 & 118 \\
\hline 20 & $\mathrm{AD}$ & 8.0 & 11.1 & 101 \\
\hline 25 & $\mathrm{DE}$ & 11.3 & 8.1 & 150 \\
\hline 21 & $\mathrm{AD}$ & 11.1 & 14.9 & 62 \\
\hline 24 & $\mathrm{DE}$ & 14.8 & 11.2 & 46 \\
\hline 22 & $\mathrm{AD}$ & 14.7 & 17.4 & 31 \\
\hline 23 & $\mathrm{DE}$ & 17.4 & 14.8 & 21 \\
\hline 36 & $\mathrm{AD}$ & 7.9 & 17.2 & 20 \\
\hline 37 & $\mathrm{DE}$ & 17.2 & 7.8 & 56 \\
\hline 38 & $\mathrm{AD}$ & 7.8 & 17.8 & 45 \\
\hline 39 & $\mathrm{DE}$ & 17.8 & 8.0 & 141 \\
\hline \multicolumn{5}{|c|}{ Parallel Passage, P2, $\mathrm{T}_{\mathrm{tc}}=30^{\circ} \mathrm{C}$} \\
\hline 40 & $\mathrm{AD}$ & 0.5 & 8.0 & 62 \\
\hline 41 & $\mathrm{DE}$ & 8.0 & 1.8 & 75 \\
\hline 42 & $\mathrm{AD}$ & 0.5 & 8.0 & 58 \\
\hline 43 & $\mathrm{AD}$ & 8.0 & 17.5 & 37 \\
\hline 44 & $\mathrm{DE}$ & 17.5 & 8.1 & 125 \\
\hline
\end{tabular}


Table 6-2. Comparison of Breakthrough Times of Adsorption and Desorption Experiments (Concluded)

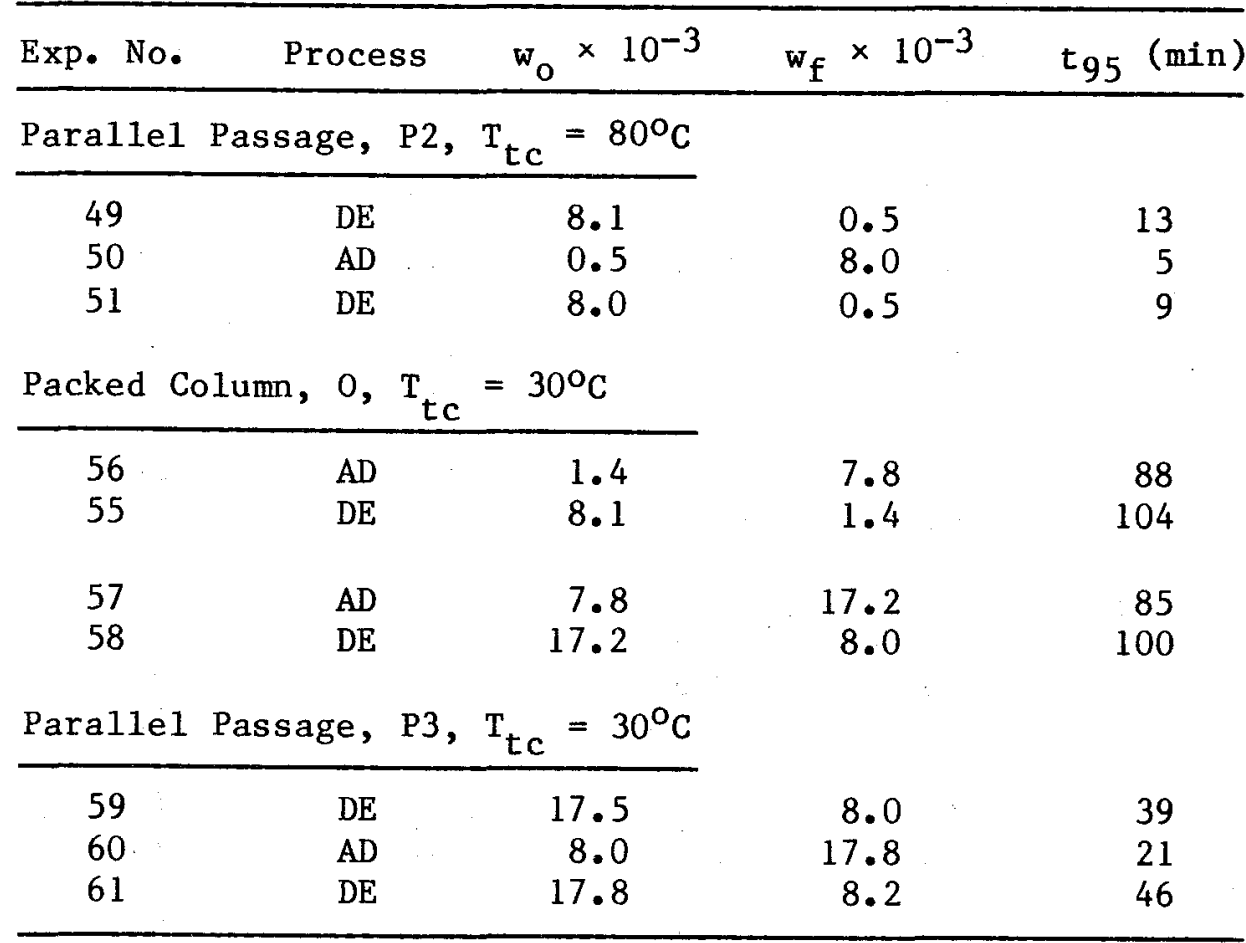

desorption. The physical reason for this behavior is that silica gel is a highly porous material and consists of very many microvoids $[3,10]$. One can visualize these voids as cylindrical pores. During adsorption, the pores are initially empty (dry silica gel) and the water molecules penetrate into the pores by surface and Knusdsen diffusion [3] and then are adsorbed on the surface of the pores. In this process all the internal surface area of the pore is available for adsorption. As time passes this area decreases until the pore fills. For the desorption the process is reverse: the surface area available for mass transfer is initially small and as time passes it increases. At the beginning of each case where the mass transfer driving force is the same $\left(w_{0}-W_{f}\right.$, or $\left.w_{0}-w_{i n}\right)$, the larger mass transfer surface area for adsorption compared to desorption causes the pore to fill faster than it empties. Therefore, the adsorption breakthrough time becomes less than desorption breakthrough time.

In order to check the repeatability of the breakthrough data, Experiment Nos. 1 and 40 were repeated. Experiment No. 40 was conducted between humidity ratios of 0.0005 and 0.008 ; its repeat experiment, Experiment No. 42, was conducted between humidity ratios of 0.002 and 0.008 with the same operating conditions. The results are presented in Figure 6-3 and show the repeatability of the experimental results. Experiment No. I was conducted between humidity ratios of 0.0005 and 0.0073 ; its repeat experiment, Experiment No. 1R, was conducted between humidity ratios of 0.0005 and 0.0069 . The outlet humidity 

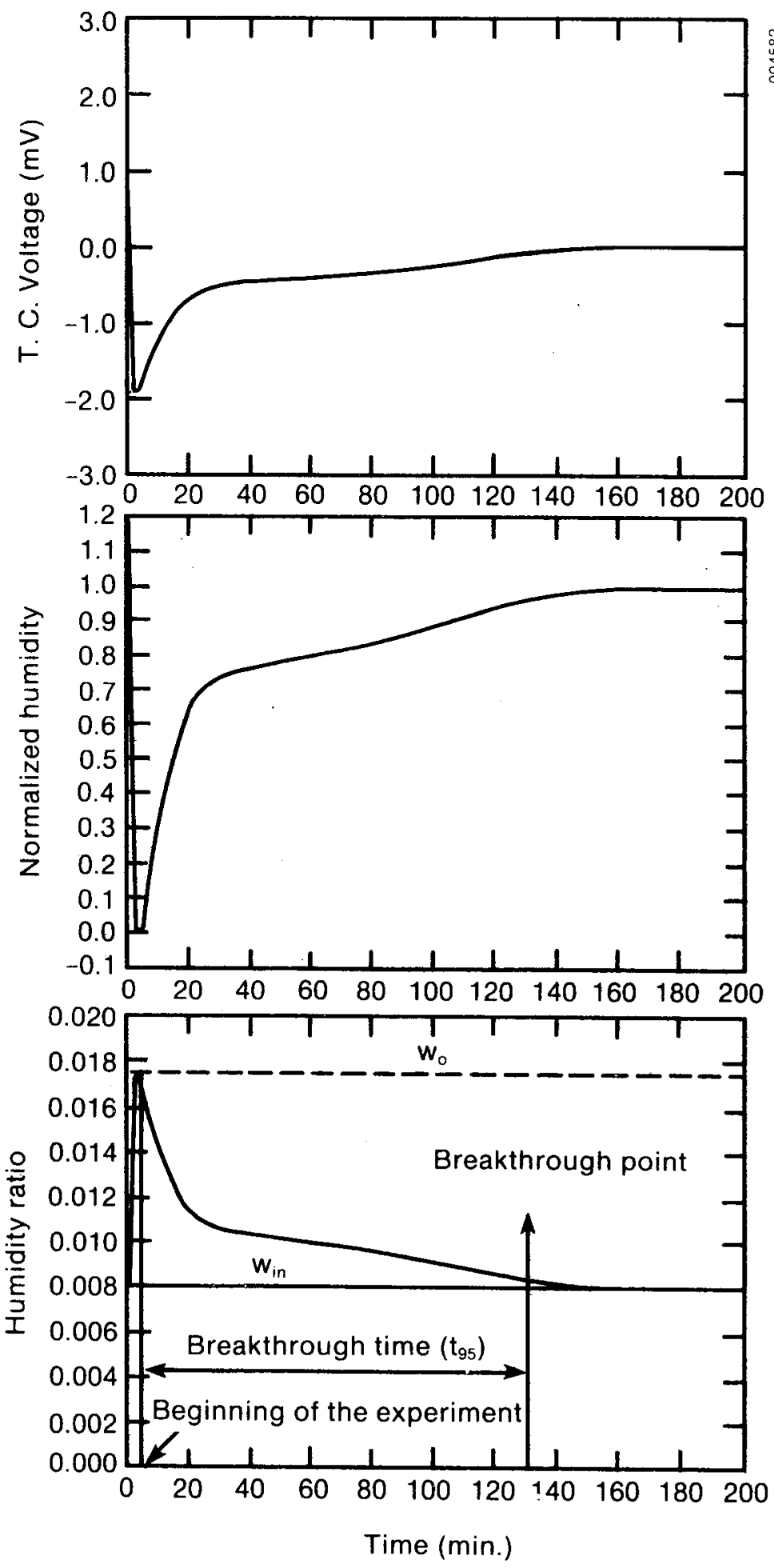

Figure 6-2. Typical Breakthrough Data for Desorption of Water Vapor from Silica Gel in a Parallel Passage Geometry (Experiment No. 44) 

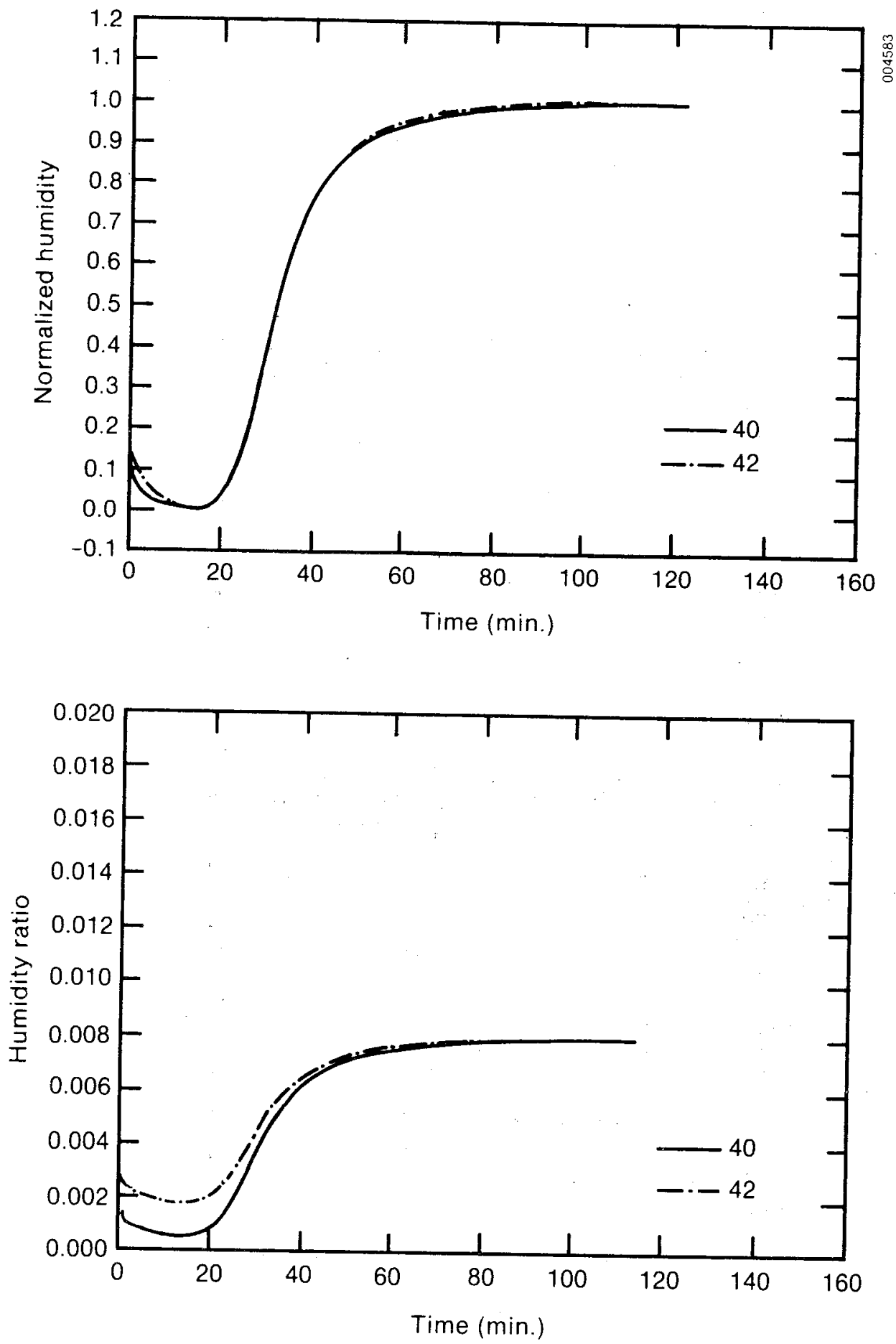

Figure 6-3. Repeatability of Breakthrough Data for Experiment Nos. 40 and 42 

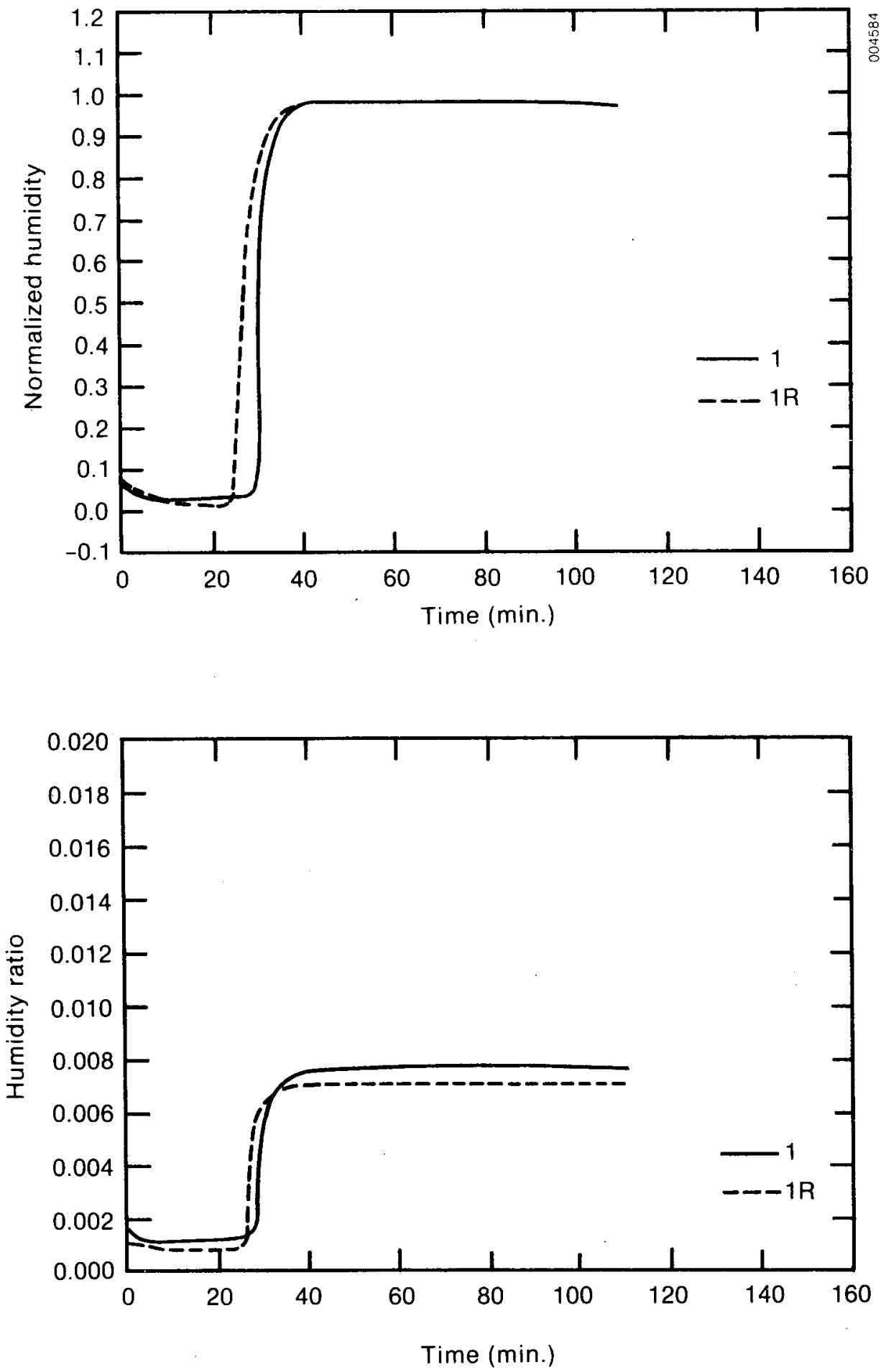

Figure 6-4. Repeatability of Breakthrough Data for Experiment Nos. 1 and 1R 

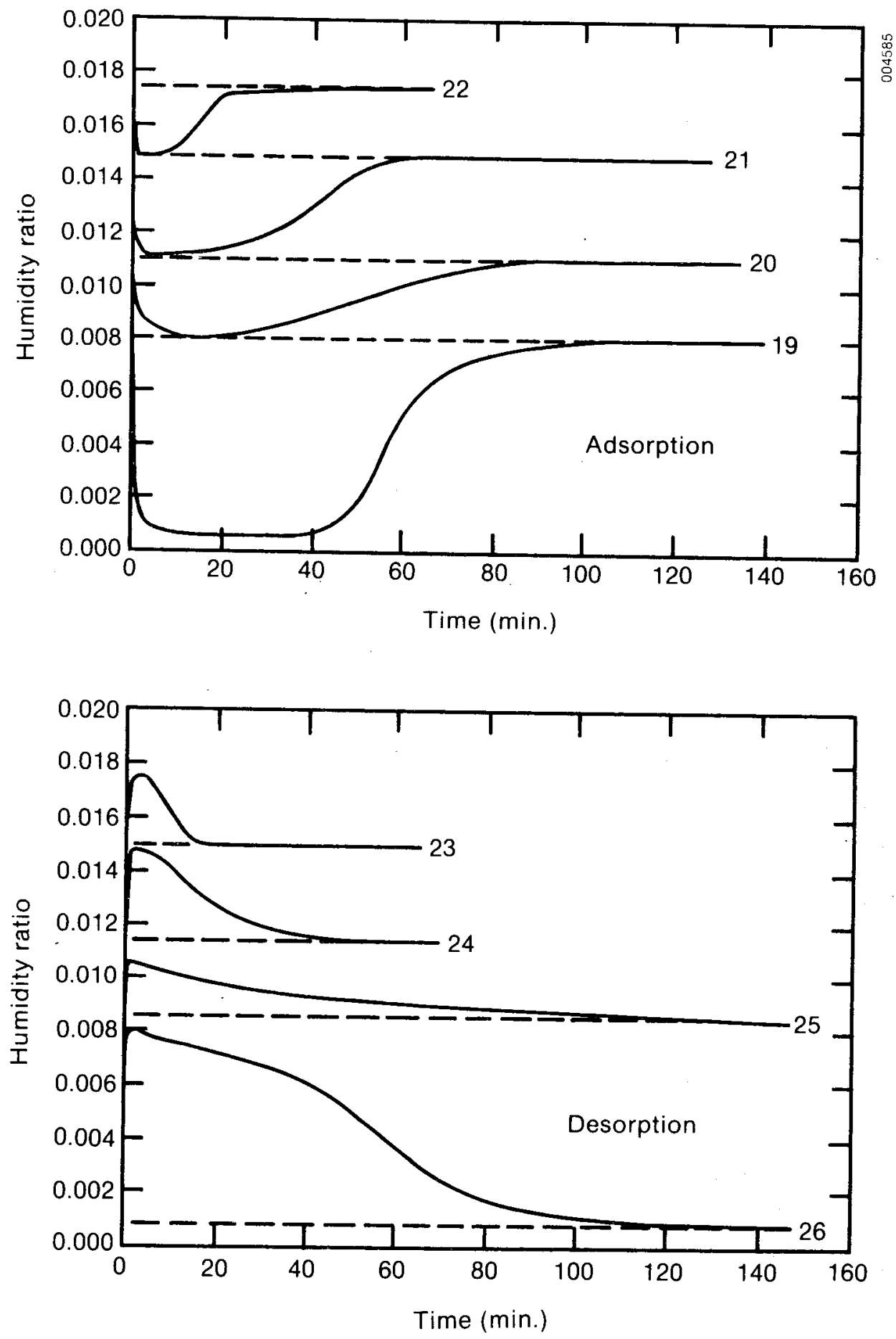

Figure 6-5. Comparison of Breakthrough Response for Four Humidity Ratio Ranges 

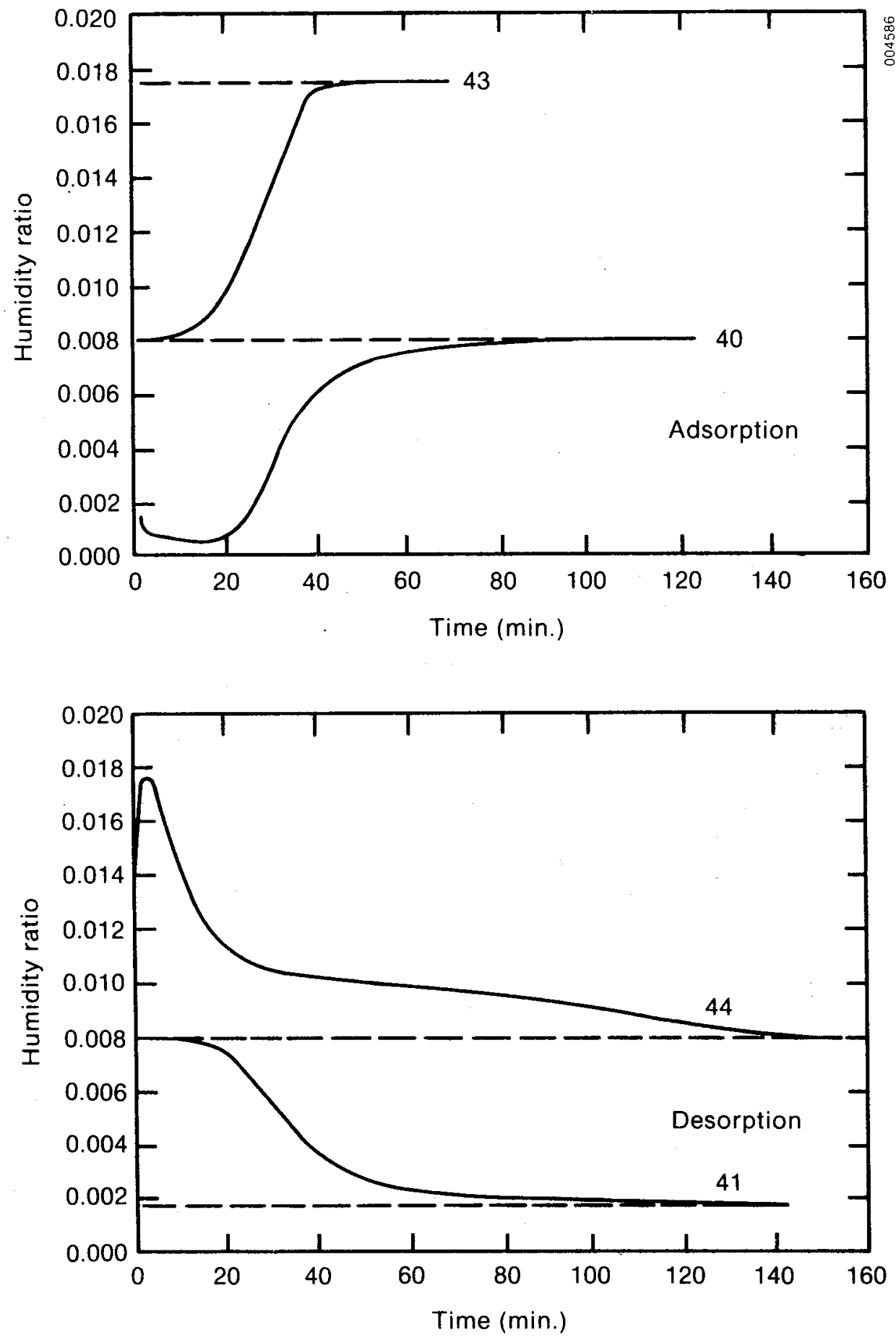

Figure 6-6. Comparison of Breakthrough Response for Two Humidity Ratio Ranges 
ratios for the two experiments are compared in Figure 6-4, which shows the repeatability of the breakthrough data.

Figure 6-5 shows the variation in outlet humidity ratio with time for a series of adsorption (Experiment Nos. 19 through 22) and desorption experiments (Experiment Nos. 23 through 26). These tests were conducted with paralle1 passage test cell $\mathrm{Pl}$, with aspect ratio $\mathrm{h} / \mathrm{L}=0.0095$, and at an air velocity of $0.15 \mathrm{~m} / \mathrm{s}$. Notice the proportionally longer breakthrough time between 0.008 and 0.011 for both adsorption and desorption. This is characteristic of all the tests conducted in the above humidity ratio range, possibly because of formation of a second layer of adsorbed molecules on the interal surfaces of the silica gel at this range. Note that the rate of adsorption of the second layer on the first layer is slower than the rate of adsorption of the first layer on the silica gel pore surfaces [12].

Figure 6-6 shows the variation in outlet humidity ratio with time for two adsorption and two desorption tests. These tests were conducted with parallel passage test cell $\mathrm{P} 2$, with aspect ratio $\mathrm{h} / \mathrm{L}=0.0192$, and at $\mathrm{u}=0.15 \mathrm{~m} / \mathrm{s}$. In contrast to Figure 6-5, where the aspect ratio is a factor of two smaller, and tests were conducted with a single interval between humidity ratios of 0.008 and 0.018 .

Figure 6-7 shows the dependence of breakthrough data on air velocity. Four experiments are compared in these graphs of normalized humidity as a function of time between the humidity ratios 0.008 and 0.017 . Experiment Nos. 36 and 37 were conducted at air velocity $u=0.44 \mathrm{~m} / \mathrm{s}$ and Experiment Nos. 38 and 39 at $\mathrm{u}=0.17 \mathrm{~m} / \mathrm{s}$ and $\mathrm{u}=0.16 \mathrm{~m} / \mathrm{s}$, respectively. Although the shape of the curves looks the same in each case, the outlet humidity in the experiments with higher velocity (Nos. 38 and 37 ) reaches its final value faster; i.e., the breakthrough times of higher velocity experiments are smaller. The physical reason for this behavior can be described in the following manner. Consider an adsorption experiment: when the air velocity is increased more mass of water vapor per mass of desiccant is exposed to the desiccant. Thus the desiccant adsorbs more in a fixed period of time and loses its adsorption capacity faster at higher air velocities. The same velocity dependence on breakthrough time can be explained for desorption cases. Note that in the adsorption cases, the breakthrough curve is only shifted, while in the desorption cases, the shift is less pronounced initially. More experimental data on dependence of air velocity on breakthrough response are presented in Figure 6-8.

The effect of aspect ratio on the breakthrough response is shown in Figure 6-9 for both adsorption and desorption tests for humidity ratios between 0.008 and 0.018 with air velocity of $u=0.17 \mathrm{~m} / \mathrm{s}$. In an at tempt to quantify the relative effect of aspect ratio on the breakthrough response, we must look at the nondimensional parameters NTU and DAR, which are commonly used in the study of desiccant dehumidifiers $[2,3,6,9,13]$. NTU is the number of transfer units and for parallel passage geometry is defined as

$$
N T U=\frac{K_{G}}{\rho u \frac{h}{L}},
$$



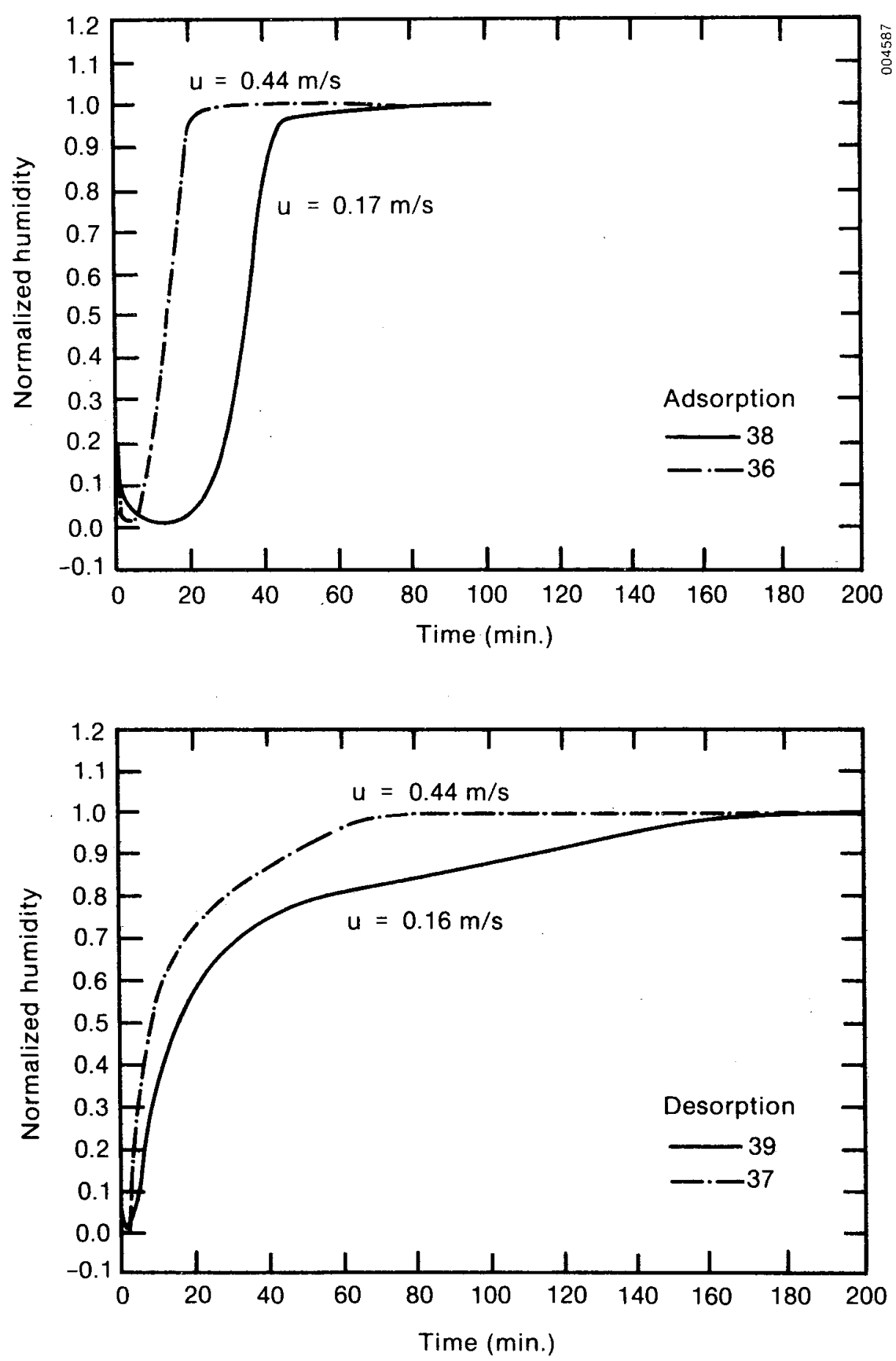

Figure 6-7. Dependence of Breakthrough Response on Air Velocity for Experiment Nos. 36, 38 and Experiment Nos. 37, 39 

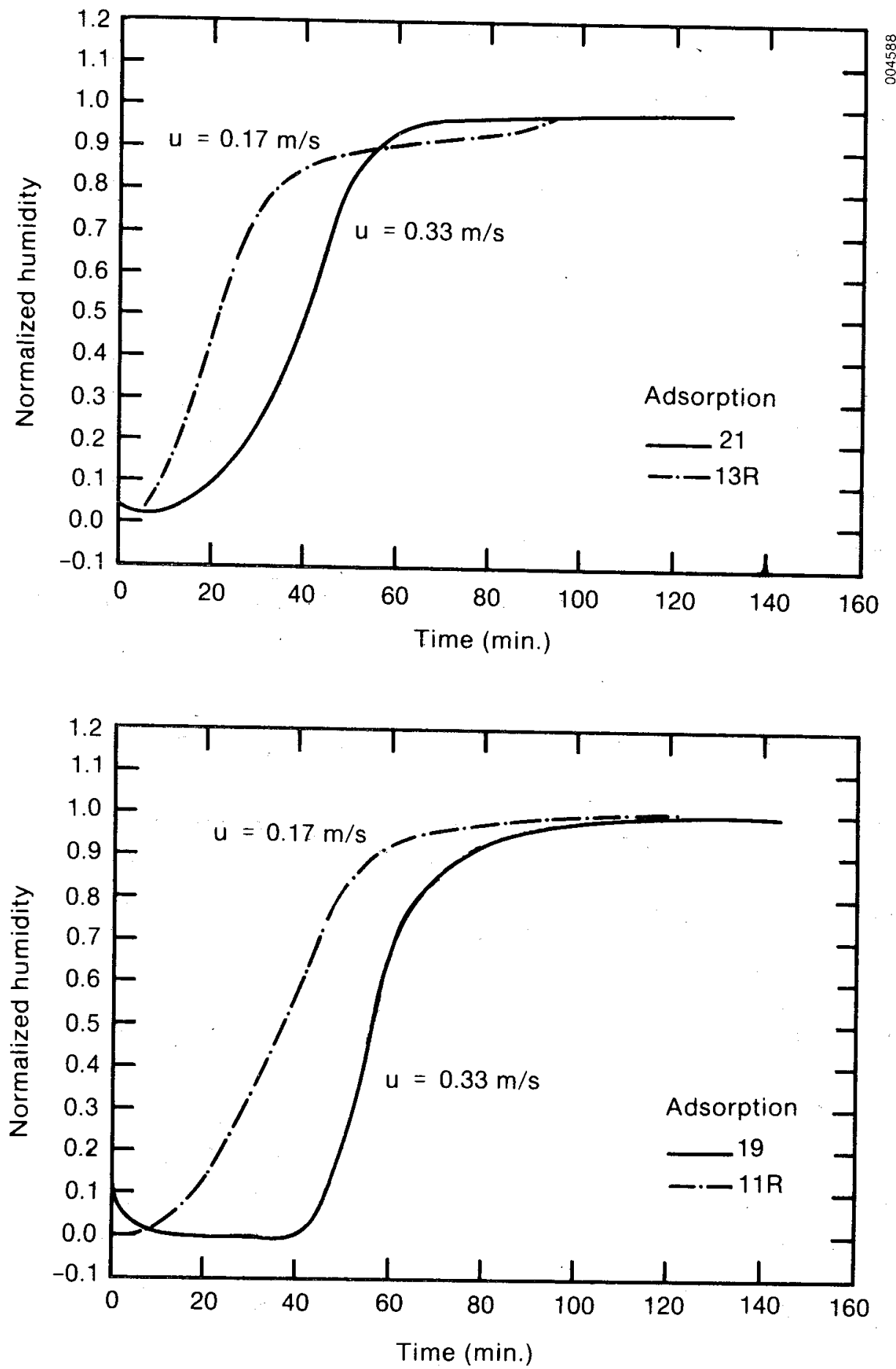

Figure 6-8. Dependence of Breakthrough Response on Air Velocity for. Experiment Nos. 13R, 21 and Experiment Nos. 11R, 19 

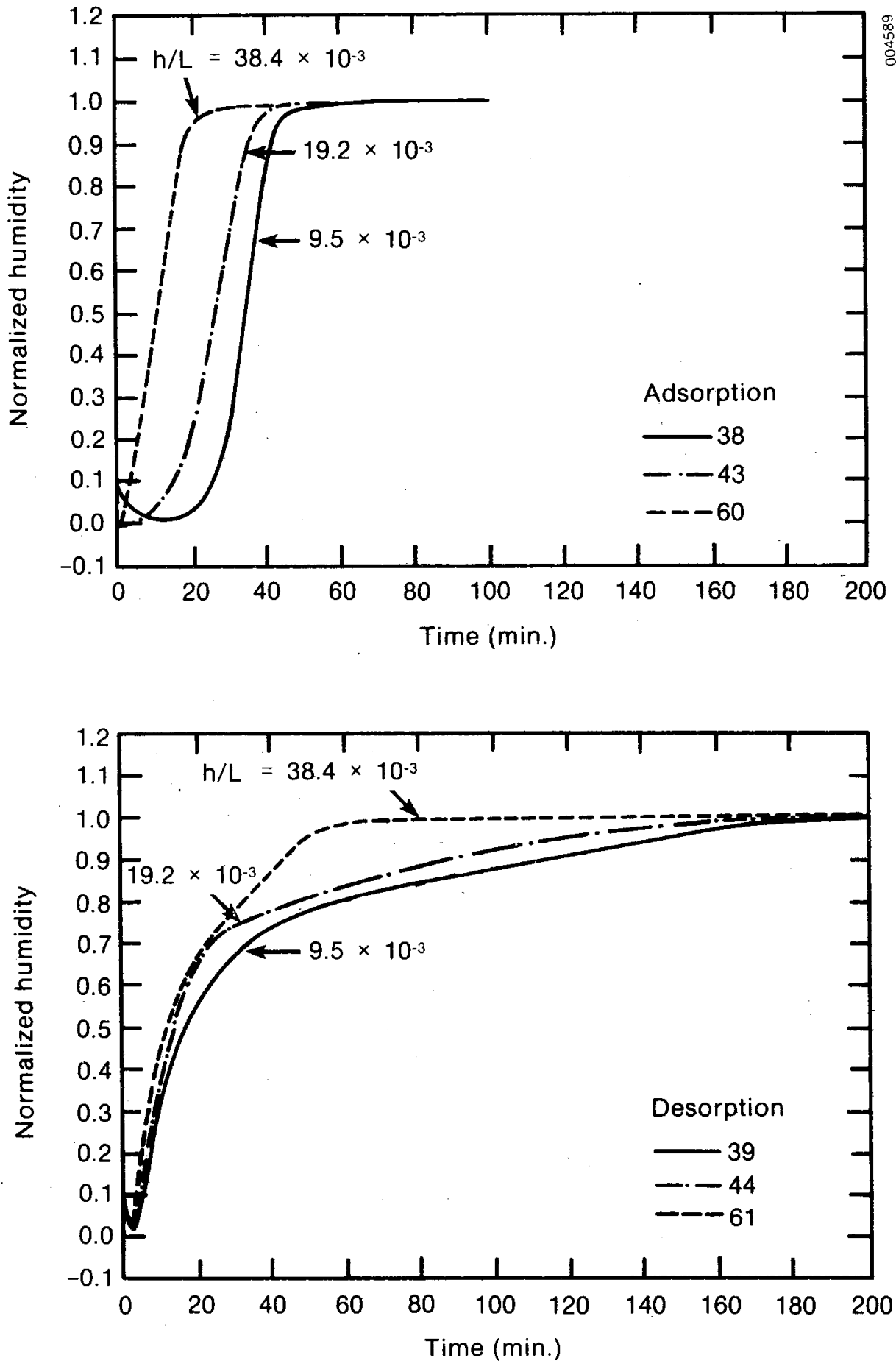

Figure 6-9. Dependence of Breakthrough Response on Aspect Ratio 
where $K_{G}$ is mass transfer coefficient; for fully developed flows in parallel passages it is [13]

$$
\mathrm{K}_{\mathrm{G}}=\frac{1}{2 \mathrm{~h}} \mathrm{Nu} \rho \mathrm{D},
$$

where $\mathrm{D}$ is $\mathrm{H}_{2} \mathrm{O}$-air diffusivity and $\mathrm{Nu}$ is the mass transfer Nusselt number and is constant [13]. DAR is the ratio of mass of desiccant to mass of air, and for parallel passage geometry it is

$$
\mathrm{DAR}=\frac{\mathrm{m}_{\mathrm{D}}}{\rho \mathrm{u} \tau} \frac{1}{\frac{\mathrm{h}}{\mathrm{L}}},
$$

where $\tau$ is the duration of the experiment. Neinberg [9] found that if DAR is increased the desiccant loses its adsorption capacity slower or the breakthrough time is longer. When aspect ratio $(h / L)$ is lowered NTU and DAR will be increased and thus the breakthrough time will increase. This can be observed from Figure 6-9: as aspect ratio decreased the curves are shifted to the right with longer breakthrough times. This observation is more clear for adsorption data. Note that when we decrease $h$ and keep everything else constant, less mass of water vapor per mass of desiccant is exposed to the desiccant, so the adsorption capacity of the desiccant will increase, which is the physical reason for the above observation.

The effect of isothermal bath temperature on breakthrough data can be seen in Figure 6-10. The responses of the parallel passage test cell $\mathrm{P} 2$ for the same inlet humidity range $(0.008$ to 0.018$)$ and air velocity at $30^{\circ}$ and $80^{\circ} \mathrm{C}$ are compared for adsorption and desorption cases. The breakthrough times are shorter for higher temperature for both cases. The physical reason for this behavior is that at higher temperatures sorption capacity of the desiccant is smaller; thus the desiccant can sorb less and becomes saturated faster.

Table 6-3 shows the results of equilibrium tests on silica ge1 and Rojas' [10] equilibrium water content. It was found that $\Delta t^{\text {He }}$, the time difference between passing helium through the test cell and the bypass column, is usually less than 20 seconds. However, $\Delta t^{*}$, the time difference between passing deuterium dioxide through the test cell and the bypass column, is usually much larger than 20 seconds. Therefore, $\Delta t^{\text {He }}$ is ignored compared to $\Delta t^{*}$ in the water content calculations (using Eq. A-21) and is not reported in Table 6-3. As can be seen the experimental equilibrium water contents $\left(W_{f, c a l}\right)$ are consistently lower than those of Rojas $\left(W_{f, R o j a s}\right)$. Rojas' data are close to the other published data (see Figure 1-1). "So one may conclude that the the equilibrium results calculated in Table 6-3 are erroneously obtained. It was found that error in the experimental measurements does not account for the discrepancies. Therefore the experimental techniques of isotope injection and detection were suspected. The isotope injection system in which $\mathrm{D}_{2} \mathrm{O}$ humidifies the air that then fills the sample loops is shown in Figure 3-5. We suspected that the concentration of $\mathrm{D}_{2} \mathrm{O}$ in the sample loop was not sufficient to be detected. To modify the injection method the air cylinder was removed and a vacuum pump was added in the isotope loop. This provides isotope vapor (at its maximum possible concentration) in the sample loop, ensuring that the isotope peak exiting the test cell is consistently 

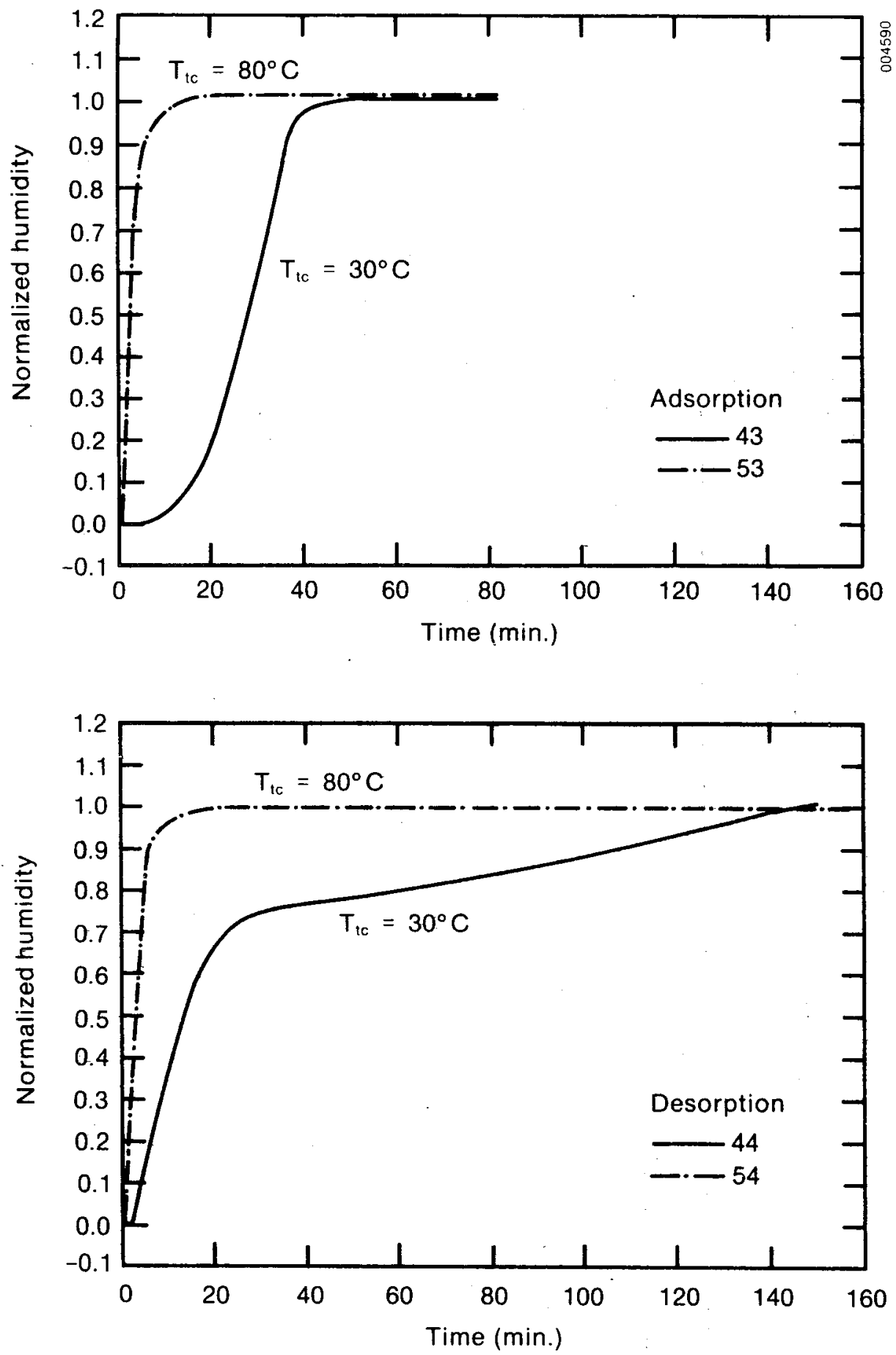

Figure 6-10. Dependence of Breakthrough Response on Isothermal Bath Temperature 
Table 6-3. Summary of Results of Equilibrium Experiments

\begin{tabular}{|c|c|c|c|c|c|c|c|c|c|}
\hline $\begin{array}{l}\text { Exp. } \\
\text { No. }\end{array}$ & Process & $\frac{\mathrm{P}_{\mathrm{tc}}}{(\mathrm{tor})}$ & $\begin{array}{c}\mathrm{u} \\
(\mathrm{m} / \mathrm{s})\end{array}$ & $\begin{array}{c}\mathrm{m} \\
(\mathrm{g})\end{array}$ & $\left(\times \quad{ }^{w} 8-3\right)$ & $\begin{array}{l}\Delta t^{*} \\
(s)\end{array}$ & $\mathrm{W}_{\mathrm{f}, \mathrm{ca} 1}$ & ${ }^{W_{f}, \operatorname{Rojas}}$ & $\left.\Delta t^{*} \underset{(s}{\operatorname{Roj}}\right)^{(a s}$ \\
\hline \multicolumn{10}{|c|}{ Packed Column, $0, \mathrm{~T}_{\mathrm{tc}}=30^{\circ} \mathrm{C}$} \\
\hline $1 R$ & $\mathrm{AD}$ & 761 & 1.03 & 0.2334 & 7.3 & 1176 & 0.082 & 0.146 & 2094 \\
\hline \multicolumn{10}{|c|}{ Paralle1 Passage, $\mathrm{P} 1, \mathrm{~T}_{\mathrm{tc}}=30^{\circ} \mathrm{C}$} \\
\hline 11 & $\mathrm{AD}$ & 713 & 0.36 & 0.6277 & 8.5 & 1116 & 0.109 & 0.160 & 1637 \\
\hline $11 R$ & $\mathrm{AD}$ & 759 & 0.33 & 0.6277 & 7.8 & 1089 & 0.099 & 0.159 & 1743 \\
\hline $14 R$ & $\mathrm{AD}$ & 765 & 0.33 & 0.6277 & 17.2 & 324 & 0.065 & 0.300 & 1506 \\
\hline $15 R$ & $\mathrm{DE}$ & 768 & 0.33 & 0.6277 & 14.1 & 324 & 0.052 & 0.262 & 1617 \\
\hline
\end{tabular}


detectable. With this method the detection of isotope was easier and more consistent. However, no major changes were detected in $\Delta t^{*}$ and thus $W_{f}, c a 1^{*}$ To find out other possible sources of error the expected $\Delta t^{*}$ were calculated from Eq. A-13, based on Rojas' data, which are reported in Table 6-3 as $\Delta \mathrm{t}^{*} \mathrm{Rojas}^{*} \Delta \mathrm{t}^{*}$ is consistently lower than $\Delta \mathrm{t}^{*}$ Rojas, which suggests that the isotope peaks exit from the test cell faster than expected. This suggests that the residence time of $\mathrm{D}_{2} \mathrm{O}$ in the desiccant is shorter than it is supposed to be according to $\mathrm{Eq}$. A-13. The validity of assumptions made in the derivation of Eq. A-13 (or Eq. 2-8) was investigated. It was found that the weakest assumption may be the one presented as Eq. 2-6. This was consistent with the comments of Dr. Anthony Fraioli of Argonne National Laboratory (ANL) in his review of the draft of this report.

The principal assumption in isotopic perturbation underlies Eq. 2-6. This assumption should perhaps be restated that the adsorption process does not distinguish between the labeled and unlabeled water molecules, and further, that isotopic exchange is rapid and complete through the mass of unlabeled pre-adsorbed $\mathrm{H}_{2} \mathrm{O}$ in time of $\mathrm{D}_{2} \mathrm{O}$ perturbation exposure [14]. It appears that the underlined addition is part of the basic assumption on which the method is derived, and that it may not be valid in practice. The work at ANL [15] has shown that certain features of the Type IV isotherm exhibited by water on silica gel can be interpreted in terms of capillary-bound water held in the pore-blocked periphery of the individual particles, and the water can be introduced into the interior of the particle until the meniscial balance is reestablished. The capillary-bound water is extremely localized (immobile adsorption), and thus the diffusion of $\mathrm{D}_{2} \mathrm{O}$ into the interior of the microporous particle is not easily achieved. In otherwords, $D_{2} O$ is restricted from free exchange into the interior of the particle, so the second part of the basic assumption above is not valid. $\mathrm{D}_{2} \mathrm{O}$ molecules interact with only the outer layers of adsorbed $\mathrm{H}_{2} \mathrm{O}$ and do not penetrate far enough into the interior of the particle. Therefore the residence time of $\mathrm{D}_{2} \mathrm{O}$ molecules in the particles is shorter than the residence time when $\mathrm{D}_{2} \mathrm{O}$ molecules penetrate completely into the interior of the particles. This is confirmed by our experimental measurement of $\Delta t^{*}$ (see Table 6-3).

The above discussion presents one possible reason why our experimental determination of silica gel water content was unreliable. In other words, isotopic perturbation chromatography for this particular setup was an unreliable method for determining silica gel water content. It is quite possible that the method is reliable at very low water contents or other desiccants such as manganese dioxide and molecular sieve. We still have not ruled out the possibility of using the method for obtaining equilibrium desiccant water content. More investigation of the theory and experimental procedure is needed. 


\section{SECTION 7.0}

\section{CONCLUSIONS AND RECOMMENDATIONS}

\subsection{CONCLUSIONS}

- A test facility to analyze the dynamic mass transfer process and equilibrium capacity of any promising desiccant material was assembled.

- The test facility can operate under a broad range of process air stream conditions with various desiccant materials in different geometries characteristic of solid desiccant dehumidifier with particular emphasis on solar cooling operations.

- Two different dehumidifier configurations, i.e., packed bed and parallel passage, were constructed using silica gel and tested.

- Breakthrough and equilibrium data were obtained for both packed bed and parallel passage under a broad range of operating conditions. These data allow for future analysis and model verification of solar dehumidifier performance.

- Both adsorption and desorption experiments under isothermal conditions were performed, and a dynamic hysteresis between these two processes was identified. The hysteresis showed fundamental differences between the adsorption/desorption process which have to be accounted for in the modeling to accurately predict solar dehumidifier performance.

- The dependence of the sorption process on air velocity and aspect ratio was determined. As the air velocity, aspect ratio, and temperature increase, the breakthrough time decreases. The practical application of this conclusion is that with an increase in air velocity and aspect ratio, the rotational speed of a parallel passage dehumidifier wheel should also increase.

- A large discrepancy between the equilibrium experimental results and published data was found. This decrepancy was attributed to the experimental procedure or the invalidity of one of the basic assumptions in the theory of isotopic perturbation chromatography for silica gel-water vapor systems.

\subsection{RECOMMENDATIONS AND FUTURE PLANS}

- The validity of assumptions in the theory of perturbation chromatography should be investigated for water vapor-silica gel systems to see whether or not this system can be used.

- The experimental procedure for isotope injection and detection should be investigated so that it would be consistent with the theory of perturbation chromatography.

- Breakthrough and equilibrium tests with other promising desiccants such as manganese dioxide under various geometries and operating conditions should be made to identify their usefulness. 
- Tests with molecular sieves will be conducted to calibrate the isotope injection and detection technique.

- The breakthrough results will be compared with the predictions of heat and mass transfer models of dehumidifiers for validation of the models.

- The test facility will be modified for adiabatic experiments, which simulate the operation of dehumidifiers more closely. 


\section{SECTION 8.0}

\section{REFERENCES}

1. Jurinak, S., Open Cycle Solid Desiccant Cooling Component Models and Systems Simulations, $\mathrm{Ph} . \mathrm{D}$. Dissertation, Madison, WI: University of Wisconsin, 1982 .

2. Barlow, R. S., Analysis of the Adsorption Process of Desiccant Cooling Systems - A Pseudo-Steady-State Model for Coupled Heat and Mass Transfer, SERI/TR-631-1330, Golden, C0: Solar Energy Research Institute, 1982.

3. Pesaran, A. A., Moisture Transport in Silica Gel Particle Beds, Ph.D. Dissertation, Los Angeles, CA: University of California, 1983.

4. Herzenberg, S. A., L. K. Hien, and R. Silberglitt, Active Solar Energy System Material Research Priorities, DHR Contract No. C5269, Washington, D.C., 1982 .

5. Pesaran, A. A., F. Zangrando, and T. Penney, Test Plan to Quantify Sorption Hysteresis of Desiccant Materials in Solar Desiccant Cooling Systems, SERI draft report to DOE, John Goldsmith, Program Manager, under Task 1600, WPA No. 443, Go1den, Co, July 1983.

6. Schlepp, D., K. Schultz, and F. Zangrando, Facility Design and Plan for Cyclic Testing of Advanced Solid Desiccant Dehumidifier, SERI Report under Task 1600.21, WPA No. 443-83, Golden, C0, 1984

7. Pitts, R., and A. Czanderna, Design for a Gas Chromatograph for Characterizing Desiccant Materials, SERI/RR-334-550, Golden, CO: Solar Energy Research Institute, 1980.

8. Lawson, A. E., Jr., and J. M. Miller, "Thermal Conductivity Detectors in Gas Chromatography," Journal of Gas Chromatography, Vo1. 4, No. 8, 1966, pp. 278-284.

9. Nienberg, J. W., Modeling of Desiccant Performance for Solar-DesiccantEvaporative Cooling Systems, M.S. Thesis, Los Angeles, CA: University of California, 1977.

10. Rojas, F., Pure Vapor Adsorption of Water on Silica Gels of Different Porosity, M.S. Thesis 2342, Golden, CO: Colorado School of Mines, 1980 .

11. Maclaine-Cross, I. L., A Theory of Combined Heat and Mass Transfer in Regenerators, Ph.D. Dissertation, Australia: Monash University, 1974.

12. Lunde, P. J., and F. L. Kester, "Chemical and Physical Gas Adsorption in Finite Multimolecular Layer," Chem. Eng. Science, Vol. 30, 1975, pp. 1497-1505. 
13. Schlepp, D., and R. Barlow, Performance of SERI Parallel-Passage Dehumidifier, final draft, SERI/TR-252-1951, Golden, CO: Solar Energy Research Institute, 1983.

14. Communication with Dr. Anthony Fraioli of Argonne National Laboratory.

15. Fraioli, A. V., Topical Report for Improved Solid Desiccants (49532), Draft Report, Argonne, IL: Argonne National Laboratory, 1984. 


\section{APPENDIX A}

\section{DATA REDUCTION}

\section{A.1 EQUILIBRIUM DATA}

We are interested in obtaining the equilibrium isotherm of a desiccant at various configurations at a specified temperature. An equilibrium isotherm curve shows the relation between desiccant water content, $W$, and water vapor concentration, $C_{t c}$ (or desirable relative humidity), of a gas in equilibrium with the desiccant. To build up an isotherm we need to know both the desiccant water content and the relative humidity of air in equilibrium with the desiccant.

\section{A.1.1 Calculation of the Relative Humidity}

The following measurements can provide the required information for calculation of relative humidity of air in equilibrium with the desiccant in a test cell: dew point temperature in the dew point sensor, $\mathrm{T}_{\mathrm{dew}}$; total pressure in the dew point sensor, $\mathrm{P}_{\mathrm{dew}}$; temperature of the desiccant in test cell, $\mathrm{T}_{t c}$; and total pressure in the test cell, $\mathrm{P}_{\mathrm{tc}} \mathrm{c}^{\circ}$

The water content of air (humidity ratio) in the dew point sensor is the same as the water content into (and out of) a test cell at equilibrium, since no water is added to the air between the sensor and the test cell (see Figure 3-1); thus

$$
\mathrm{w}_{\mathrm{tc}}=\mathrm{w}_{\mathrm{dew}}
$$

Assuming air and water vapor are ideal gases, then

$$
\mathrm{w}=\frac{\rho_{\text {water }}}{\rho_{\text {air }}}=\frac{\frac{p_{\text {water }} M_{\text {water }}}{R T}}{\frac{p_{\text {air }} M_{\text {air }}}{R T}}=\frac{p_{\text {water }}}{p_{\text {air }}} \frac{{ }_{\text {water }}}{M_{\text {air }}} \text {. }
$$

Using these relations:

$$
\frac{M_{\text {water }}}{M_{\text {air }}}=\frac{18}{28.94}=0.622 \text {, }
$$

and

$$
\mathrm{p}_{\text {air }}=\mathrm{P}_{\text {total }}-\mathrm{p}_{\text {water }} \text {, }
$$

one can obtain 


$$
w=0.622 \frac{p_{\text {water }}}{P_{\text {total }}-P_{\text {water }}} .
$$

Dew point temperature is the temperature at which water vapor starts condensing, thus the air is saturated and

$$
p_{\text {water }}=P_{\text {sat }}\left(T_{\text {dew }}\right) \text {. }
$$

The humidity ratio of air in the dew point sensor using the above equation is

$$
\mathrm{w}_{\text {dew }}=0.622 \frac{\mathrm{P}_{\text {sat }}\left(\mathrm{T}_{\text {dew }}\right)}{\mathrm{P}_{\text {dew }}-\mathrm{P}_{\text {sat }}\left(\mathrm{T}_{\text {dew }}\right)} .
$$

The relative humidity in the test cell, $\mathrm{RH}_{t c}$, is

$$
\mathrm{RH}_{t c}=\frac{\mathrm{P}_{\text {water, }} \mathrm{tc}}{\mathrm{P}_{\text {sat }}\left(\mathrm{T}_{t c}\right)} .
$$

From Eq. A-3 one can obtain

$$
\mathrm{p}_{\text {water }}=\frac{\mathrm{w}}{0.622+\mathrm{w}} \mathrm{P}_{\text {total }}
$$

Substitute Eq. A-7 in Eq. A-6 for the test cell to obtain

$$
\mathrm{RH}_{t c}=\frac{w_{t c}}{0.622+w_{t c}} \frac{P_{t c}}{P_{s a t}\left(T_{t c}\right)} .
$$

However, $\mathrm{w}_{\mathrm{tc}}=\mathrm{w}_{\mathrm{dew}}$, and $\mathrm{P}_{\mathrm{tc}}=\mathrm{P}_{\mathrm{dew}}-1 / 2 \Delta \mathrm{P}_{\mathrm{tc}}$, thus

$$
\mathrm{RH}_{\mathrm{tc}}=\frac{\mathrm{w}_{\text {dew }}}{0.622+\mathrm{w}_{\text {dew }}} \frac{\mathrm{P}_{\text {dew }}-\frac{1}{2} \Delta \mathrm{P}_{\mathrm{tc}}}{\mathrm{P}_{\text {sat }}\left(\mathrm{T}_{\mathrm{tc}}\right)} .
$$

Substitute Eq. A-5 into Eq. A-9 to obtain

$$
\mathrm{RH}_{\mathrm{tc}}=\frac{\mathrm{P}_{\mathrm{sat}}\left(\mathrm{T}_{\mathrm{dew}}\right)}{\mathrm{P}_{\text {sat }}\left(\mathrm{T}_{t c}\right)} \frac{\mathrm{P}_{\text {dew }}-\frac{1}{2} \Delta \mathrm{P}_{\mathrm{tc}}}{\mathrm{P}_{\text {dew }}} .
$$

Equation A-10, which is in terms of measuring parameters, can be used to ca1culate relative humidity of air in the test cell.

Water vapor saturation pressure can be obtained from a correlation by Maclaine-Cross [11]: 


$$
\mathrm{P}_{\text {sat }}(\mathrm{T})=7.5001 \times 10^{-3} \exp 23.28199-\frac{3780.82}{\mathrm{~T}}-\frac{225805}{\mathrm{~T}^{2}}, \quad(\mathrm{~A}-11)
$$

where $\mathrm{T}$ in kelvins and $\mathrm{P}$ is in torrs.

\section{A.1.2 Calculation of Desiccant Water Content}

In Section 2.0 the following relation was derived to obtain gel water content from the perturbation chromatography and flow conditions:

$$
W=\left[\dot{Q}_{t c}\left(t_{t c}^{*}-t_{t c}^{H e}\right)-\dot{Q}_{b p}\left(t_{b p}^{*}-t_{b p}^{H e}\right)\right] \frac{M_{\text {water }} C_{t c}}{m} .
$$

If the pressure difference between the bypass and the test cell is small, then $\dot{\mathrm{Q}}_{\mathrm{tc}} \sim \dot{\mathrm{Q}}_{\mathrm{bp}} \cdot$ Defining

$$
\Delta t^{*}=t_{t c}^{*}-t_{b p}^{*}
$$

and

$$
\Delta t^{\mathrm{He}}=t_{t c}^{\mathrm{He}}-t_{b p}^{\mathrm{He}} \text {, }
$$

then Eq. A-12 can be expressed as

$$
W=\left(\Delta t^{*}-\Delta t^{H e}\right) \dot{Q}_{t c} \frac{{ }_{w} C_{t c}}{m},
$$

where

$\dot{Q}_{t c}=$ air volume flow rate in the test cell $\left(\mathrm{m}^{3} / \mathrm{s}\right)$

$C_{t c}=$ air water vapor concentration in the test cell $\left(\mathrm{kmol} / \mathrm{m}^{3}\right)$

$\mathrm{m}_{*}=$ mass of desiccant in the test cell ( $\left.\mathrm{kg}\right)$

$\Delta t^{*}=$ time difference between passing $D_{2} 0$ through the test cell and bypass column (s)

$\Delta t^{\text {He }}=$ time difference between passing helium through the test cell and bypass column (s).

Using the ideal gas law,

$$
C_{t c}=\frac{P_{\text {water, } t c}}{R T_{t c}}=\frac{R_{t c} P_{s a t}\left(T_{t c}\right)}{R T_{t c}} \text {, }
$$

where $p_{\text {water, }}$ tc is the partial pressure of water in the test cell.

The mass flow rate of humid air to the test cell is related to the bone-dry air mass flow rate through the mass flow controller: 


$$
\dot{\mathrm{m}}_{\mathrm{tc}}=\dot{\mathrm{m}}_{\mathrm{air}}\left(1+\mathrm{w}_{\mathrm{dew}}\right) \text {. }
$$

Bone-dry air mass flow rate is related to the standard conditions $\left(P_{0}, T_{0}\right)$ and volume flow rate reading of the mass flow meters. Assuming the ideal gas law,

$$
\dot{\mathrm{m}}_{\text {air }}=\dot{\mathrm{Q}}_{\text {reading }} \frac{\mathrm{P}_{\mathrm{O}} \mathrm{M}_{\text {air }}}{\mathrm{R} \mathrm{T}_{\mathrm{O}}} \text {. }
$$

Substitute Eq. A-16 in Eq. A-15 to obtain

$$
\dot{\mathrm{m}}_{\mathrm{tc}}=\dot{\mathrm{Q}}_{\text {reading }} \frac{\mathrm{P}_{\mathrm{o}} \mathrm{M}_{\mathrm{air}}}{\mathrm{RT} \mathrm{T}_{\mathrm{o}}}\left(1+w_{\text {dew }}\right) \text {. }
$$

$\dot{Q}_{t c}$ is related to $\dot{m}_{t c}$ through the ideal gas law:

$$
\dot{Q}_{t c}=\dot{\mathrm{m}}_{t c} \frac{\mathrm{R} \mathrm{T}_{t c}}{\mathrm{P}_{t c} \mathrm{M}_{t c}}
$$

Substituting $E q \cdot A-17$ in $E q \cdot A-18$ and noting that $M_{t c}=M_{a i r}$ since $\mathrm{w}_{\mathrm{dew}}=\mathrm{w}_{\mathrm{tc}}<<1$, we obtain

$$
\dot{Q}_{t c}=\dot{Q}_{\text {reading }} \frac{P_{O}}{P_{t c}} \frac{T_{t c}}{T_{o}}\left(1+w_{d e w}\right) \cdot
$$

Substituting Eq. A-14 and A-19 into Eq. A-13 we obtain

$$
\begin{aligned}
W= & \left(\Delta t^{*}-\Delta t \mathrm{He}\right) \dot{Q}_{\text {reading }} \frac{P_{o}}{P_{t c}} \frac{1}{T_{O}} \\
& \left(1+w_{d e w}\right) M_{W} \frac{R H_{t c} P_{s a t}\left(T_{t c}\right)}{R m} .
\end{aligned}
$$

Using Eqs. $A-5$ and $A-10, E q \cdot A-20$ can be rearranged in terms of measurable quantities $\dot{\mathrm{Q}}_{\text {reading, }} \mathrm{T}_{\mathrm{tc}}, \mathrm{T}_{\mathrm{dew}}, \mathrm{P}_{\mathrm{dew}}, \Delta \mathrm{t}^{*}$, and $\Delta \mathrm{t}$ He

$$
\begin{aligned}
W= & \left(\Delta t^{*}-\Delta t^{H e}\right) \dot{Q}_{\text {reading }} \frac{P_{0}^{M} \text { water }}{T_{0} R m} \\
& \frac{P_{\text {dew }}-0.378 P_{\text {sat }}\left(T_{\text {dew }}\right)}{P_{\text {dew }}-P_{\text {sat }}\left(T_{\text {dew }}\right)} \cdot \frac{P_{\text {sat }}\left(T_{\text {dew }}\right)}{P_{\text {dew }}} .
\end{aligned}
$$

Note that in the above equations we have

$$
\Delta t^{*}=t_{t c}^{*}-t_{b p}^{*},
$$


and

$$
\begin{aligned}
\Delta t^{H e} & =t_{t c}^{*}-t_{b p}^{*}, \\
P_{0} & =760 \text { torr }, \\
T_{o} & =273.15 \mathrm{k} .
\end{aligned}
$$

\section{A.1.3 Procedure for Obtaining an Isotherm}

1. Calculate $\mathrm{w}_{\text {dew }}$ using Eqs. $\mathrm{A}-11$ and $\mathrm{A}-5$.

2. Estimate the average value of $P_{t c}$ using

$$
\mathrm{P}_{\mathrm{tc}}=\mathrm{P}_{\mathrm{dew}}-\Delta \mathrm{P}_{\mathrm{tc}} / 2
$$

3. Calculate $\mathrm{RH}_{t c}$ using Eqs. $\mathrm{A}-10$ and $\mathrm{A}-1 \mathrm{l}$.

4. Calculate $C_{\text {tc }}$ using Eqs. $A-11$ and $A-14$.

5. Calculate

6. Estimate $\Delta t{ }^{* t c}$ and $\Delta t{ }^{\text {He }}$ using Eqs. $A-22$ and $A-23$.

7. Calculate $\mathrm{W}$ using $\mathrm{Eq} \cdot \mathrm{A}-13$.

8. Repeat steps 1 through 7 for one set of experiments at one temperature.

9. Plot $W$ versus $\mathrm{RH}_{\mathrm{tc}}$ '

A BASIC computer program (DATRED) performs steps 1 through 7 . A 1isting of DATRED is given at the end of this Appendix.

\section{A.2 BREAKTHROUGH DATA}

\section{A.2.1 Conversion of Thermal Conductivity Detector Output}

The output signal of the thermal conductivity detector needs to be converted to concentration of water vapor. A calibration curve was obtained to convert output voltage to concentration level by humidifying air to a known level of concentration, having it flow through one cavity of the thermal conductivity detector, and then passing the humid air through a completely dried packed bed test cell. Initially, the moisture in the effluent air stream is fully adsorbed by the desiccant; therefore, dry air comes out of the test cell and passes through the other cavity of the detector. In this way the filament in the first cavity responds to humid air, while the second filament responds to dry air. Since the output signal of the detector is a measure of relative concentration of air in the first cavity to concentration of air in the second cavity, this output signal can be used to obtain the absolute level of concentration in the first cavity, since the concentration in the second cavity is zero. Figure A-1 shows the results of the calibration of the thermal conductivity detector (mode1 10-680). It can be seen that the output voltage of the thermal conductivity detector is approximately linear ( $\pm 5 \%$ ) with air humidity ratio.

\section{A.2.2 Calculation of Normalized Humidity and Outlet Humidity Ratio}

The data from the thermal conductivity detector during the breakthrough experiment can be converted to concentration, or humidity ratio, as follows. 


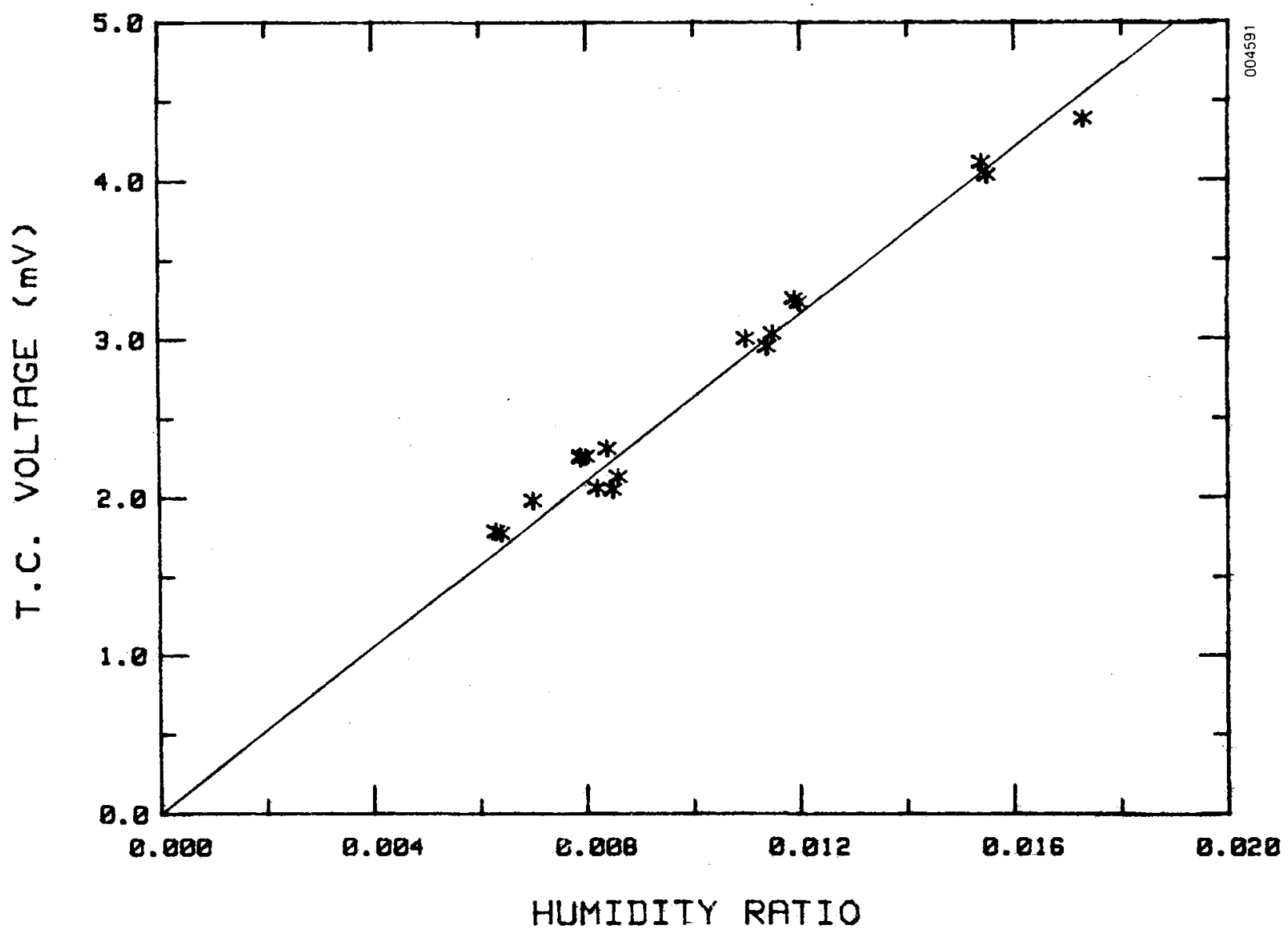

Figure A-1. Dependence of Therma1 Conductivity Detector (Gow-Mac Mode1 10-680) Output Voltage on Air Humidity Ratio

Consider an adsorption case where the inlet humidity is $w_{\text {in }}$ and the desiccant has an initial water content of $\mathrm{W}_{\mathrm{O}}$, which is drier relative to the inlet air. After adsorption of water vapor from the air by the desiccant in the test cell, the outlet concentration from the test cell is initially in equilibrium with the desiccant in the test cell; i.e.,

$$
w_{0}=f\left(W_{0}, T_{t c}, P_{t c}\right)
$$


At this time, the difference between the outlet concentration $\left(w_{0}\right)$ and inlet concentration $\left(w_{i n}\right)$ is at its largest value, so the output of the thermal conductivity detector is also at its largest value. As time passes, the desiccant in the test cell loses its adsorption capacity and the outlet concentration increases, while the output voltage of the thermal conductivity detector decreases, until the outlet concentration reaches its final value, $\mathrm{w}_{\mathrm{f}}=\mathrm{w}_{\mathrm{in}}$, when the test cell has reached equilibrium. The first graph in Figure $\mathrm{A}-2$ shows the general trend for an adsorption case.

We define the normalized voltage as

$$
v_{n}(t)=\frac{V_{\text {max }}-V(t)}{V_{\text {max }}-V_{\min }}
$$

and the normalized humidity as

$$
w_{n}(t)=\frac{w_{o}-w(t)}{w_{o}-w_{f}} .
$$

Since the output voltage depends linearly on humidity ratio (Figure A-1), we can use the normalized voltage to determine the shape of the normalized humidity curve.

By equating the two normalized values, we obtain

$$
v_{n}(t)=w_{n}(t)=\frac{w_{o}-w(t)}{w_{0}-w_{f}} ;
$$

therefore, the dimensional outlet humidity ratio is

$$
w(t)=w_{o}+v_{n}(t)\left(w_{f}-w_{o}\right)
$$

where $\mathrm{w}_{\mathrm{f}}=\mathrm{w}_{\mathrm{in}} \cdot$

The inlet humidity ratio can be calculated from measured quantities using Eq. A-5. The equilibrium humidity ratio can be obtained from the initial conditions of the test cell which, in turn, depend on the inlet conditions of the air for the previous experiment. $V_{n}(t)$ is the quantity that can be calculated from the output of the thermal conductivity detector.

The second graph in Figure A-2 shows the general trend for a desorption case and shows that Eqs. A-24 to A-27 are the same for the desorption case.

A BASIC program (CAL) is used to calculate $w_{\text {in }}$ and $w_{e q}$. A listing of CAL is given at the end of this Appendix. 

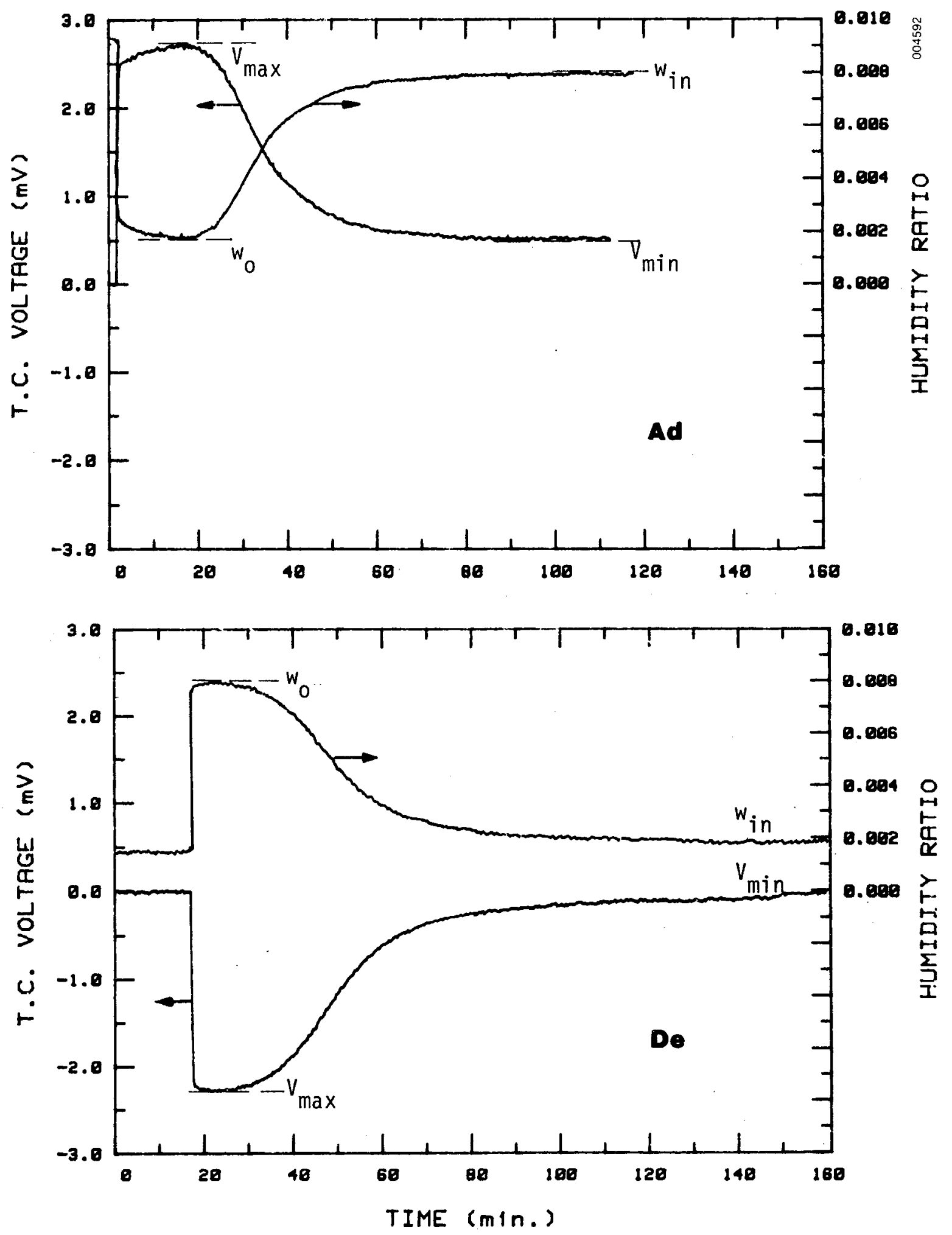

Figure A-2. Relation between Output Voltage of Thermal Conductivity Detector and Air Humidity Ratio (Experiments No. 41, 42). Voltage output is positive for adsorption (Ad), negative for desorption (De). 
The advantage of using the normalized humidity curves is that the shape of the breakthrough data can be compared directly, whether the tests were for adsorption or desorption and whether the inlet and equilibrium conditions were different for each test. In this manner, the dynamic performance can be evaluated directly, as discussed in Section 6.0 . 


\section{CAL}

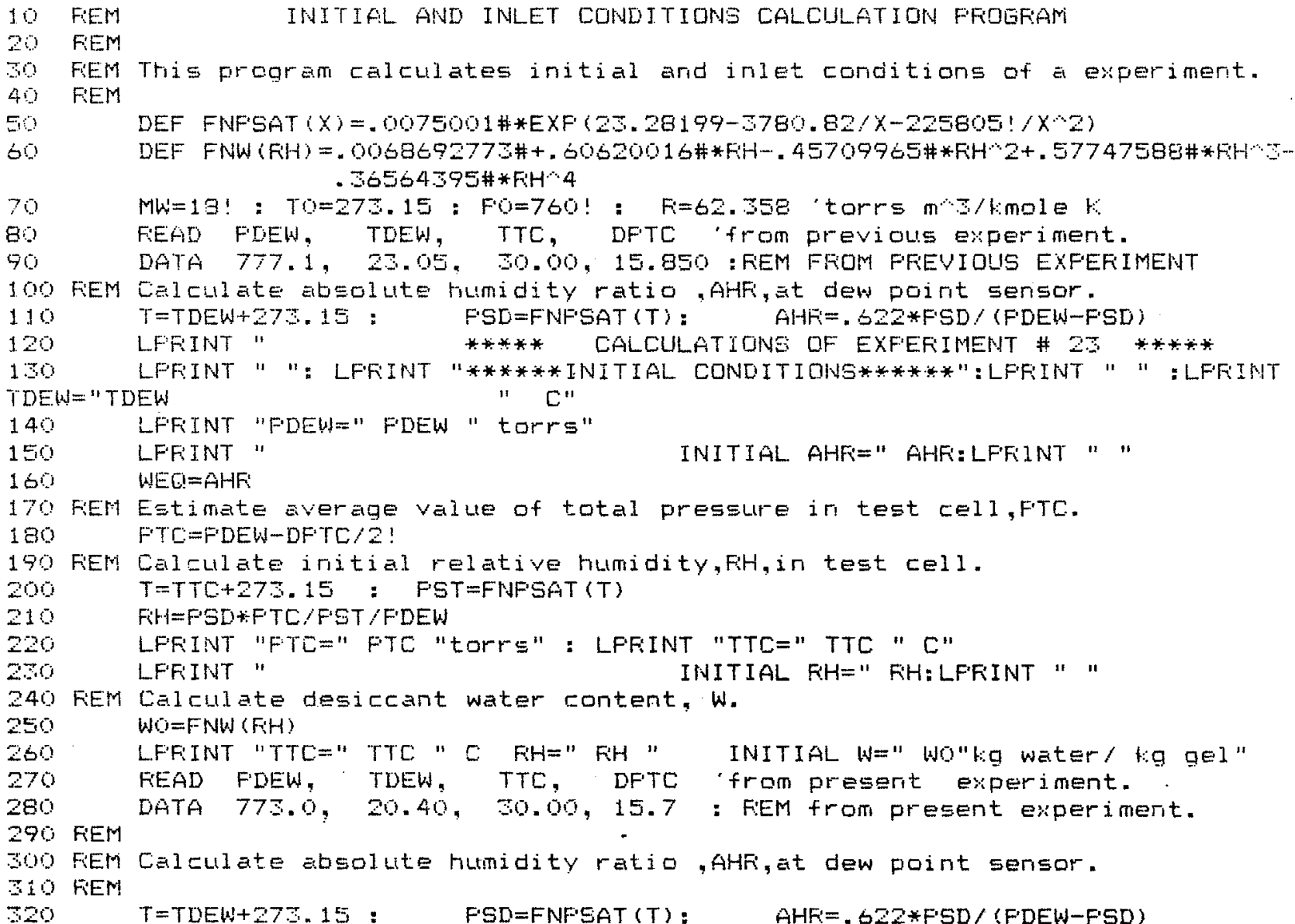

GFFINT" "

DEW=" TDEW "

340 LFFINTT "FDEW=" FDEW "torrs"

350

SBO FIEM

370 FEM Estimate average value of total pressure in test cell,FTC.

SBO FEM

$390 \quad$ F.TC=FDEW-DF'TC/2!

400 FEM

410 FEH Calculate inlet relative humidity, FiH, to test cell.

420 FEM

$450 \quad T=\mathrm{TTC}+27.15:$ : $\mathrm{FST}=\mathrm{FNFSAT}(T)$

$440 \quad \mathrm{~F} H=F \mathrm{SD} * \mathrm{~F} \cdot \mathrm{TC} / \mathrm{F} \mathrm{ST} / \mathrm{F}$ DEW

450 LFRINT "FTC=" FTC "torrE" : LFFINT "TTC=" TTC " $C$ "

460 LFFINT" INLET FH=" BH:LFFINT" "

470 FIEM

480 FEM Calculate desiccant water content, $w$.

490 FIEM

$500 \quad W F=F N W(F H)$

510 LFFINT "TTC=" TTC " $C$ FH $="$ FHH " FINAL W=" wF"lg water/ kg gel"

520 LFFINT " "LFFINT "*** wi $n=$ "AHF"***** weg="WEQ"***"

$530 \quad$ VMAX $=-.30 \quad:$ VMIN=-.03

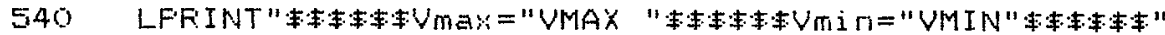

541 LFFIINT " " LFFINT" ": LFFIINT" "

542 LFFINT" FILENAME \# LINE TIME STEF TIME DIFF. FILENAME'

550

END 


\section{DATRED}

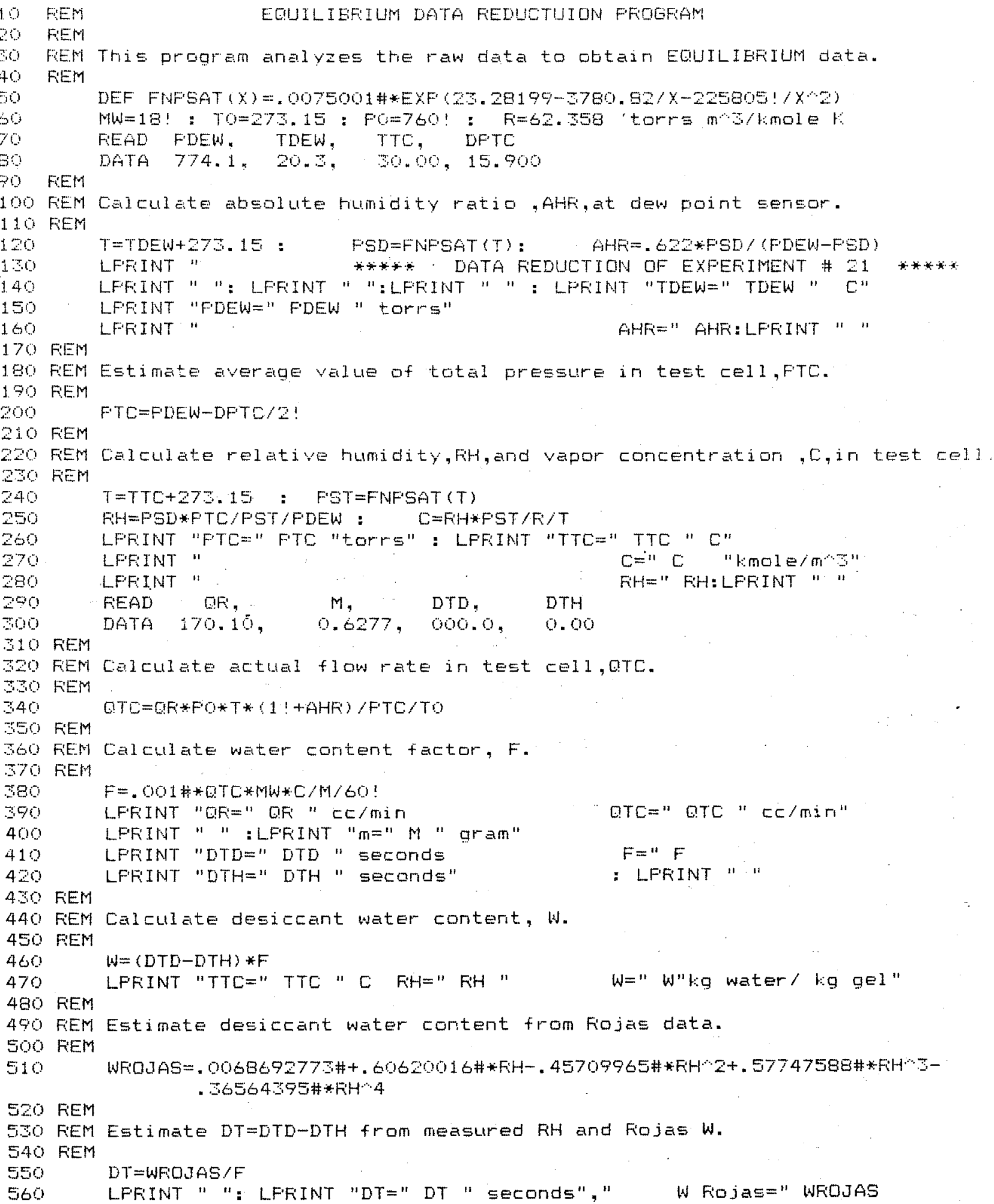




\section{APPENDIX B}

\section{PREPARATION OF TEST CELLS}

\section{B.1 PACKED BED TEST CELL}

1. Connect the empty test cell to a dry air tank.

2. Wrap heat tape around the test cell and air line and heat to about $100^{\circ} \mathrm{C}$.

3. While at $100^{\circ} \mathrm{C}$, purge with the dry air for about 30-45 min.

4. After purging, close both valves of the test cell, turn off the heating tape, close the valve of the air tank, and let the test cell cool down to ambient temperature.

5. Measure and record the weight of the dry and empty test cell five times, then calculate the average weight by using the electrical balance Mettler AK160, (160-g maximum).

6. Record the ambient temperature near the balance.

7. Pack the test cell with silica gel according to "How Packed Columns Are Made." Record the particle size.

8. Plug both ends of the test cell with glass wool.

9. Repeat steps B.1.1, B.1.2, and B.1.3 with one exception: purge for $1 \mathrm{~h}$.

10. Repeat step B.1.4.

11. Measure and record the weight of the dry and packed test cell five times, and calculate the average weight.

12. Record the ambient temperature near the balance. (Now the packed test cell is ready for installation. Keep this test cell in a clean enclosure; e.g., a $\mathrm{Zip}-10 \mathrm{c}^{\circledR}$ bag, until it is ready for installation.)

13. Subtract the average weights obtained in steps $B .1 .5$ and $B .1 .11$ to get the average weight of the dry silica gel and glass wool.

14. At the end of the experiment(s), take out the glass wool plugs and free the glass wool of all silica gel particles. Dry the glass wool and weigh it five times. Calculate the average weight.

15. Subtract the averages obtained in steps B.1.13 and B.1.14 to get the average weight of the dry silica gel.

\section{B.2 Parallel Passage Test cell}

1. Preparation of the empty test cell:

a. Calculate the desired $\mathrm{h} / \mathrm{L}$ ratio.

b. Calculate the number of Mylar $^{R}$ tapes needed for the desired height.

c. Cut the specified pieces of $\mathrm{Mylar}^{\mathrm{R}}$ tape (length and width).

d. Paste the tapes on the top and bottom walls of the test cells. 
e. Install the flow straightener and the screens.

f. Close the test cell and tighten the screws thoroughly.

g. Connect the Swagelok ${ }^{R}$ fittings and the two valves.

h. Leak test the test ce11 with soap bubbles.

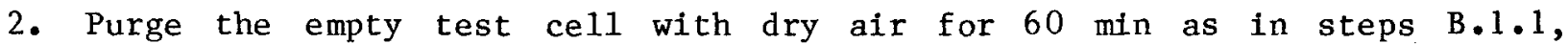
$\mathrm{B} .1 .2$. , and $\mathrm{B} \cdot 1.3$, but heat to only $60^{\circ} \mathrm{C}$.

3. Close both valves of the test cell, turn off the heating element, close the valve of the air tank, and let the test cell cool down to ambient temperature (as in step B.1.4).

4. Measure and record the weight of the dry and empty test cell five times. Calculate the average weight using the optical balance Mettler H315 (1000-g maximum).

5. Record the ambient temperature near the balance.

6. Open the test cell and sprinkle the specified size of silica gel particles evenly on the top and bottom tapes. Gently brush the excess particles of silica gel away from all parts of the test cell. Record the size of the silica gel particles used.

7. Close the test cell and leak test it with soap bubbles. In leak testing, do not exceed 20 PSI.

8. Purge and heat the test cell for 60 minutes to remove all moisture from the silica gel. (This step is similar to step B.2.2).

9. Close both valves of the test cell and proceed as in step B.2.3.

10. Measure and record the weight of the dry, silica gel loaded test cell five times. Calculate the average weight.

11. The silica gel loaded test cell is now ready for installation. Keep the test ce11 in a clean and dry environment (e.g., a Zip-loc ${ }^{\circledR}$ bag) until time of installation.

12. Subtract the average values obtained in steps B.2.4 and B.2.10 to obtain the average weight of the dry silica gel in the test cell. 


\section{APPENDIX C}

\section{DETAILED OPERATING PROCEDURE}

\section{1 PROCEDURE}

1. Insta11 the test cell with specified characteristics between ports 非 and \#6 of Valco port valve V3. Set V3 in S.

2. Start the preliminary set-up. See Section C.2.

3. Refer to Data Sheet for values of the experimental parameters.

4. Start the isothermal bath for the bubbler at the specified temperature (TBBL). See Section C.3.

5. Start the isothermal tank (40 gal) at the specified temperature (TBTH). See Section C.4.

6. LOAD and RUN the specified HP-85 computer program with specified parameters.

7. Turn on the Mass Flow Controller Unit. Open the bypass gas bubbler valve completely. Close the gas bubbler valves $\# 1$ and $\# 2$ completely.

8. Turn on the Dew Point Hygrometer indicator. Try to BALANCE it, then set it to OPERATE position.

9. Set the dials of the Mass Flow Controller unit at the specified settings to obtain the desired flow rates (Q2, Q3).

10. Open the cut-off valve of the zero air cylinder and set the supply pressure at specified value. (PS) with the regulator while the shut-off valve of the regulator is closed (fully CW).

11. Open the shut-off valve(s) of the Mass F1ow Controllers (valve of mass flow controller $\# 2$ or $\# 3$ or both $\# 2$ and $\# 3)$.

12. Open the pressure control valves completely. If the line pressure of this experiment is the same as the line pressure of previous experiment, there is no need to change the setting of the valves.

13. Turn on the vacuum pump while the vacuum exhaust valve is closed. Note that if the pressure of this experiment is the same as the pressure of previous experiment, there is no need to change the setting of this valve.

14. Open the shut-off valve of the regulator of the supply air and regulate the supply pressure if necessary.

15. Open the vacuum exhaust valve so that the line pressure (channel \#4 of MKS indicator on the instrument rack) reaches within 10-50 torr of the specified pressure $P(T)$. This is a coarse adjustment.

16. Close (or open) the pressure control valves to reach the specified pressure $P(T)$ within \pm 5 torr. This is a fine adjustment.

17. Turn on the thermal conductivity power supply unit and the chart recorder. Leave the chart switch at off position. See Section C.5. 
18. Moisturize the dry air at the specified dew point temperature (TDEW).

a. If the specified TDEW is below $-7^{\circ} \mathrm{C}$, leave the bypass gas bubbler valve open and gas bubbler valves $\# 1$ and $\left.\right|_{2}$ closed.

b. If the specified TDEW is above $-7^{\circ} \mathrm{C}$, open gas bubbler valves $\#_{1}$ and \#2 completely, and close the bypass gas bubbler valve completely.

19. When TDEW is steady $\left( \pm 0.3^{\circ} \mathrm{C}\right)$ try to "zero" the Thermal Conductivity Unit within $\pm 0.01 \mathrm{mV}$ at sensitivity of $1-8$. Use a DVM or channe1 18 of $\mathrm{HP}-$ $3497 \mathrm{~A}$ for monitoring.

19a. Open the U1tra High Vacuum (UHV) valve to sample the process air into the UHV chamber for analysis. See Section C.6.

\section{C.1.1 Start of the Breakthrough Part}

20. Reset the time step (Push K5) of the HP-45 computer program to new specified time step and store the data.

21. Start feeding the paper of the chart recorder at a specified speed, response, and span.

21 . Set the mass spectrometer to TREND ANALYSIS of mass 18.

22. Switch V3 to P (air flow through test cel1).

23. Observe the trend of response of the thermal conductivity detector to the effluent air from test cell on the chart recorder. When there are no changes of voltage $( \pm 0.1 \mathrm{mV})$ and the thermal conductivity detector is "zeroed" again $( \pm 0.1 \mathrm{mV})$, the silica gel in the test cell has reached equilibrium and the breakthrough part is finished.

23a. Record the results of the sample gas analysis of the Mass Spectrometer on its chart printer every minute. See Section C.6.

24. Store the data with specified file name on a tape by pushing "STOP," key $\mathrm{K} 3$, of $\mathrm{HP}-85$.

25. Stop the chart paper of chart recorder.

\section{C.1.2 Start of the Equilibriun Part}

26. Load the inactive loop of the 10-port valve (V2) with $\mathrm{D}_{2} \mathrm{O}$ plus dry air:

a. Make sure that there is enough heavy water $\left(D_{2} 0\right)$ in the $D_{2} 0$ chamber.

b. Turn off $\mathrm{D}_{2} \mathrm{O}$ shut off valve, LV2.

c. Turn on air shut off valve, LV1, at 5 PSi.

d. Turn on $\mathrm{D}_{2} \mathrm{O}$ purge valve, LV4.

e. Turn on $\mathrm{D}_{2} \mathrm{O}$ shut off valve, LV2, slightly so that air does not bubble through the heavy water vigorously.

f. Purge $\mathrm{D}_{2} \mathrm{O}$ air for 1 to 2 minutes, then close $\mathrm{D}_{2} \mathrm{O}$ purge valve, LV4.

g. Close $\mathrm{D}_{2} \mathrm{O}$ shut off valve, LV2.

h. Close air shut off valve, LVl. 
27. "Rezero" the thermal conductivity detector and then start the chart paper with paper speed of $20 \mathrm{~cm} / \mathrm{min}$ and span of $2 \mathrm{mV}$.

28. Restart the computer program by pushing $\mathrm{K} 1, \mathrm{~K} 2$ keys of $\mathrm{HP}-85$.

29. Switch the position of V2 (from Secondary to Primary or P to S) while starting the stop watch. Observe the response of the thermal conductivity detector on the chart recorder. Turn the paper feed off after a peak is observed. Record on the chart paper the speed, span, response, sensitivity, and action taken.

$29 \mathrm{a}$. Observe the trend of analysis of $D_{2} O$ on mass spectrometer and stop the stop watch when a peak is observed. Use the mass spectrometer printer to print the results, and record the action taken and the time difference.

30. Load the inactive loop of ten-port valve (V2) with helium gas:

a. Turn on He shut off valve, LV5, at 15 PSi.

b. Turn on He purge valve, LV3.

c. Close He purge valve (LV3) after purging 1 to 2 minutes.

d. Close He shut off valve, LV5.

31. "Rezero" the thermal conductivity detector and then start the chart paper with paper speed of $20 \mathrm{~cm} / \mathrm{min}$ and span of $20 \mathrm{mV}$.

32. Switch the position of V2 (P to S) while starting the stop watch. Observe the response of thermal conductivity detector on the chart recorder. Turn off the paper feed after a peak is observed. Record on the chart paper the speed, span, response, sensitivity and the action taken.

32a. Observe the trend of analysis of He on the mass spectrometer and record the time when a peak is observed. Use mass spectrometer printer to print the results, also record the action taken and the time difference.

33. Switch $V 3$ to Secondary position to flow through the bypass and wait until pressure, flow rate and dew point temperature become steady.

34. Load the inactive loop of ten-port valve (V2) with He gas:

a. Turn on He shut off valve (LVS) at 15 PSi.

b. Turn on He purge valve (LV3).

c. Close He purge valve (LV3) after purging 1 to 2 minutes.

d. Close He shut off valve (LV5).

35. "Rezero" the thermal conductivity detector and then start the chart paper with paper speed of $20 \mathrm{~cm} / \mathrm{min}$ and span of $20 \mathrm{mV}$.

36. Switch the position of V2 ( $P$ to $S$ ) while starting the stop watch. Observe the response of the thermal conductivity detector on the chart recorder. Turn off the paper feed after a peak is observed. Record on the chart paper the speed, span, response, sensitivity and the action taken.

36a. Observe the trend of analysis of He on mass spectrometer and stop the stop watch when a peak is observed. Use mass spectrometer printer to print the results, also record the action taken and the time difference. 
37. Load the inactive loop of ten-port valve (V2) with $\mathrm{D}_{2} \mathrm{O}$ and zero air:

a. Make sure that there is enough heavy water $\left(D_{2} 0\right)$ in the $D_{2} 0$ chamber.

b. Turn off $\mathrm{D}_{2} \mathrm{O}$ shut off valve, LV2.

c. Turn on air shut off valve, LV1, at 5 PSi.

d. Turn on $\mathrm{D}_{2} \mathrm{O}$ purge valve, LV4.

e. Turn on $\mathrm{D}_{2} \mathrm{O}$ shut off valve, LV2, slightly so that air does not bubble through the heavy water vigorously.

f Purge $\mathrm{D}_{2} \mathrm{O}$ air for 1 to 2 minutes, then close $\mathrm{D}_{2} \mathrm{O}$ purge valve, LV4.

. Close $\mathrm{D}_{2} \mathrm{O}$ shut off valve, LV2.

h. Close air shut off valve, LVl.

38. "Rezero" the thermal conductivity detector and then start the chart paper with paper speed of $20 \mathrm{~cm} / \mathrm{min}$ and span of $2 \mathrm{mV}$.

39. Switch the position of V2 (from Secondary to Primary or $P$ to $S$ ) while starting the stop watch. Observe the response of the thermal conductivity detector on the chart recorder. Turn the paper feed off after a peak is observed. Record on the chart paper the speed, span, response, sensitivity and the action taken.

40. The Equilibrium Part is finished. Make sure that switch $\mathrm{V} 3$ is in $\mathrm{S}$ (secondary).

41. Follow either 41 (a) or 41 (b) below as specified in Data Sheet:

a. Test is finished. Follow the shut down instructions. See Section C.7.

b. Change the specified experimental parameters as mentioned in the Data Sheet and follow Steps 3 to 41 .

\section{C.2 PRELIMINARY SET-UP}

\section{C.2.1 Valves}

1. Set Valco port valve, V1, to primary.

2. Set Valco port valve, V2, to secondary.

3. Set Valco port valve, V3, to secondary (test cell out).

4. Set the by-pass valve to open (CCW).

5. Set the two (2) pressure control valves to open (CCW).

6. Set the coarse and fine bypass exhaust valve to close position (fully CW).

7. Set the by-pass gas bubbler valve to open (fully $\mathrm{CCW}$ ).

8. Set the gas bubbler valve $\# 1$ and \#2 to close (fu1ly CW).

9. Set all the valves of helium or $\mathrm{D}_{2} 0$ loading to open. 


\section{C.2.2 Gas or Air Supply}

1. Valves on gas or air cylinders closed (CW position).

2. Regulator valve closed (CW position).

\section{C.2.3 Therma1 Conductivity Power Supply Control Unit, Hode1 40-002}

1. Set zero potentiometer to 500 .

2. Set sensitivity control to 1 .

3. Set polarity switch to either position ( + or - ).

4. Set power switch to "off" position.

5. Set coarse current potentiometer fully CCW.

6. Set fine current potentiometer about mid-range.

\section{C.2.4 Mass F1ow Controller Read-out Box, Mode1 R0-14-300}

1. Set the function switch to the "off" position.

\section{C.2.5 Gould 110 Strip Chart Recorder, Model 15-4328-10}

1. Set power switch to "off" position.

2. Set the chart switch to "off" position.

3. Remaining controls to be determined.

4. Connect a Digital Valt Meter (DVM) to the chart recorder for monitoring. Use $200-\mathrm{mV}$ scale.

\section{C.2.6 Vacuum Pump}

1. Set the power switch of the Vacuum Pump to "off" position.

\section{C.3 ISOTHERMAL BATH FOR THE GAS BUBBLER}

\section{C.3.1 Start-Up}

1. Insure that the isothermal bath is filled with deionized water.

2. Insure that the temperature is set to the desired temperature.

3. The safety cutout should be set at about $20^{\circ}$ above the temperature setting.

4. The Heating Capacity control should be set to fully CW position.

5. Set the Cool-Flow temperature $1^{\circ}$ to $3^{\circ} \mathrm{C}$ below the isothermal bath temperature. 
6. Turn on the Main Power switch of the isothermal bath.

7. Turn on the Boost Heater switch, if necessary.

8. Turn on the main power switch of the Coo1-Flow 75.

9. Monitor the bath temperature on the instrument rack or on the printer under TBBL.

\section{C.3.2 Shut-Down}

Check the experimental matrix before shutting down the isothermal bath and the Cool-Flow 75. It may be feasible to let these run constantly or be allowed to run through one or more tests.

1. To shut down, turn off the main power switch on the Cool-Flow 75.

2. Turn off the main power switch on the isothermal bath.

\section{C.4 HEATERS ( $2 \mathrm{~kW}$ and $6 \mathrm{~kW})$}

\section{C.4.1 Start-Up Procedure}

Before applying power to the heaters, the precautions in steps 1 through 11 should be taken.

1. The main (100-A) circuit breaker is in the "off" position in pane1 PP129H.

2. The $35-\mathrm{kW}(60-\mathrm{A})$ circuit breaker is in the "off" position in pane1 PP129H.

3. The safety latch is down and holding closed the door of the control pane1 adjoining pane1 PP129H.

4. The arm switch on the control panel door is in the "off" position.

5. The toggle switch on the control panel is in the "off" position (toggle down).

6. The temperature control knob for the temperature controller for the 6-kW heaters is turned fully CCW.

7. On the YSI mode1 72 proportional temperature controller:

a. The power switch is set to "off" position (toggle down).

b. The band-width ${ }^{\circ} \mathrm{C}$ is set to any position.

c. All three temperature set point knobs are set to 0 .

d. The line cord for the $2-\mathrm{kW}$ heaters is disconnected.

8. The 40-gal tank is full of water; when this is confirmed, raise the tank sufficiently to fully engage the lid.

9. The metal safety block is placed in its proper position.

10. A sufficient amount of water is in the overflow container. 
11. The stir is activated by opening the input air valve.

12. Connect the line cord for the 2-kW heater.

13. On the YSI model 72:

a. Set the power switch to "on".

b. Set desired temperature.

c. Set desired band width.

14. Set desired temperature for the $6-\mathrm{kW}$ heaters. (This setting should be about $4^{\circ}$ to $5^{\circ} \mathrm{C}$ lower than the setting for the $2-\mathrm{kW}$ heater.)

15. Turn on main 100-A circuit breaker.

16. Turn on the 60-A circuit breaker.

17. Set the arm switch to "on."

18. Switch the toggle switch to "on" (up position).

19. Monitor the temperature of the 40-gal tank by:

a. "TBTH" of the printer read-out,

b. Digital read-out "water" on the instrument rack.

\section{C.4.2 Shut Down Procedure}

20. 6-kW Heaters

a. Turn temperature controller knob fully CCW.

b. Switch the toggle switch to "off" (down position).

c. Set the arm switch to "off."

d. Set the 60-A circuit breaker to "off."

e. Set the 100-A circuit breaker to "off."

21. 2-kW Heaters

a. Set the power switch to "off."

b. Set the three temperature set point knobs to "0."

c. Disconnect the line cord for the $2-\mathrm{kW}$ heater.

\section{C.5 THERMAL CONDUCTIVITY POWER UNIT START-UP}

1. Insure that air is flowing through the thermal conductivity cel1.

2. Set the power switch on the power supply control unit to the "on" position.

3. With the coarse and fine current controls, set the current to 3-7 mA depending on the temperature of the thermal conductivity cell; DO NOT EXCEED $8 \mathrm{~mA}$. Consult the manufacturer's graph. Allow time for warm-up. 
4. With the zero control of the power supply control unit, zero (balance) the circuit of the thermal conductivity cell.

5. Allow the system to stabilize; re-zero if necessary.

6. Switch polarity on the power supply control unit, if necessary, to give a positive reading on the DVM or an upward swing on the recorder.

\section{C.6 OPERATION OF ULTRA HIGH VACUUM SYSTEM}

\section{C.6.1 Chamber}

1. Let about $20 \mathrm{~L} / \mathrm{min}$ of tap water flow through the cooling unit of TSU-170 pumping unit.

2. Turn on the "pump" switch of TSU-170.

3. Monjtor the pressure of the chamber using convection vacuum gauge above $10^{-4}$ torr.

4. When the vacuum reaches $10^{-4}$ torr turn on the "heat" switch of TSU-170.

5. Apply power to the heating tapes on the chamber to maintain a surface temperature of about $100^{\circ} \mathrm{C}(40 \%$ power $)$. Bake the chamber at higher temperatures if necessary.

6. The time required for the vacuum in the chamber to reach $10^{-9}$ to $10^{-8}$ torr depends on the cleanliness of the chamber and the start-up pressure in the chamber.

7. The chamber can be degased using the ionization gauge tube and associating ionization gauge controller. Maintain the vacuum between $10^{-4}$ to $10^{-9}$ torr using the ionization gauge controller.

8. Best results can be obtained if the TSU-170 unit is not turned off; i.e., is running at all times.

\section{C.6.2 Mass Spectrometer (DATAQUAD)}

1. Turn on the power and follow the instructions of the DATAQUAD manual.

2. Go to BARGRAPH mode with PERC 5, GAIN $-10 \mathrm{M}$. Store it in BACKGROUND and print it.

3. Sample the process air for analysis:

a. Turn on the forepump (Rotary Vane Pump, DUO $1.5 \mathrm{~A}$ ).

b. Turn on the capillary tube heater.

c. Open the gas inlet valve of the chamber to create a chamber vacuum of $10^{-6}$ to $10^{-5}$ torr.

4. Go to BARGRAPH mode with different gains (and PERC) for analysis of a uniform composition process air.

5. Go to TREND ANALYSIS for qualitative analysis of a desired mass to electron ratio as instructed in the DATAQUAD manual. 
6. When finished with sample analysis:

a. Close the gas inlet valve of the chamber.

b. Turn off the capillary tube heater.

c. Turn off the forepump.

\section{C.7 OVERALL SHUT-DOWN INSTRUCTIONS}

To insure that the power switch on the thermal conductivity power supply control unit is turned to the "off" position before the air or gas supply is cut off, proceed as follows:

1. Switch Valco port valve, V3, to secondary (test cell out).

2. Reduce the current by turning the coarse current control on the power supply control unit all the way to CCW.

3. Turn the power switch of the power supply control unit to the "off" position.

4. Open the bypass bubbler valve, then close bubbler valves $\# 1$ and $2^{2}$.

5. Turn the function switch of the mass flow controller read-out box to the "off" position.

6. Close the cut-off valve regulator of the air supply by turning it to CW.

7. Turn off the vacuum pump.

8. Close the cylinder valves of the air or gas supplies by turning to CW.

9. If the air or gas is to be bled off in the system, do it very slowly.

10. Close the ultra high vacuum gas inlet valve. Turn off the forepump and the capillary tube heater.

11. Turn off the $6-\mathrm{kW}$ and $2-\mathrm{kW}$ heaters according to Section C.4.

12. Turn off the isothermal bath according to Section C.3.

13. Close all the valves for loading of helium or $\mathrm{D}_{2} 0$. 


\section{APPENDIX D}

\section{RAW DATA}

\section{D.1 SAMPLES OF DATA FROM THE RESIDUAL GAS ANALYZER AND THERMAL CONDUCTIVITY DETECTOR}

Samples of raw data obtained in Experiment No. 7 are shown in Figures D-1 through D-5 for the following operating conditions:

Test Ce11: Packed Column 0

$$
\begin{aligned}
\mathrm{T}_{\text {tc }} & =30^{\circ} \mathrm{C} \\
\mathrm{T}_{\text {dew }} & =11.2^{\circ} \mathrm{C} \\
\mathrm{P}_{\text {dew }} & =852.1 \text { torr } \\
\mathrm{Q}_{\text {reading }} & =100 \mathrm{~cm}^{3} / \mathrm{min} \\
\mathrm{P}_{\text {tc }} & =738 \text { torr. }
\end{aligned}
$$

\section{D.2 BREAKTHROUGH DATA FOR EACH EXPERTMENT}

As discussed in Appendix $A$ and shown in Figures 6-1 and 6-2 the output of the thermal conductivity detector can be converted to a normalized humidity and an absolute humidity ratio. In the graphs at the end of this appendix, these two quantities are plotted as a function of real time for each experiment. For experimental conditions of each experiment see Table 6-1.

A11 experiments conducted at $\mathrm{T}_{\mathrm{tc}}=30^{\circ} \mathrm{C}$ are plotted at an interval of $160 \mathrm{~min}$ for ease of comparison between experiments, even if the duration of the experiment was longer. Tests lasting longer than $160 \mathrm{~min}$ are discussed in Section 6.0 , where the full breakthrough response is shown. Tests conducted at $\mathrm{T}_{\mathrm{tc}}=80^{\circ} \mathrm{C}$ are plotted with a time interval of $60 \mathrm{~min}$, in order to display the rapid response. Characteristic results are compared in Section 6.0 . 
面

BAF GFEFH

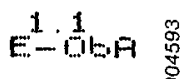

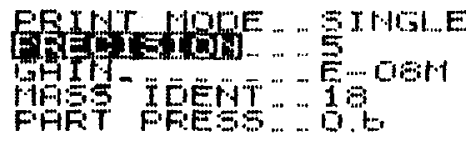

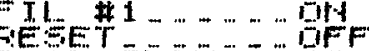

वा:

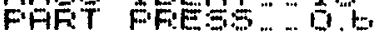

FiLi...

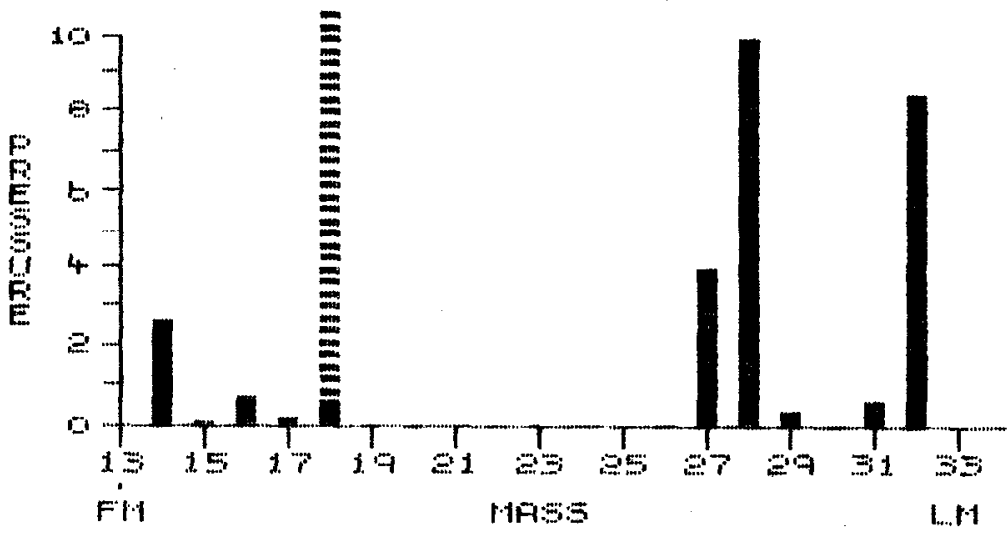

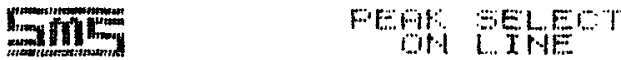

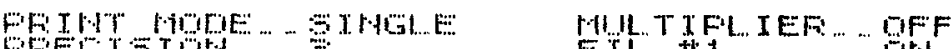

FED $\mathrm{STH}+\ldots .3$.

\begin{tabular}{|c|c|c|c|c|c|}
\hline \multicolumn{2}{|c|}{ CHFHAEI } & 14158 & Fil Ffort & FWE $=\because 17 E$ & AII \\
\hline j. & ard & 2 & OFF & $\because$. & $E=-197$ \\
\hline 3 & $61 \%$ & 13 & $O F F$ & $\bullet$. & E. \\
\hline$=$ & $\sigma \mathrm{H}$ & 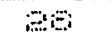 & UF"F & 3. & $E \ldots 197$ \\
\hline 4 & $0+1$ & 30 & $\mathrm{DFF}$ & $B \equiv$ & $E-01 \%$ \\
\hline$E$ & ots & 17 & $\overline{D F F}$ & $x 9$ & $E-1019$ \\
\hline t. & and & $1 t$ & $\mathrm{OFF}$ & 7.7 & $E-19 A$ \\
\hline 7 & Det & 14. & DFF & $\Xi 9$ & $E \ldots B A$ \\
\hline$\vdots$ & DIt & 20 & $B F=$ & 5.2 & $E-11 F$ \\
\hline
\end{tabular}

Figure D-1. Output of DATAQUAD for the Composition of Inlet Air to the Test Ce11 before the Breakthrough Part 

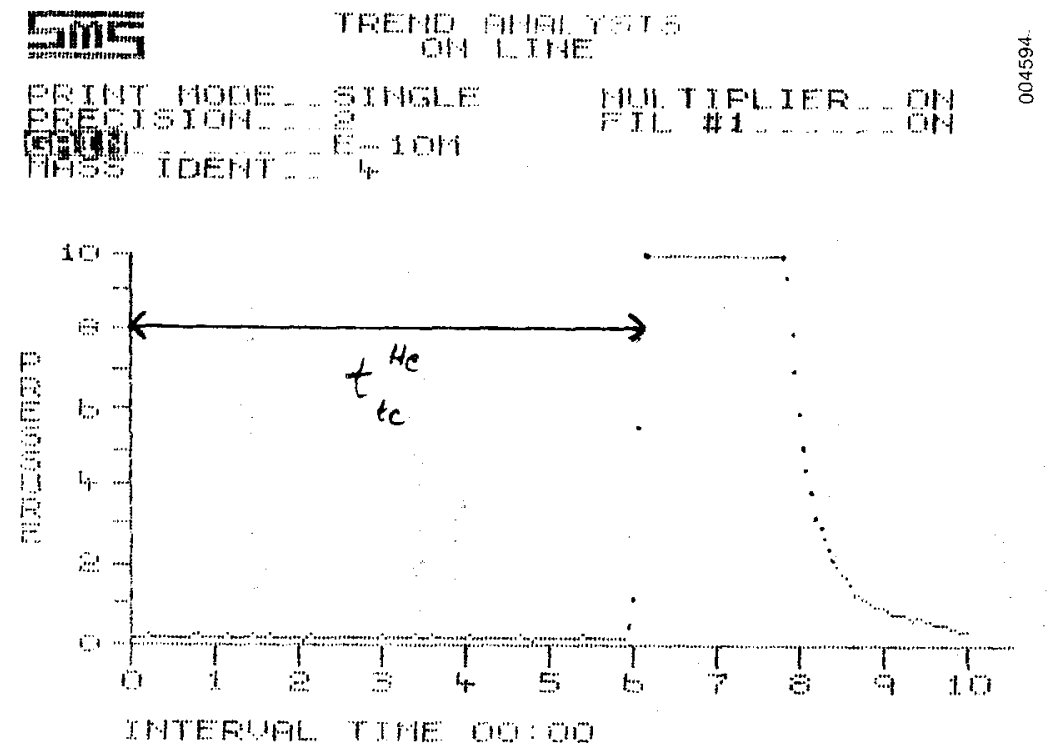

Figure D-2. Output of DATAQUAD after Helium Gas is Injected to the Test Ce11

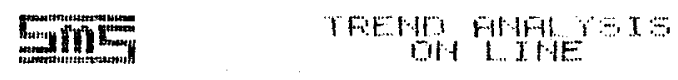
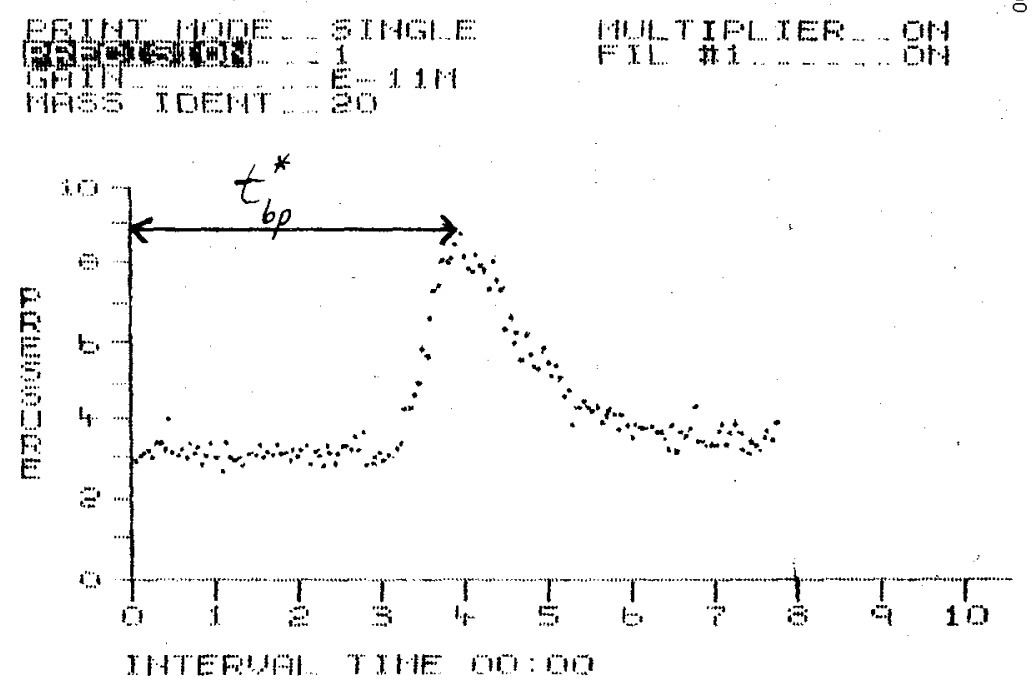

Figure D-3. Output of DATAQUAD after Injection of $\mathrm{D}_{2} \mathrm{O}$ to the Bypass Column 
,

W
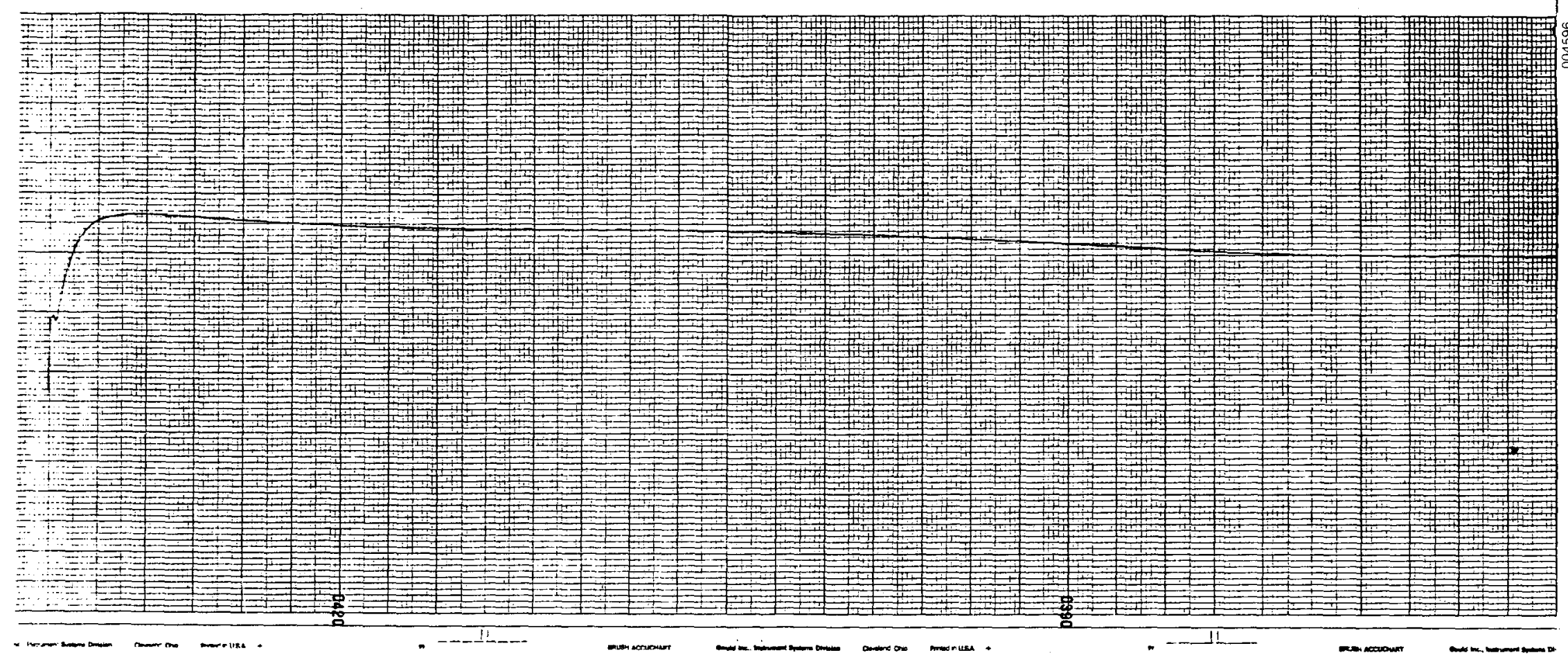

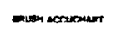

-in- - 


\section{EXPEFIMENT \# 1}
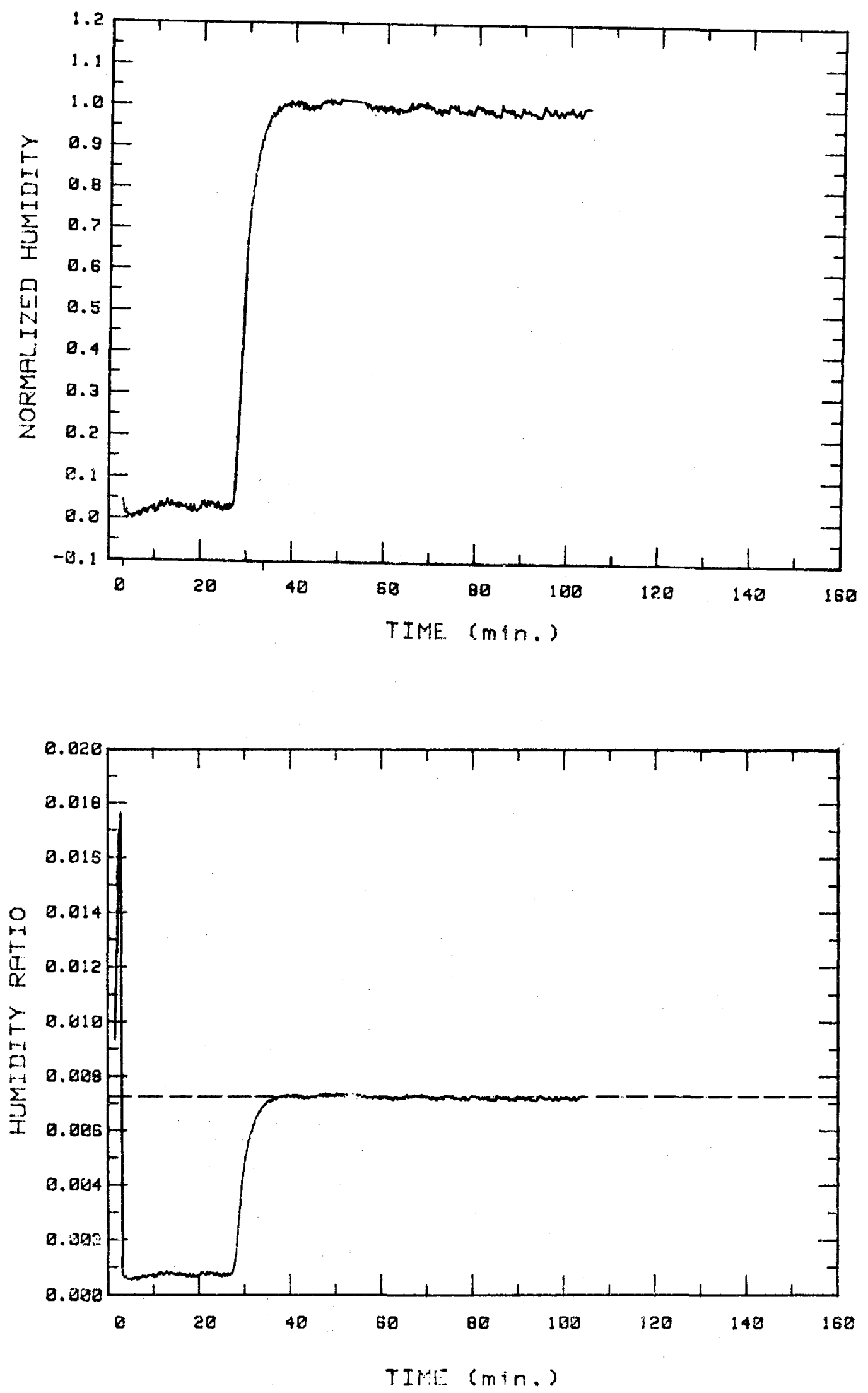

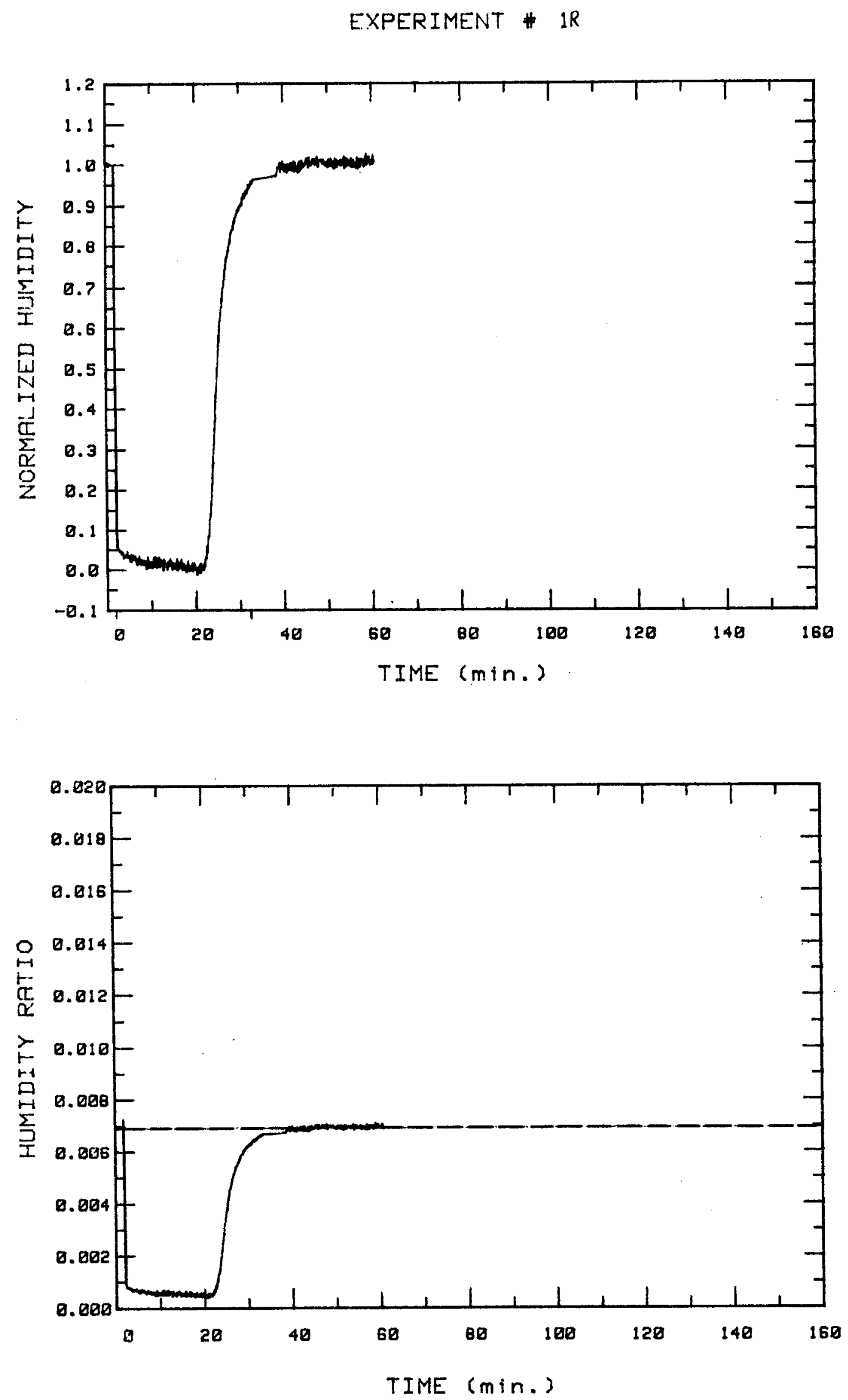

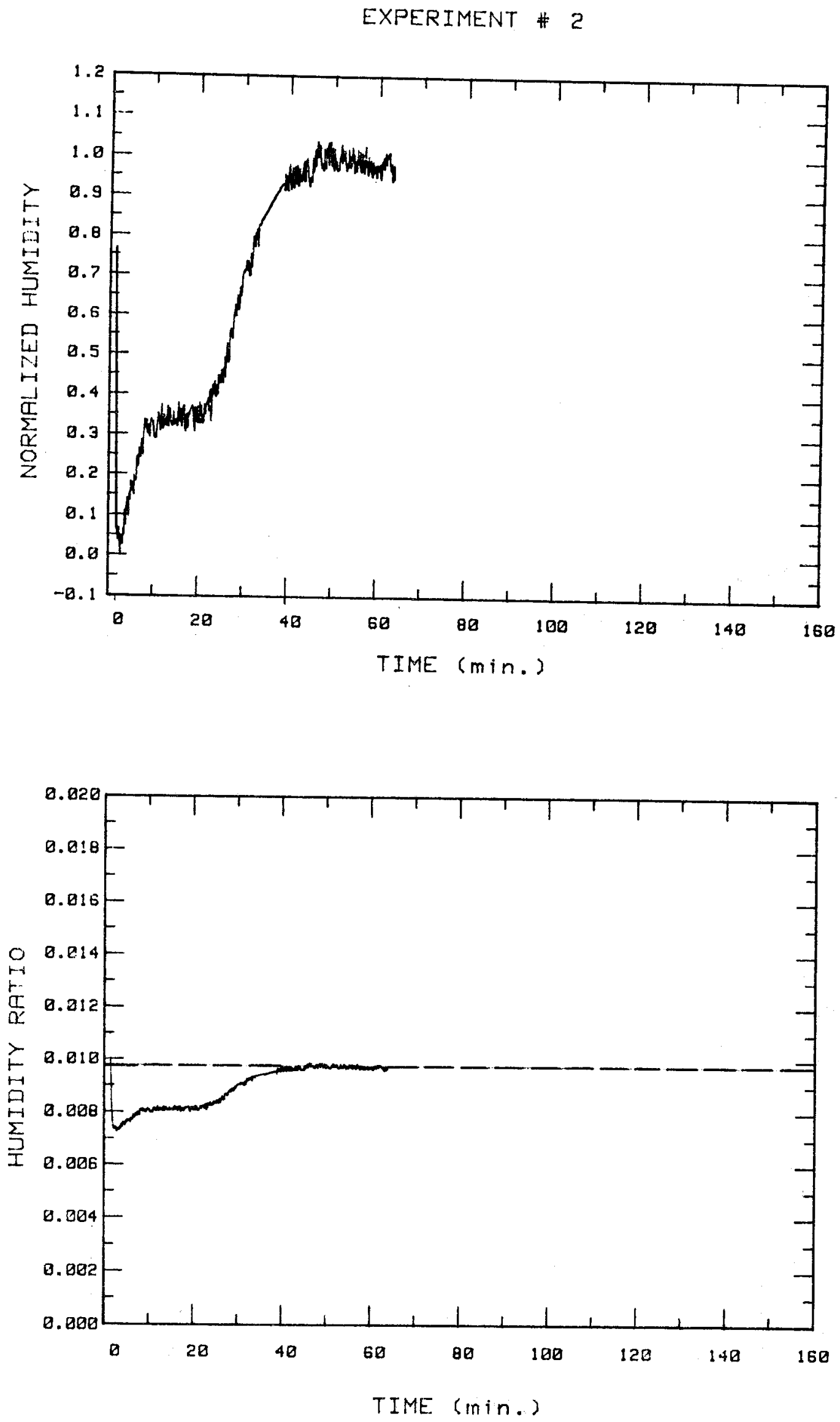


\section{EXPERIMENT \# 3}
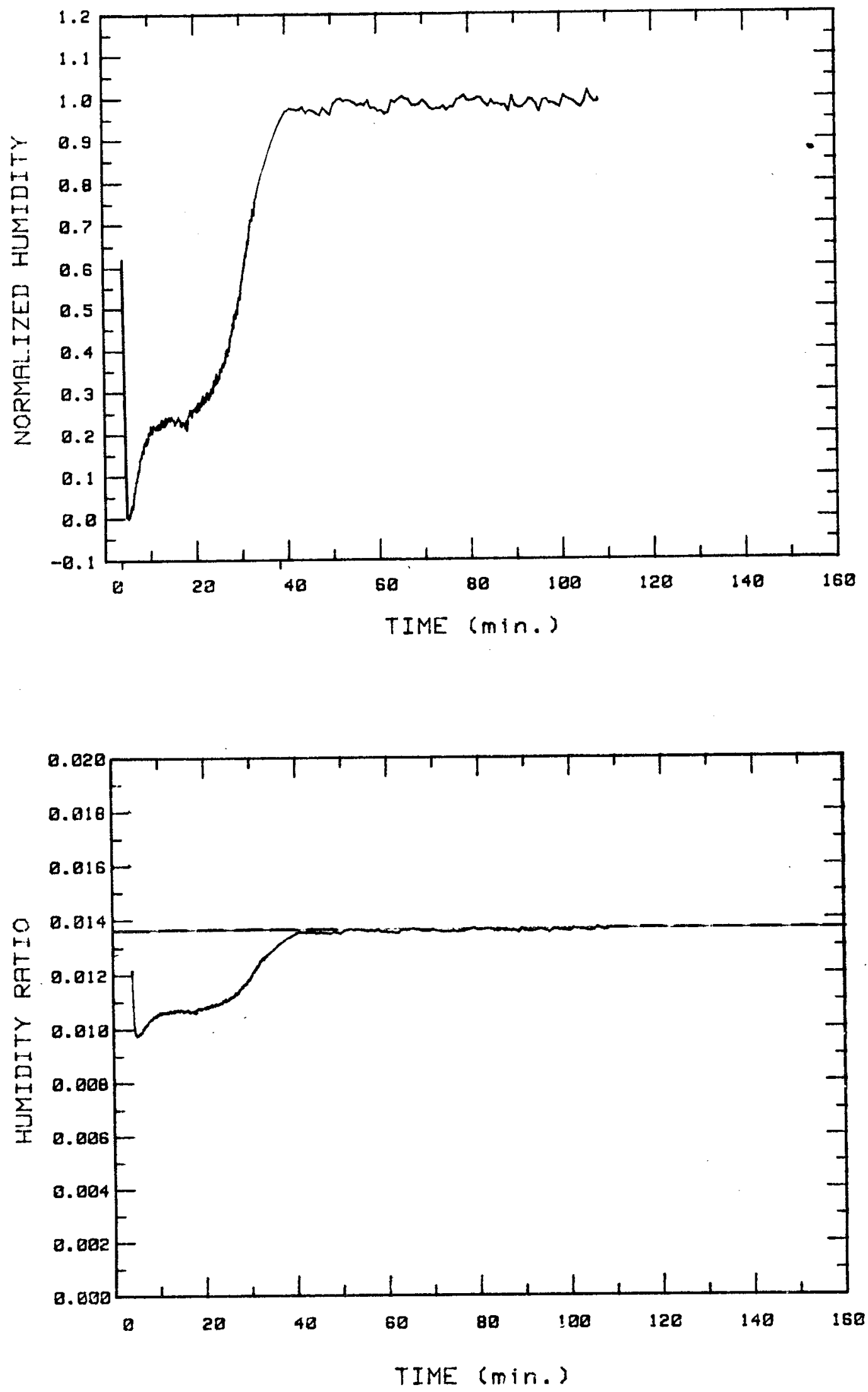

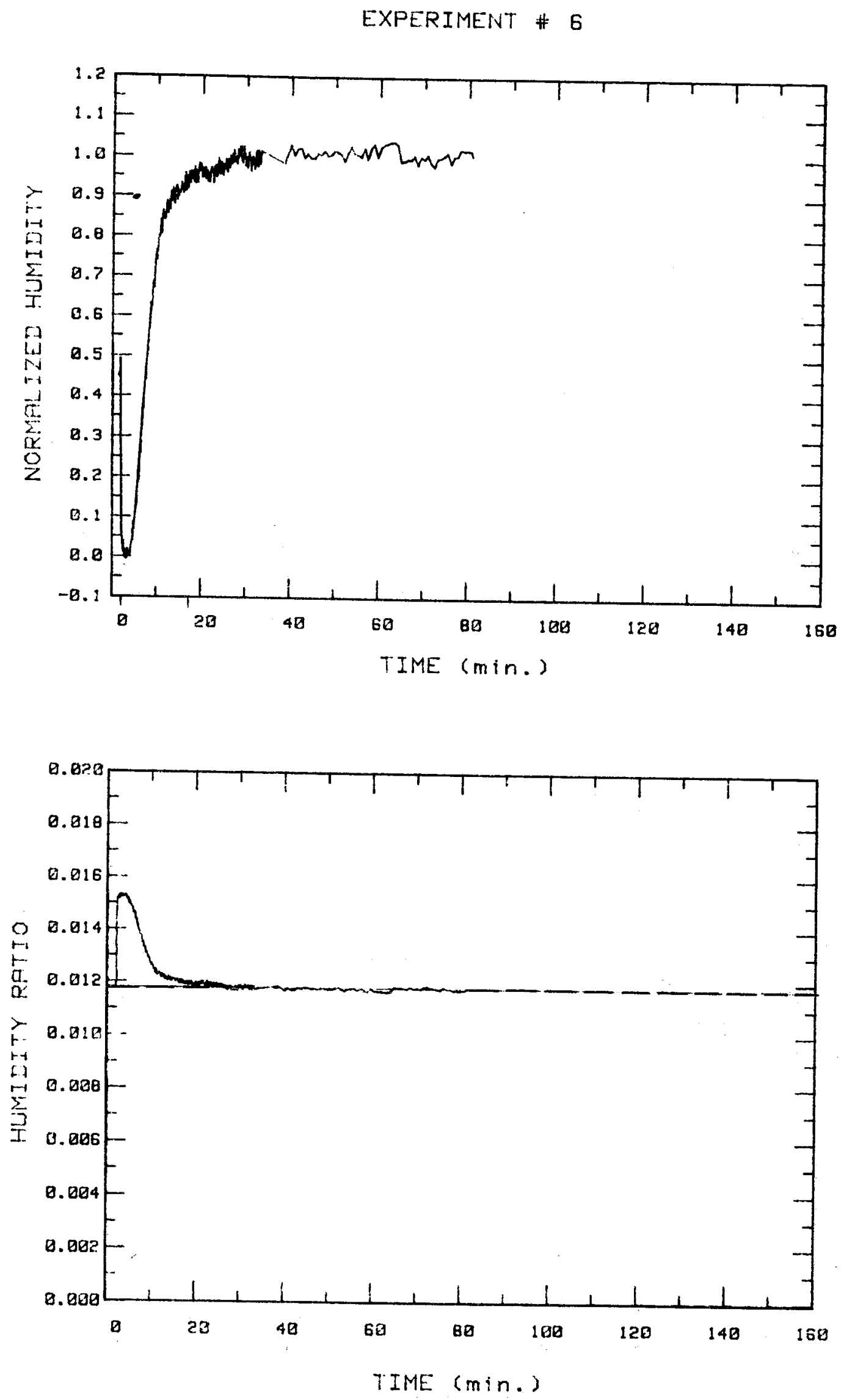


\section{EXPERIMENT \# ?}
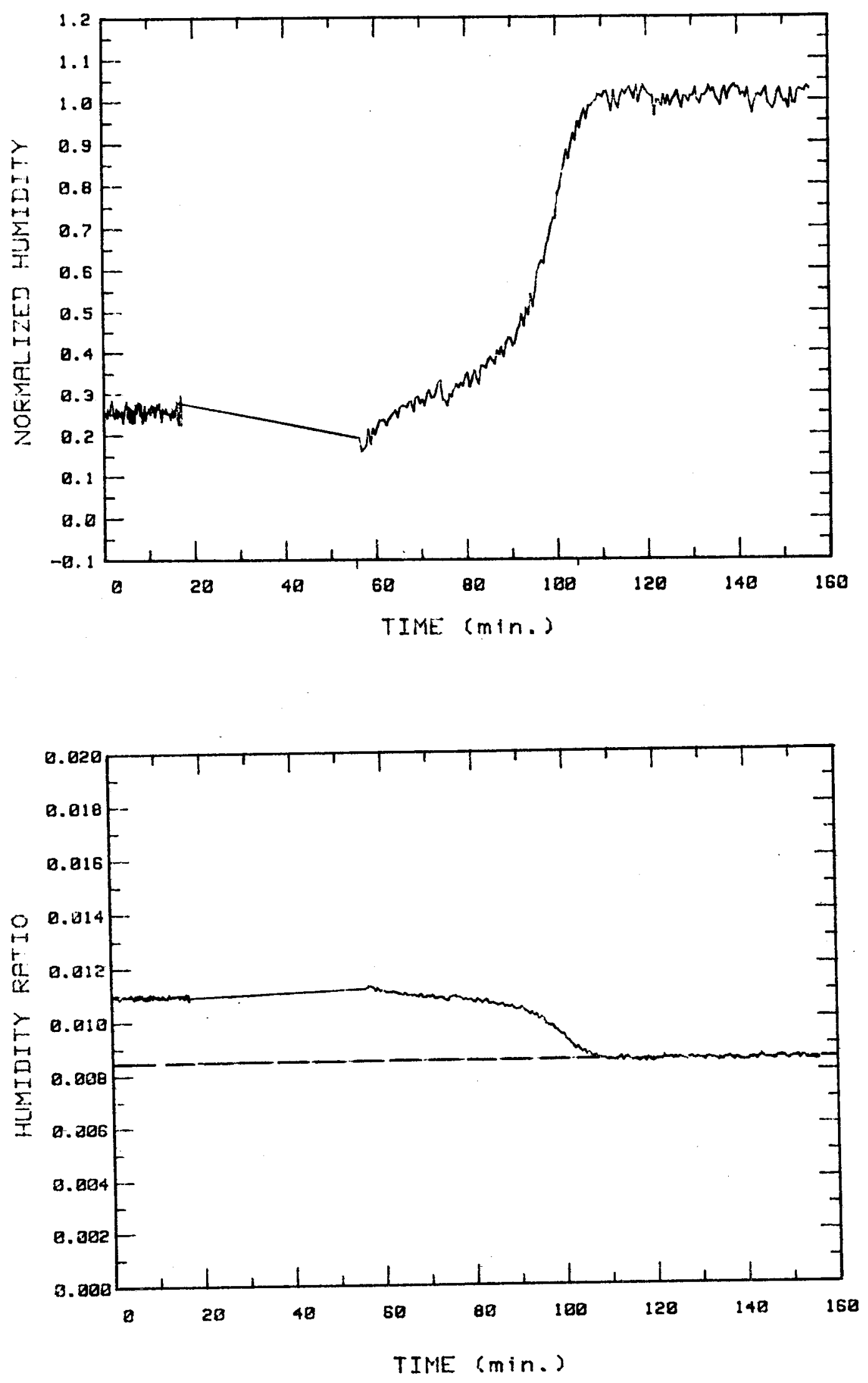

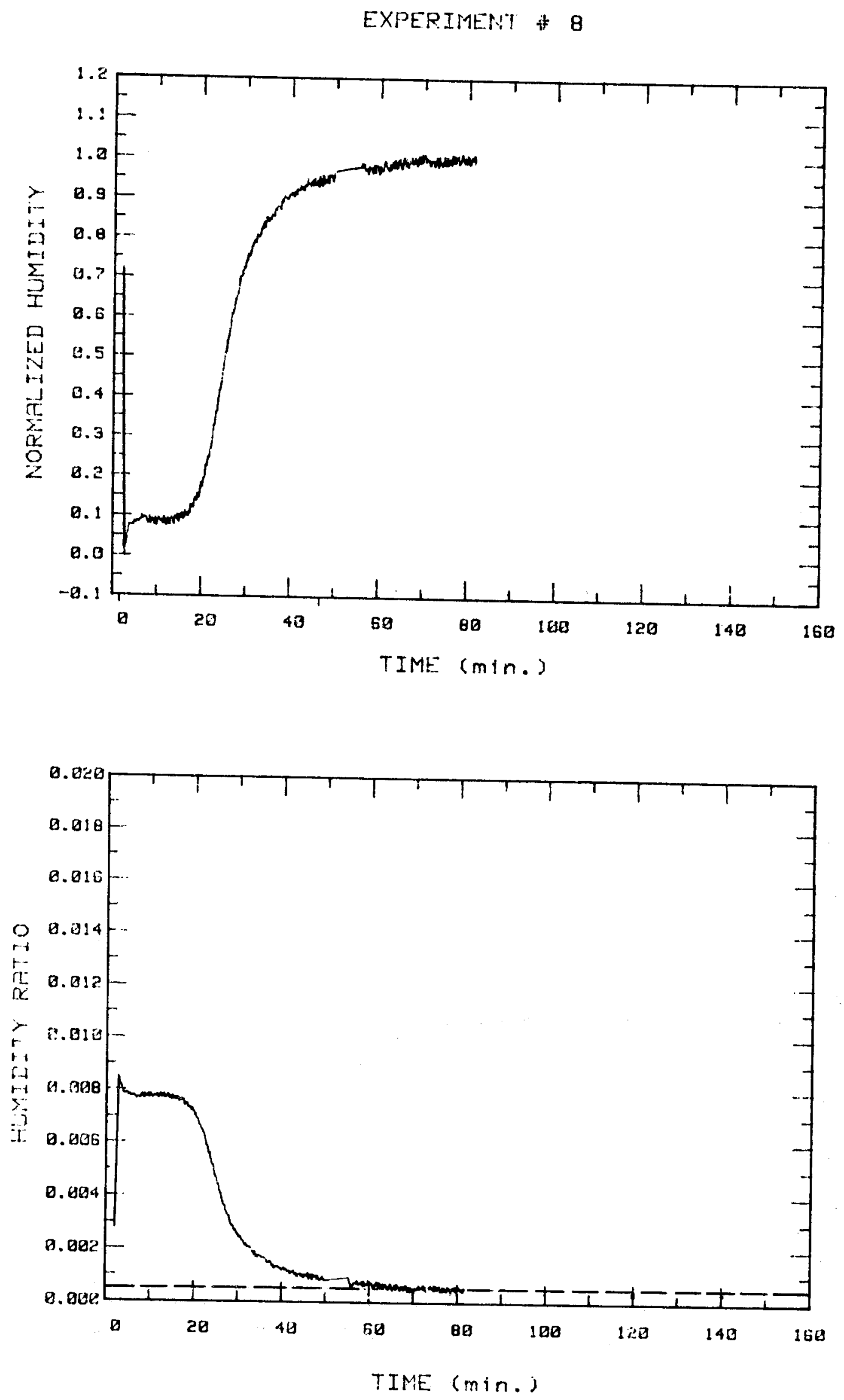
EXPERIMENT \# $11 R$
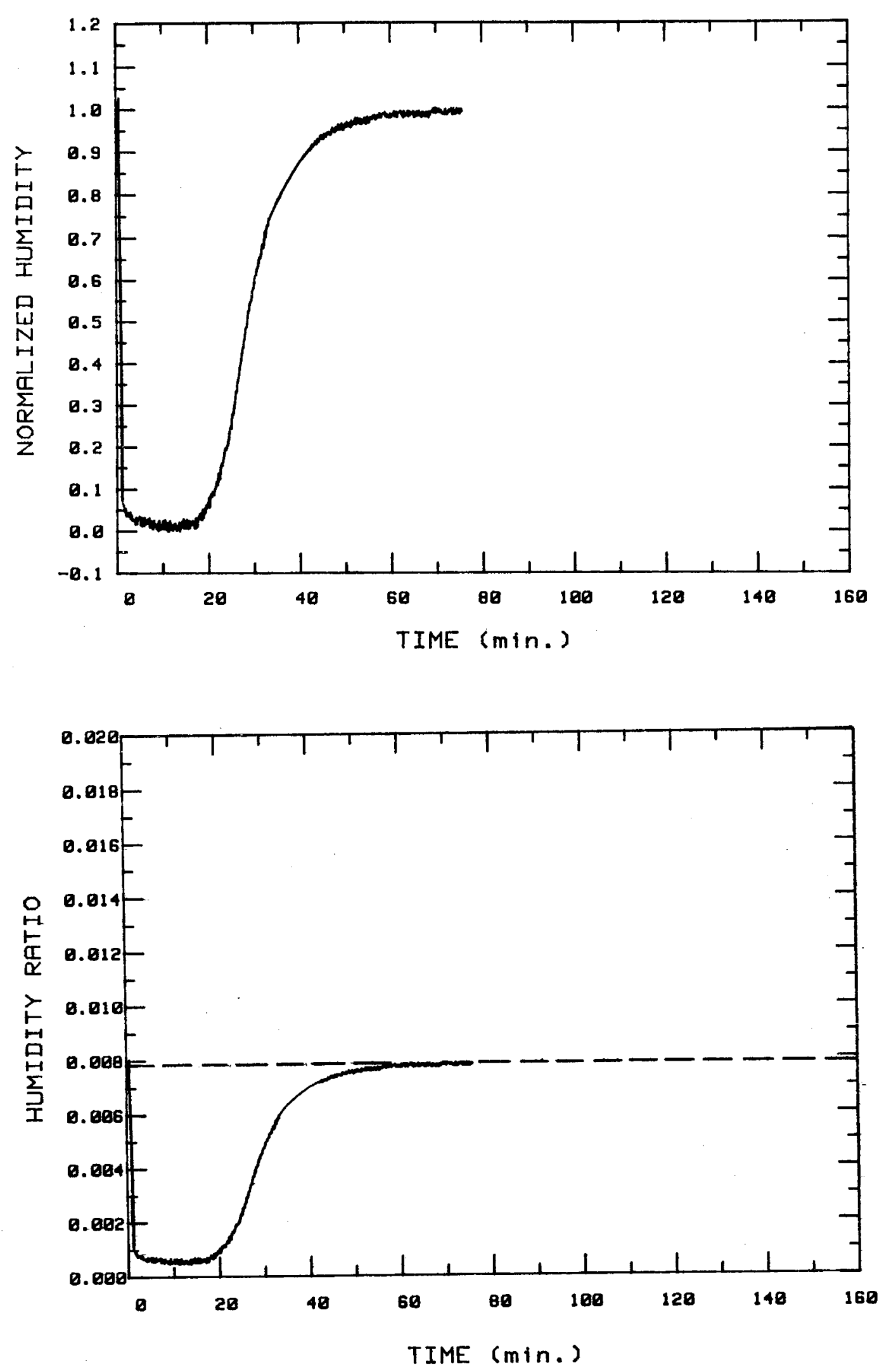


\section{EXPERIMENT *12R}
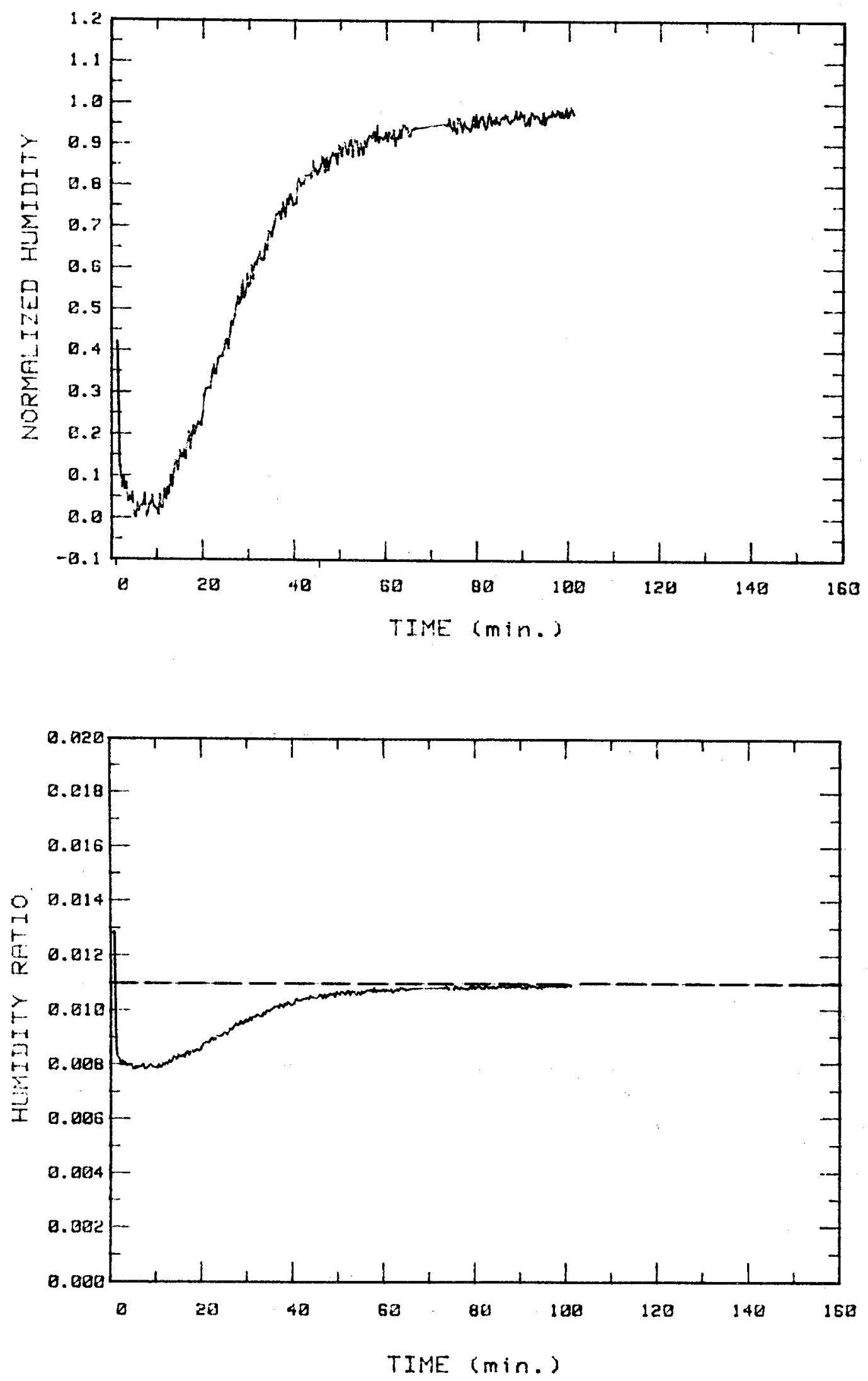

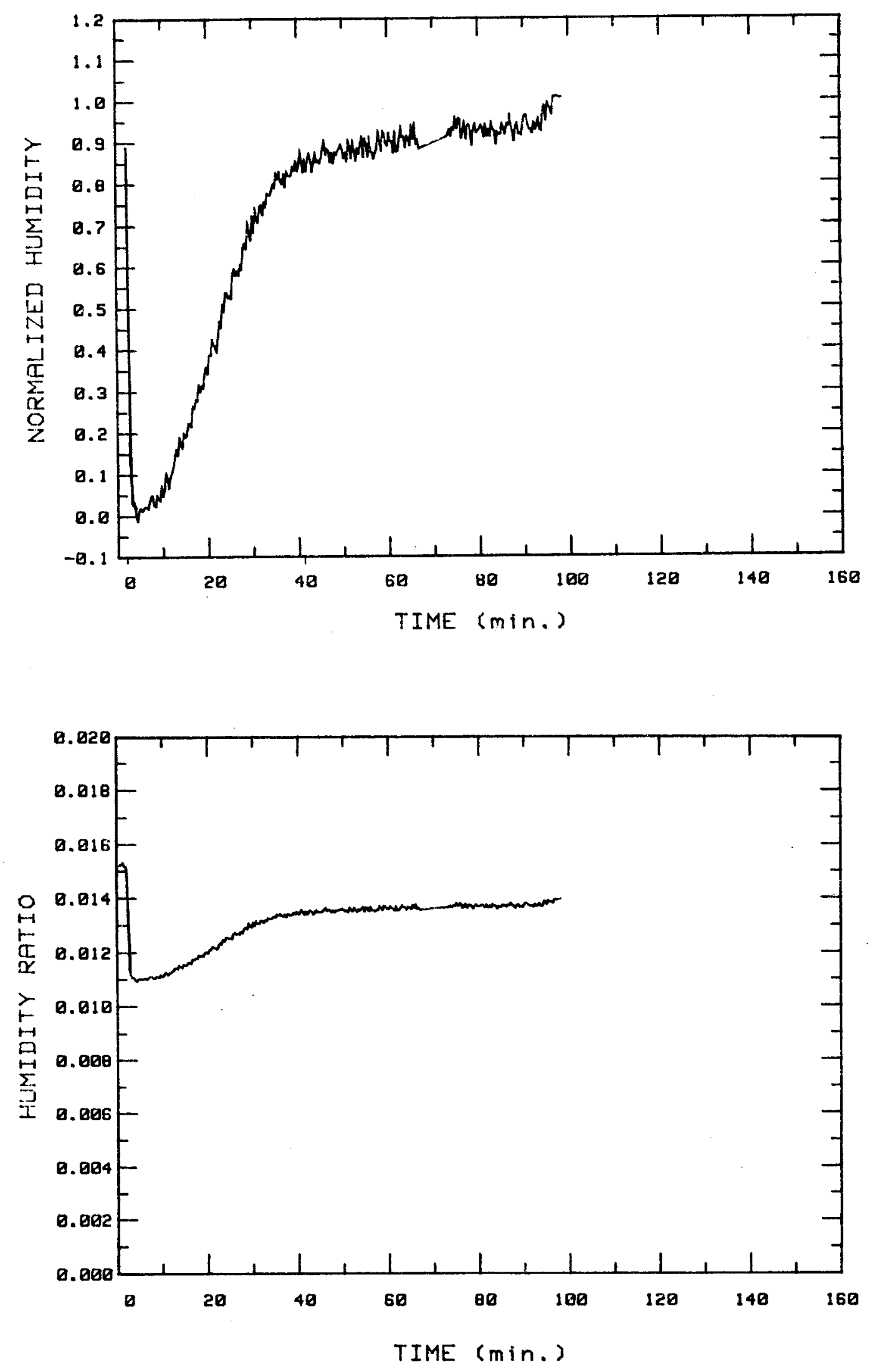
EXPERIIVENT \#:4
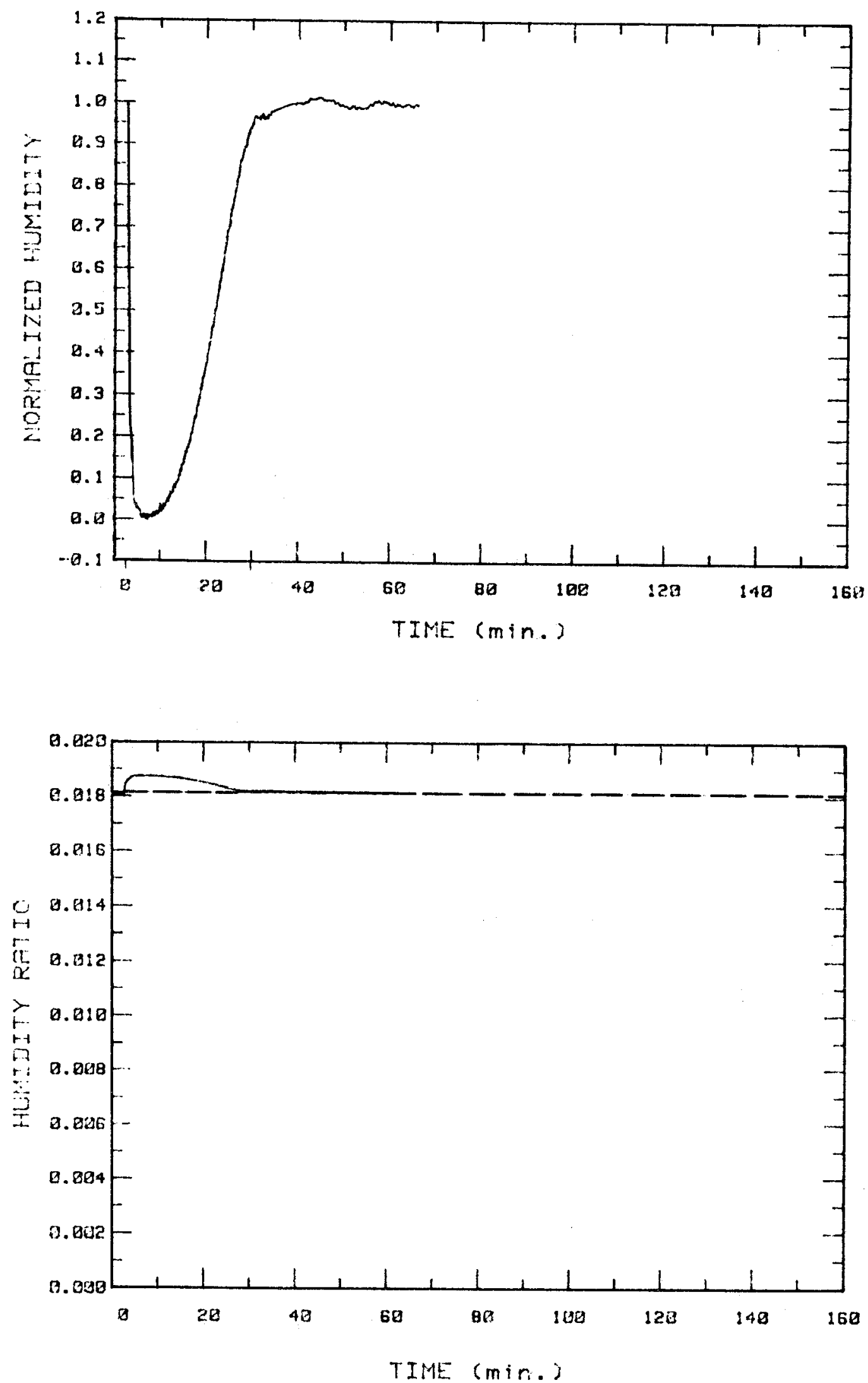


\section{EXPERIMENT \# 17}
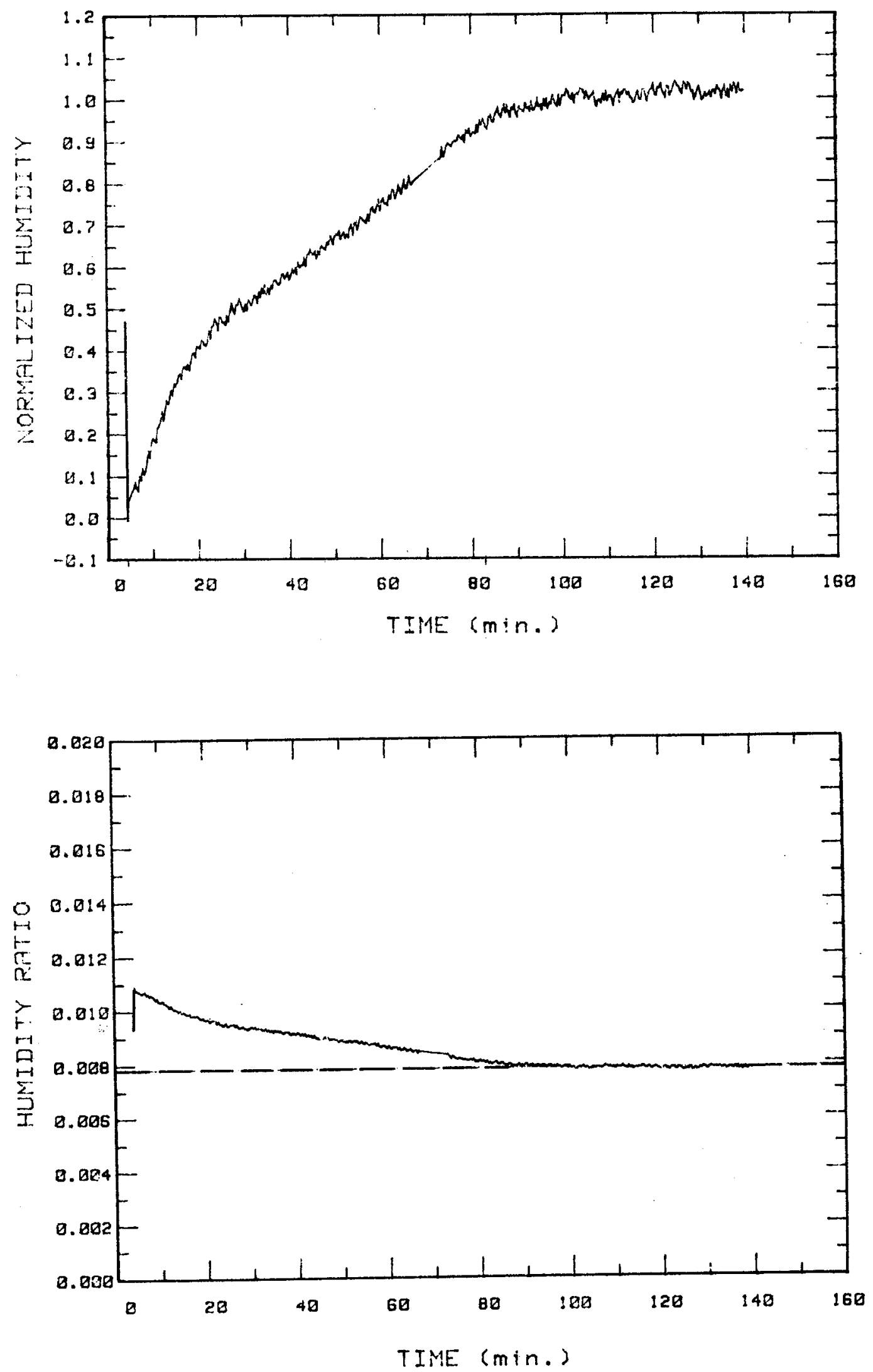

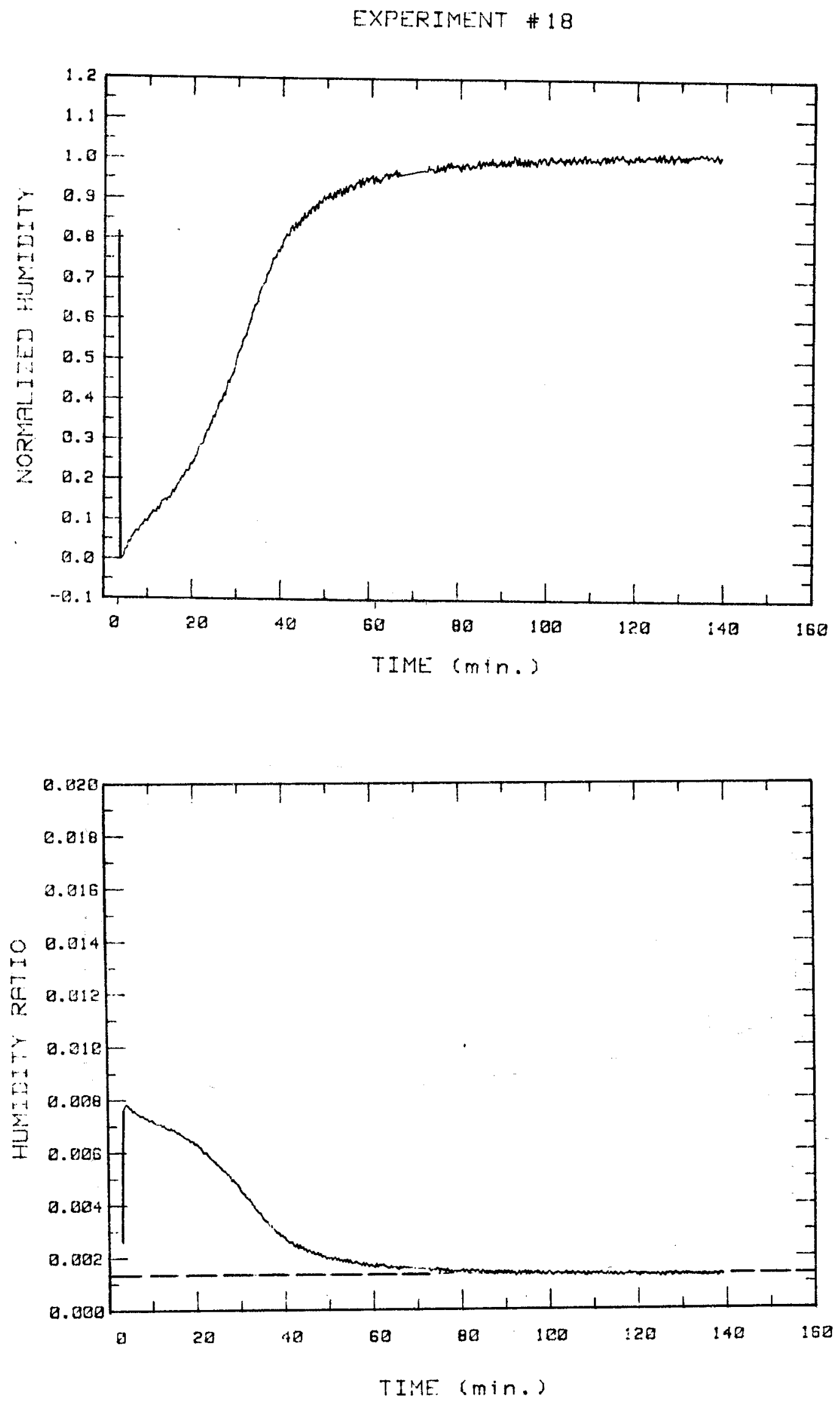


\section{EXPERTMEIT \#13}
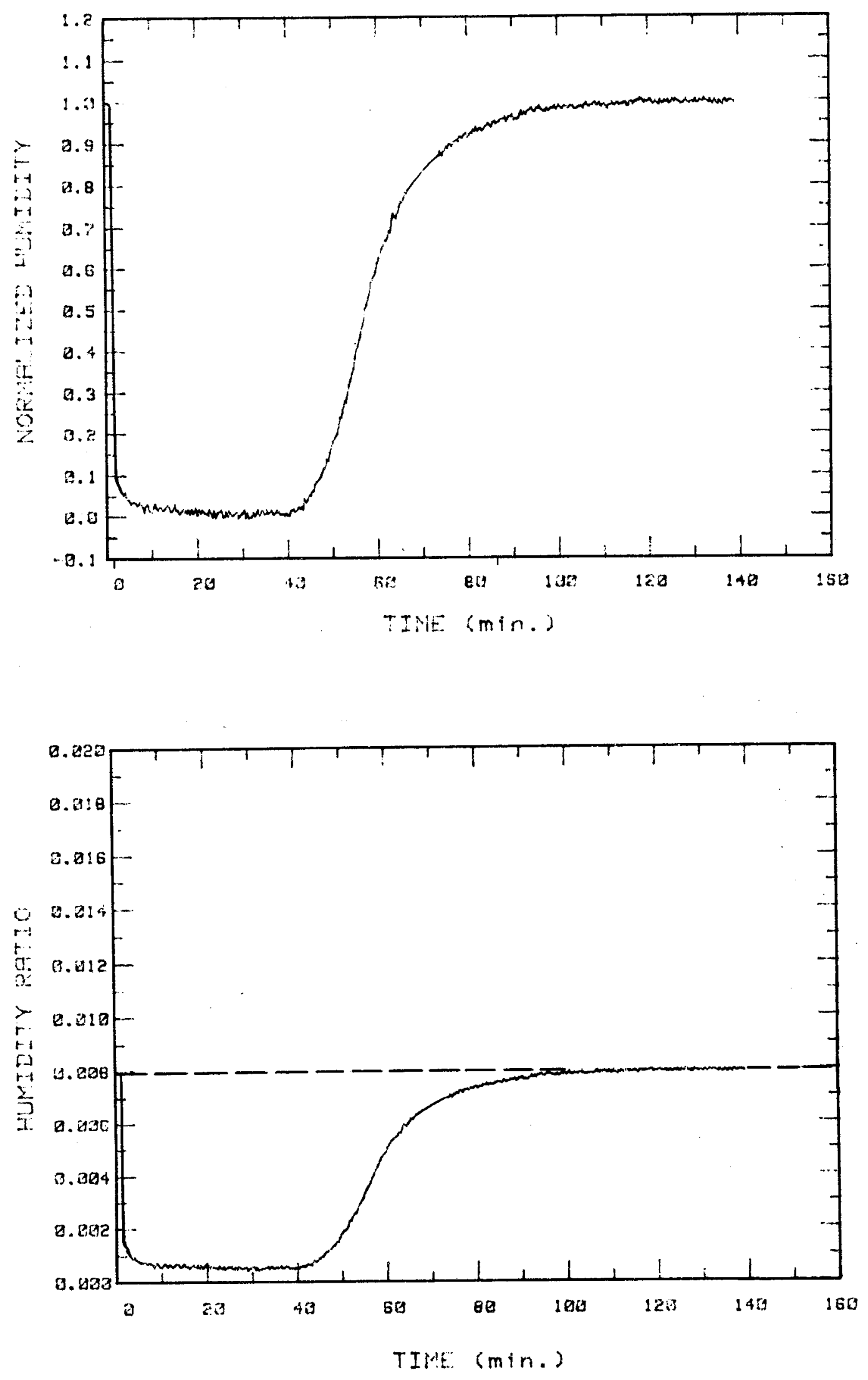


\section{EXPERIMENT \#20}
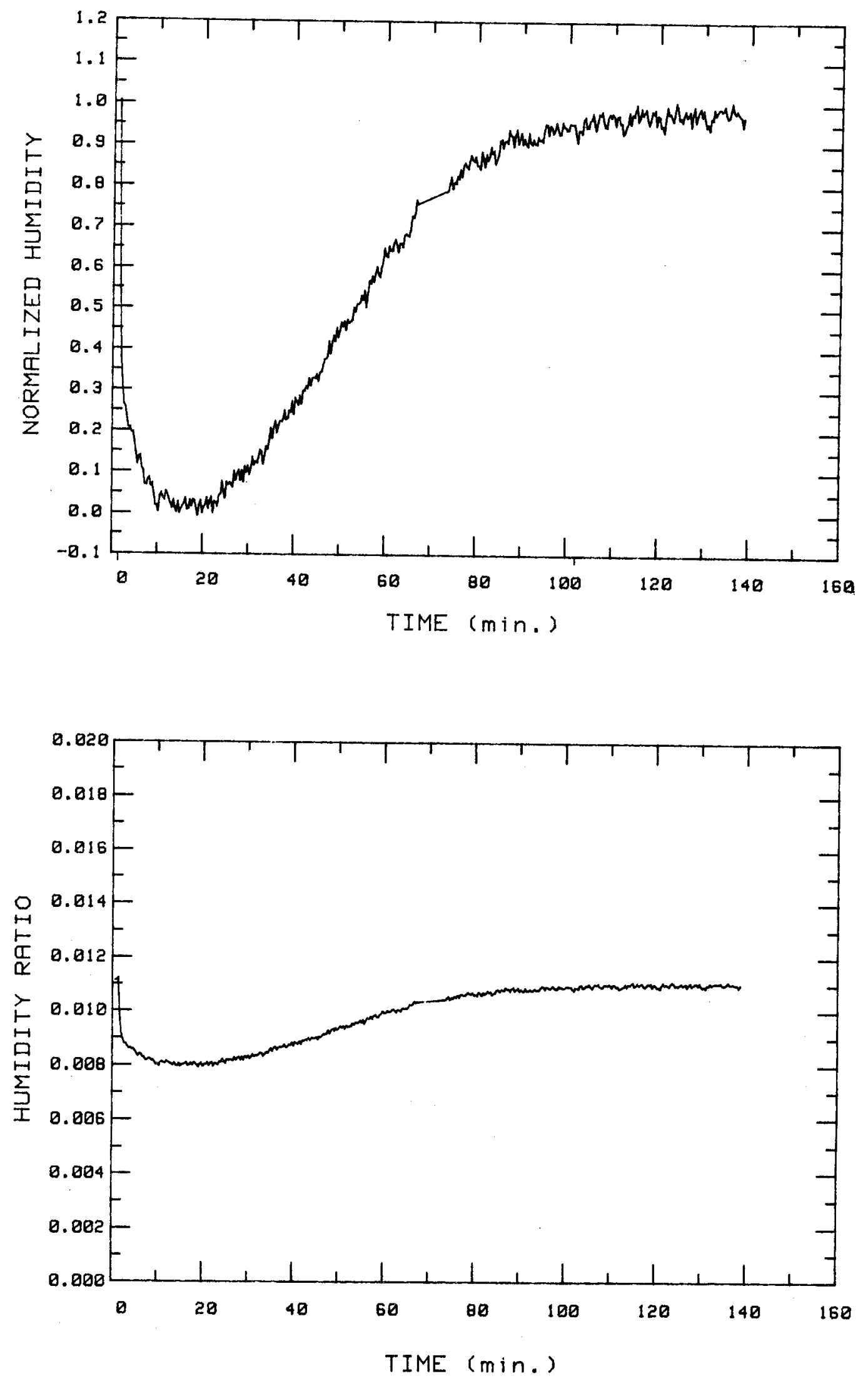

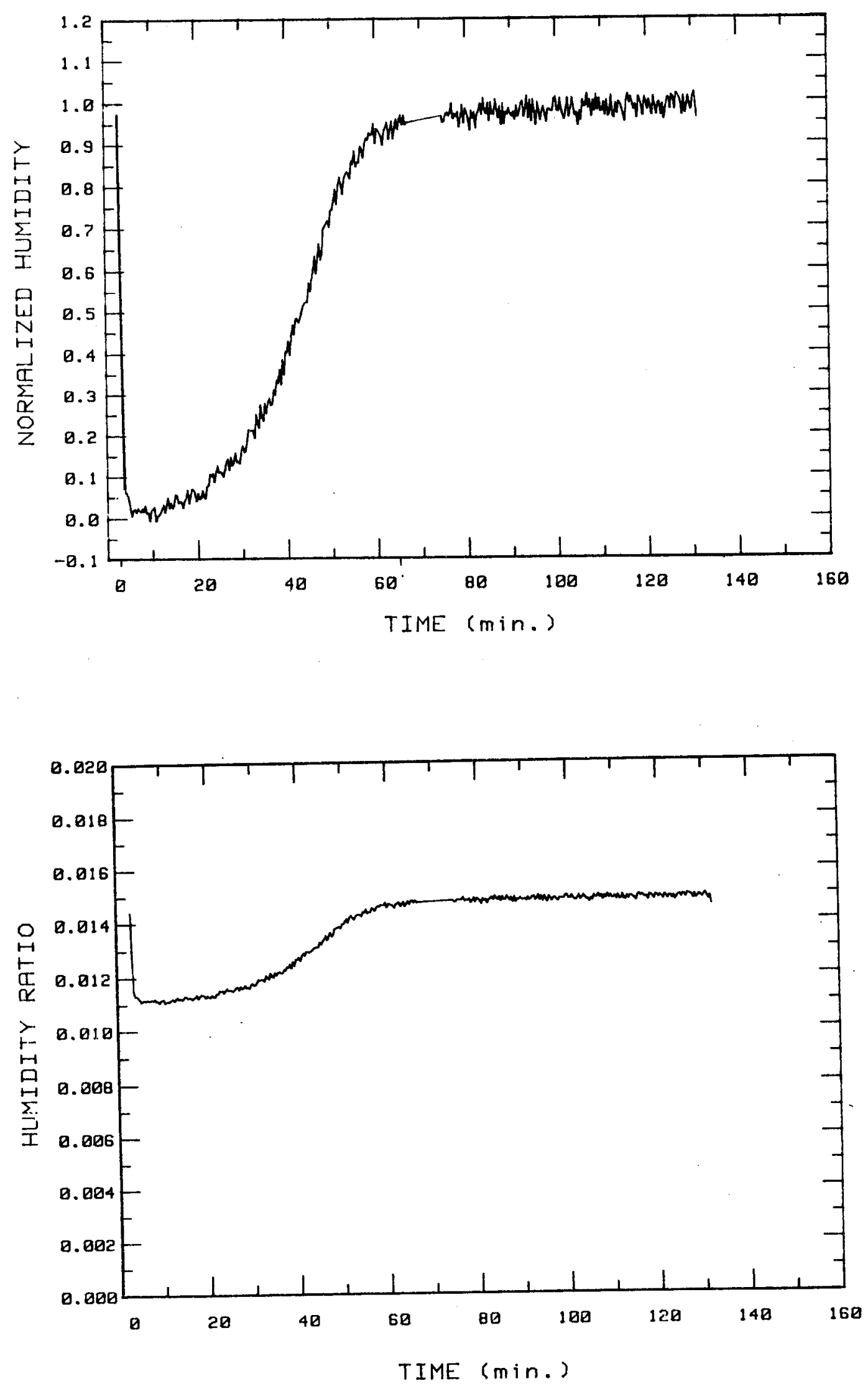
EXPERIMENT \#22
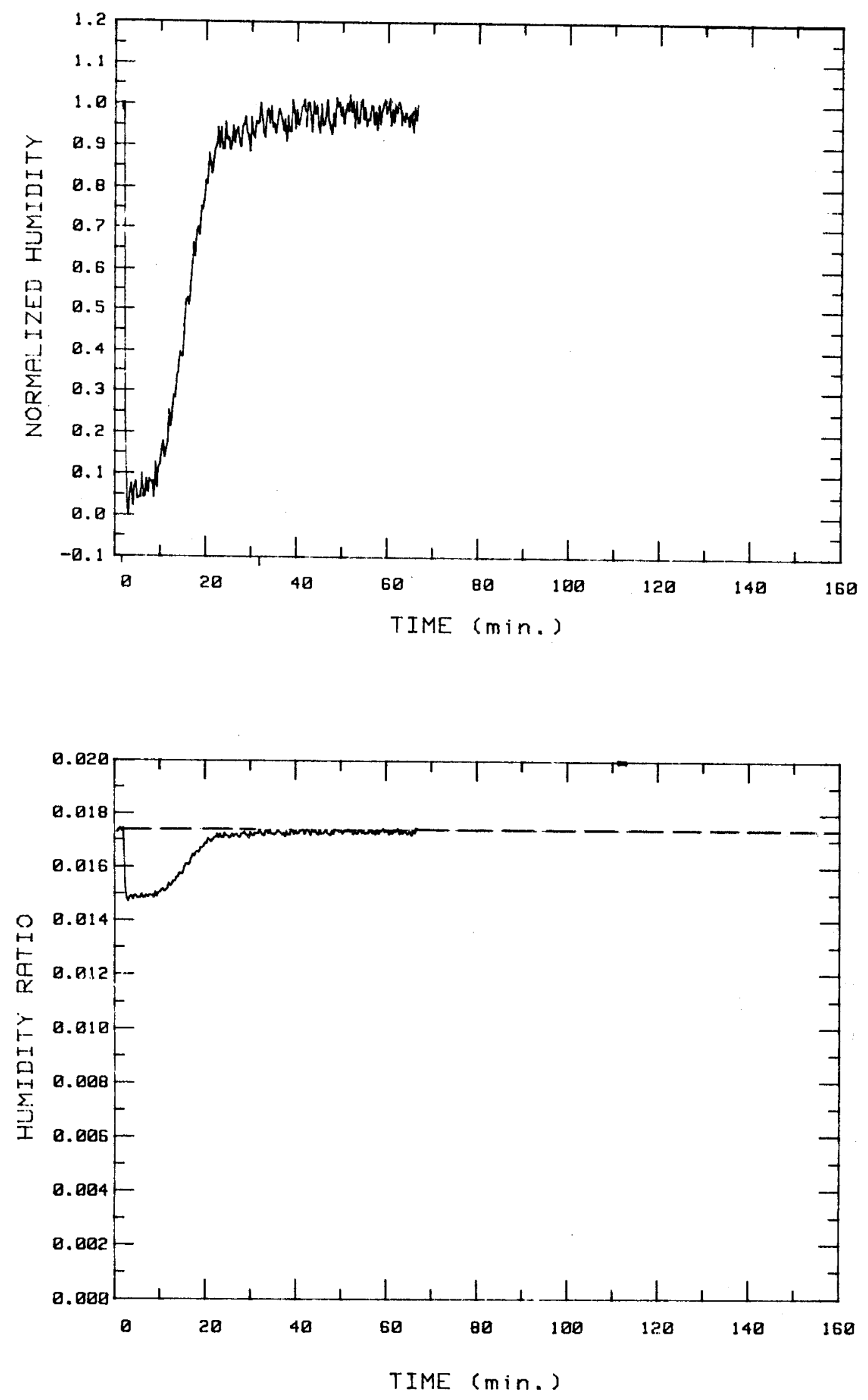

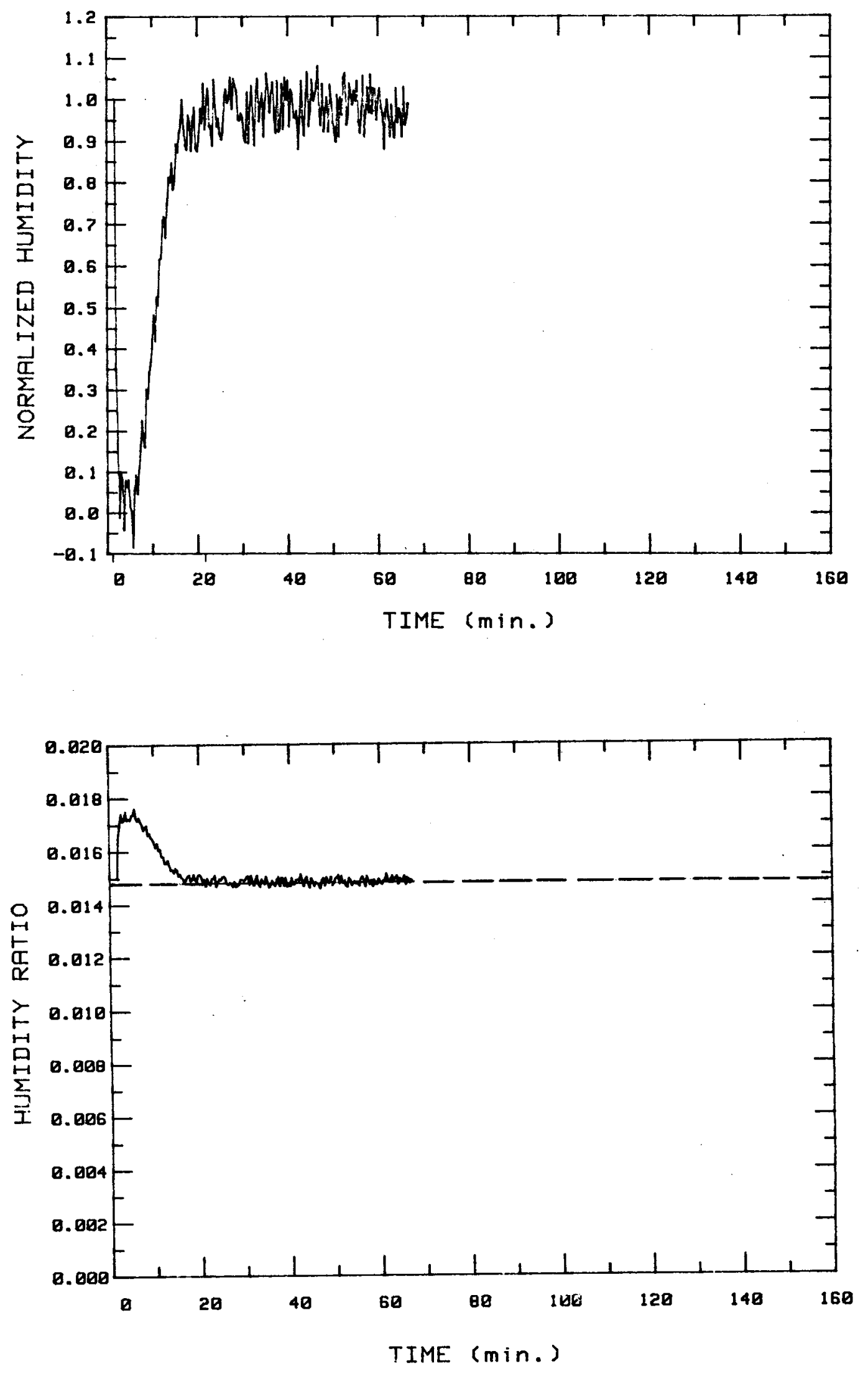
EXPERIMENT \#24
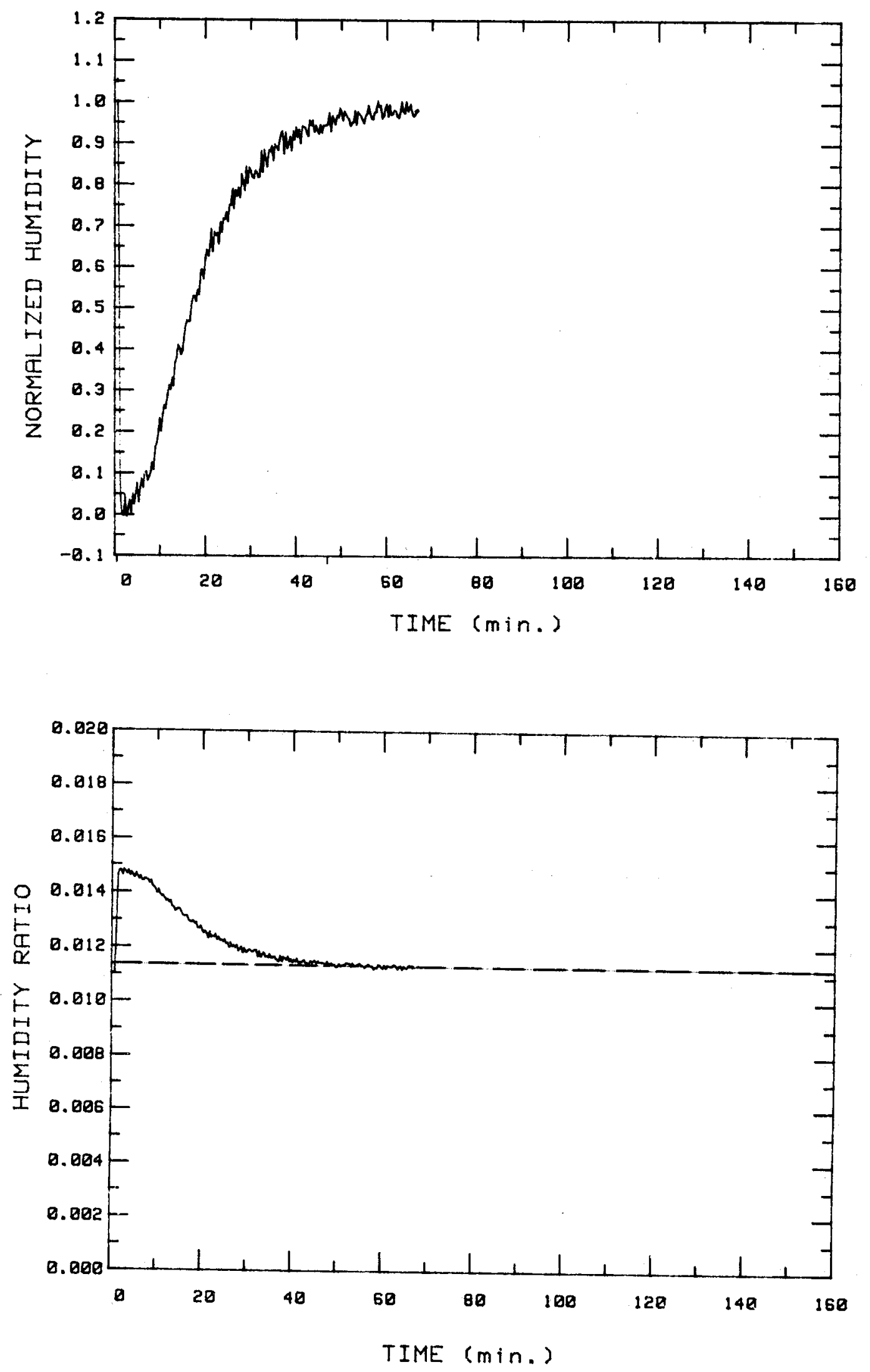


\section{EXPERIMENT \#25}
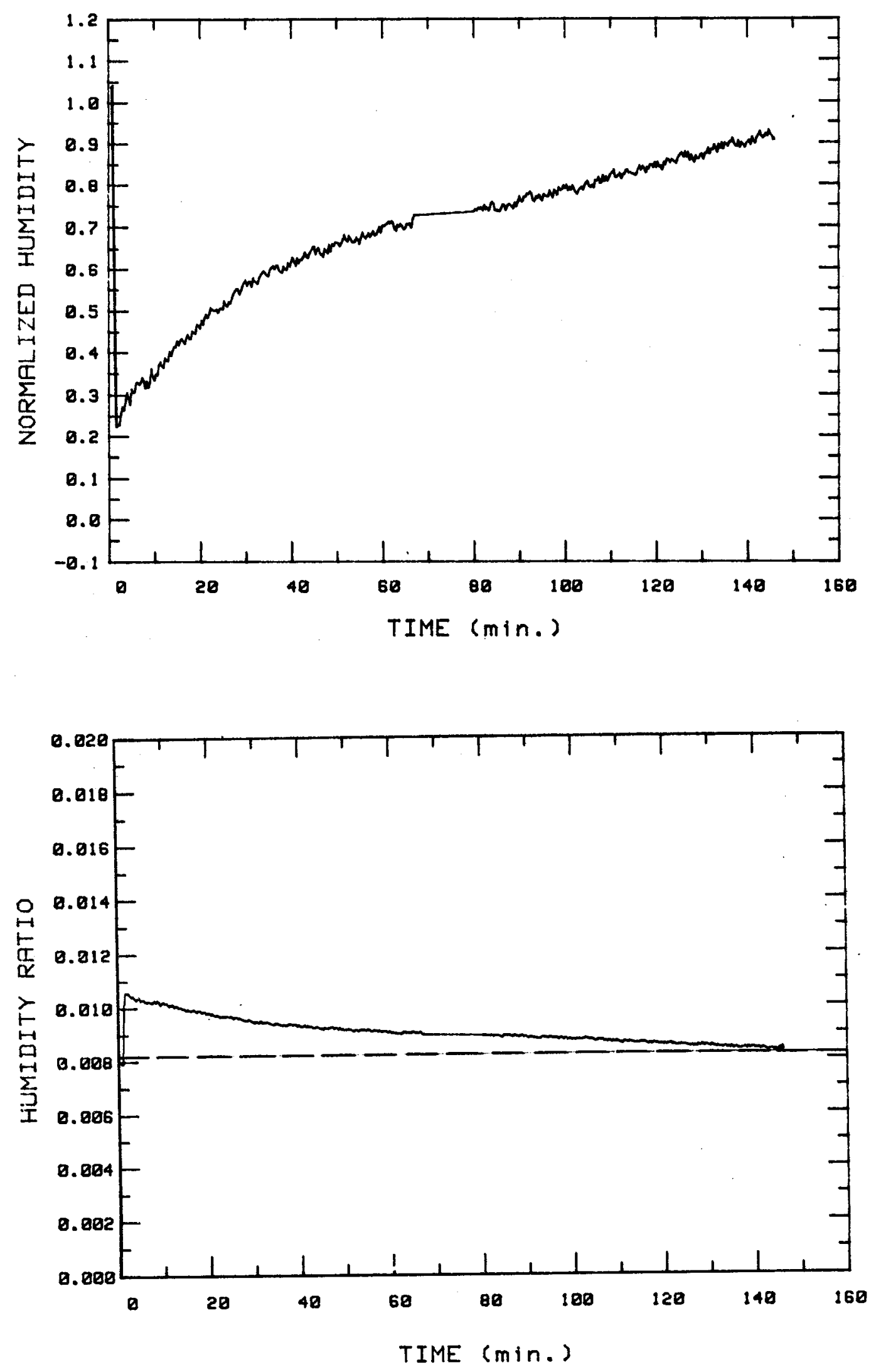
EXPERIMENT \#26
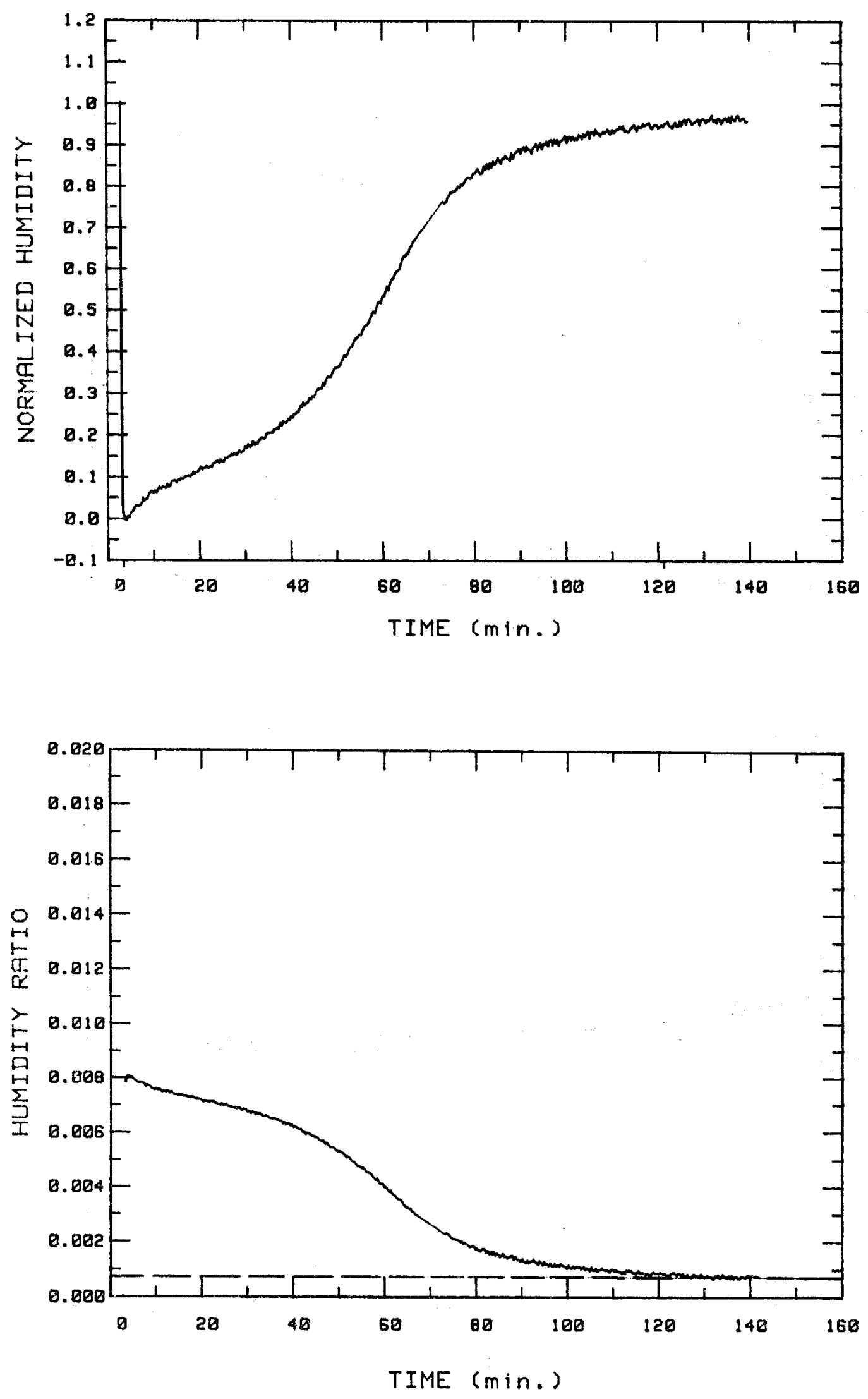


\section{EXPERIMENT \#35}
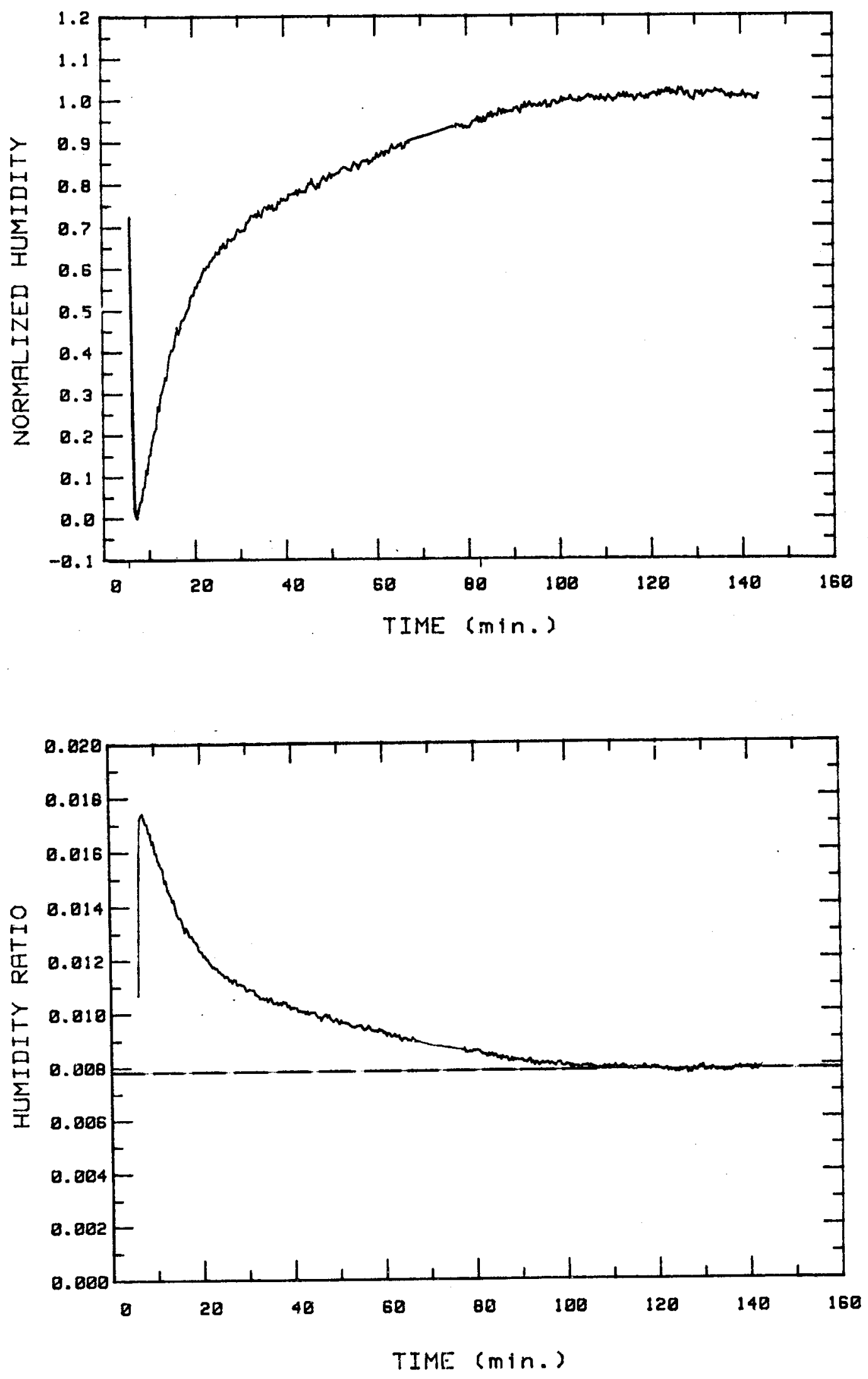
EXPERIMENT \#36
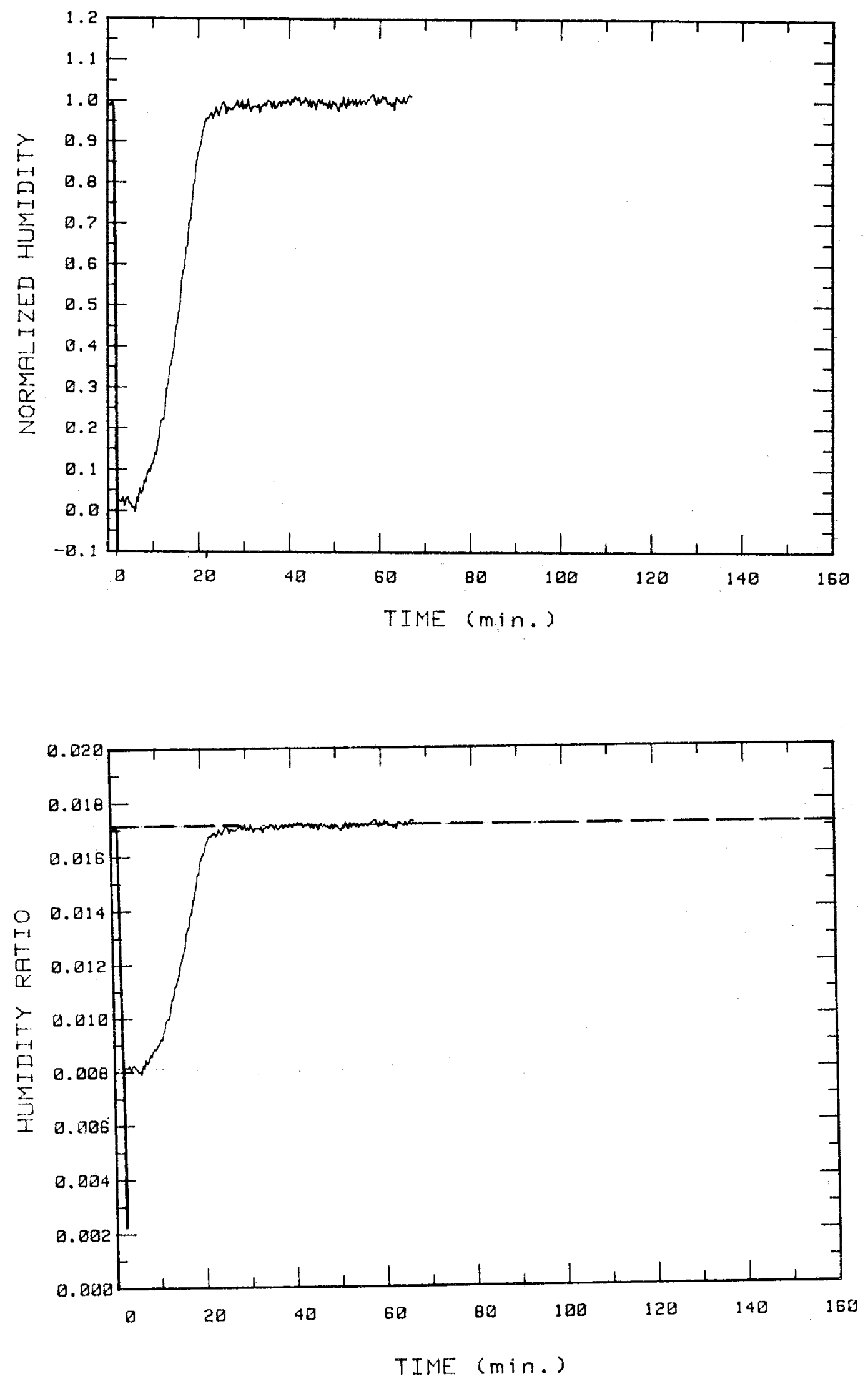

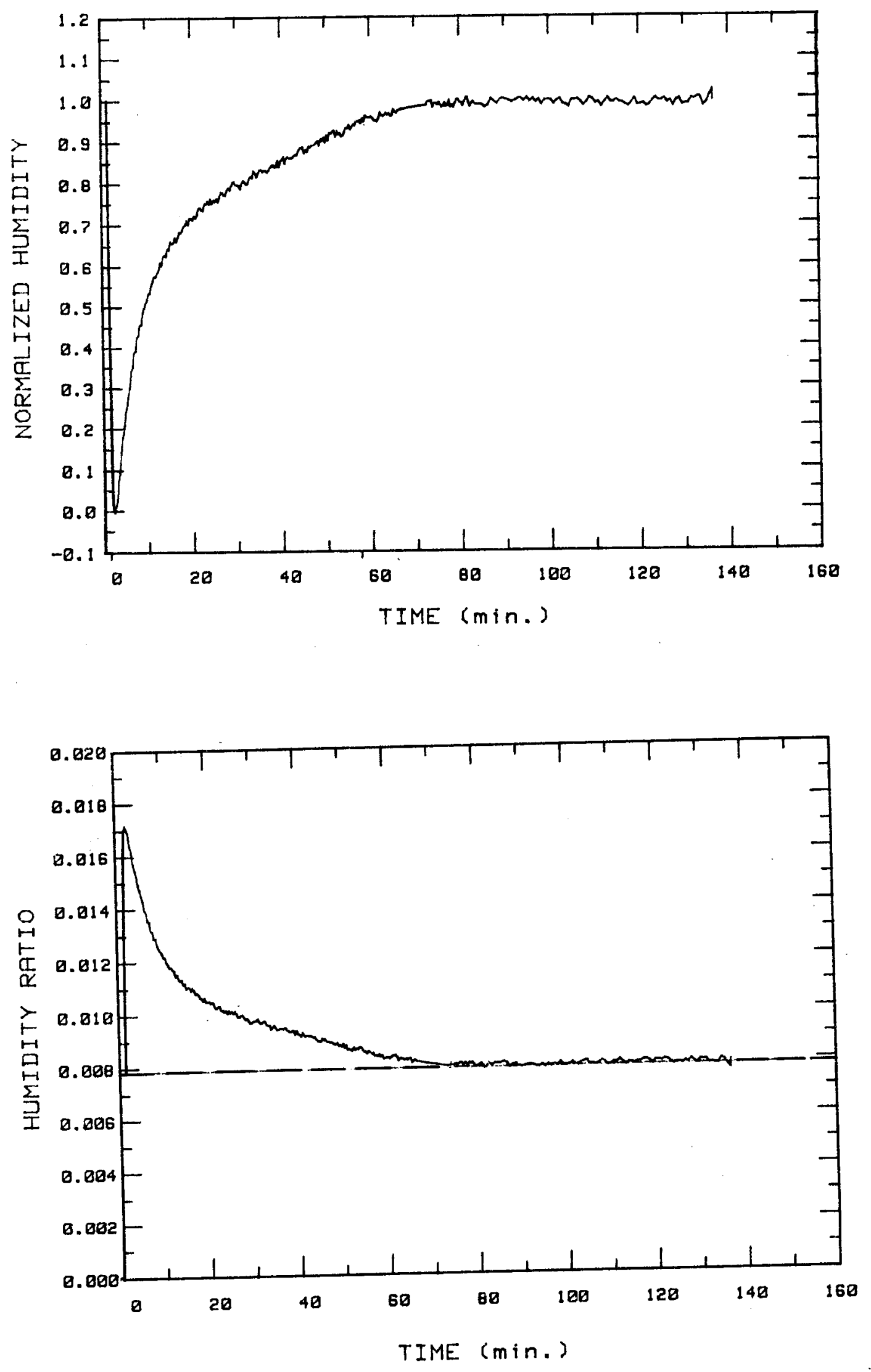


\section{EXPERIMENT \#38}
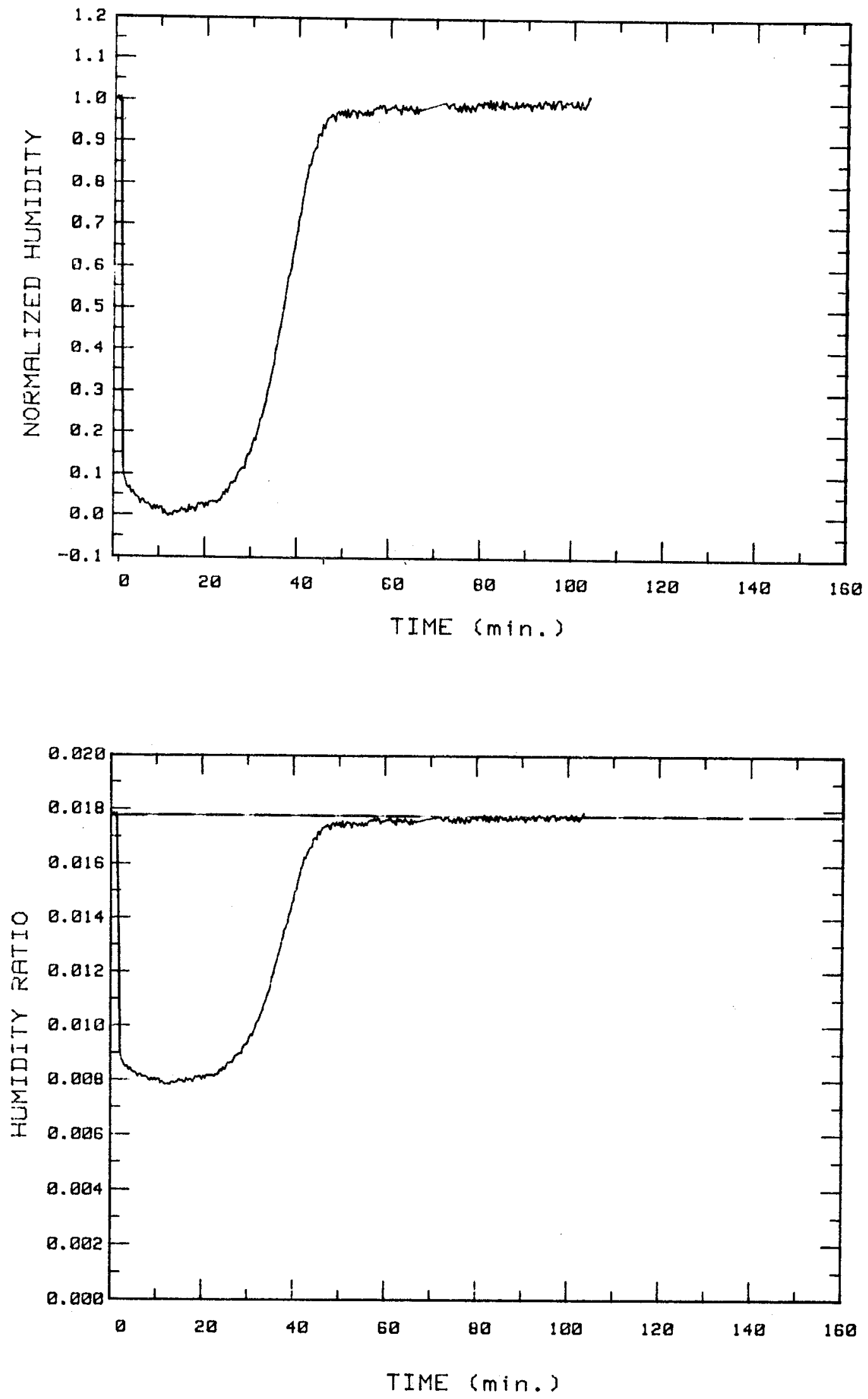

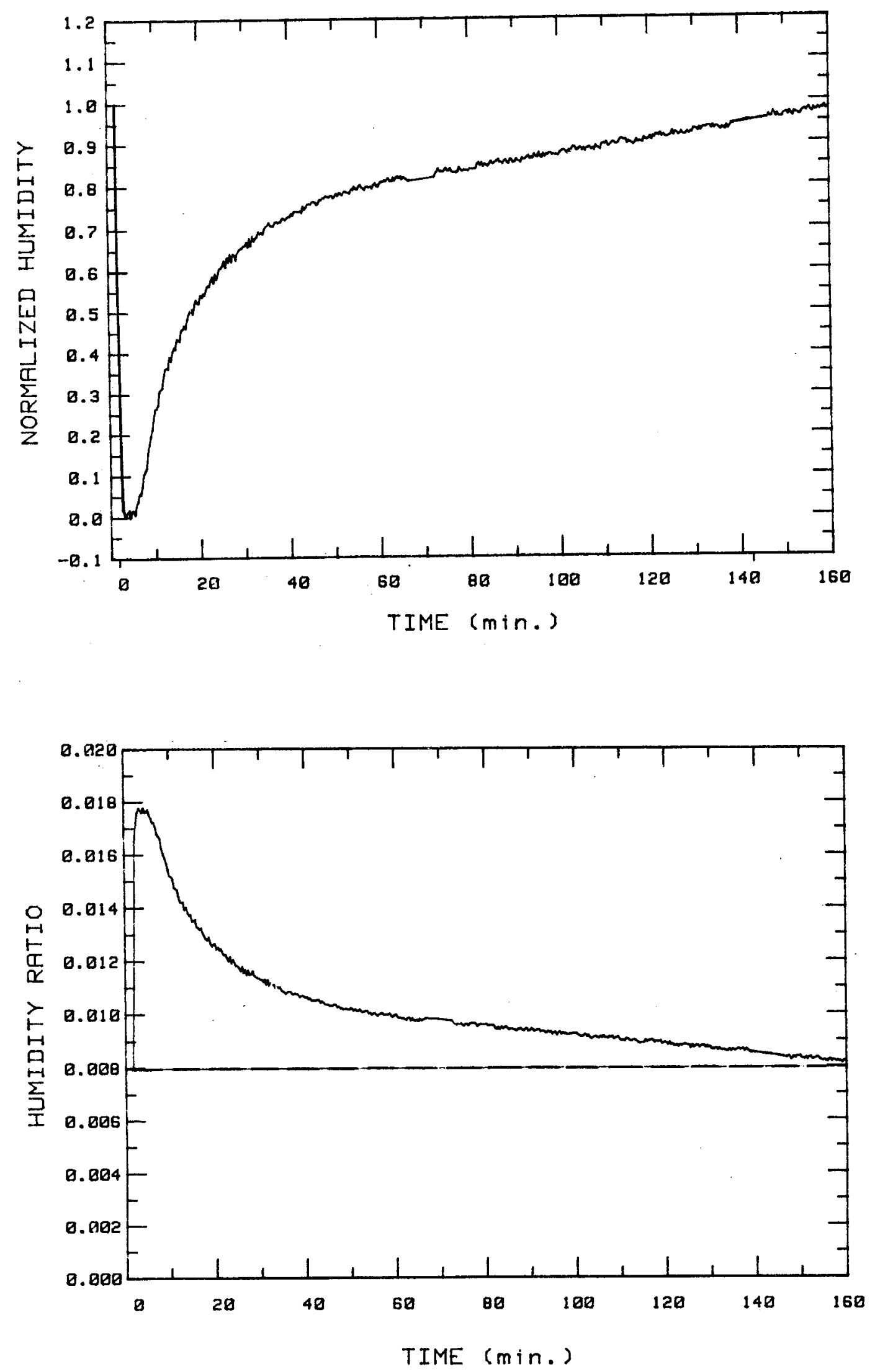

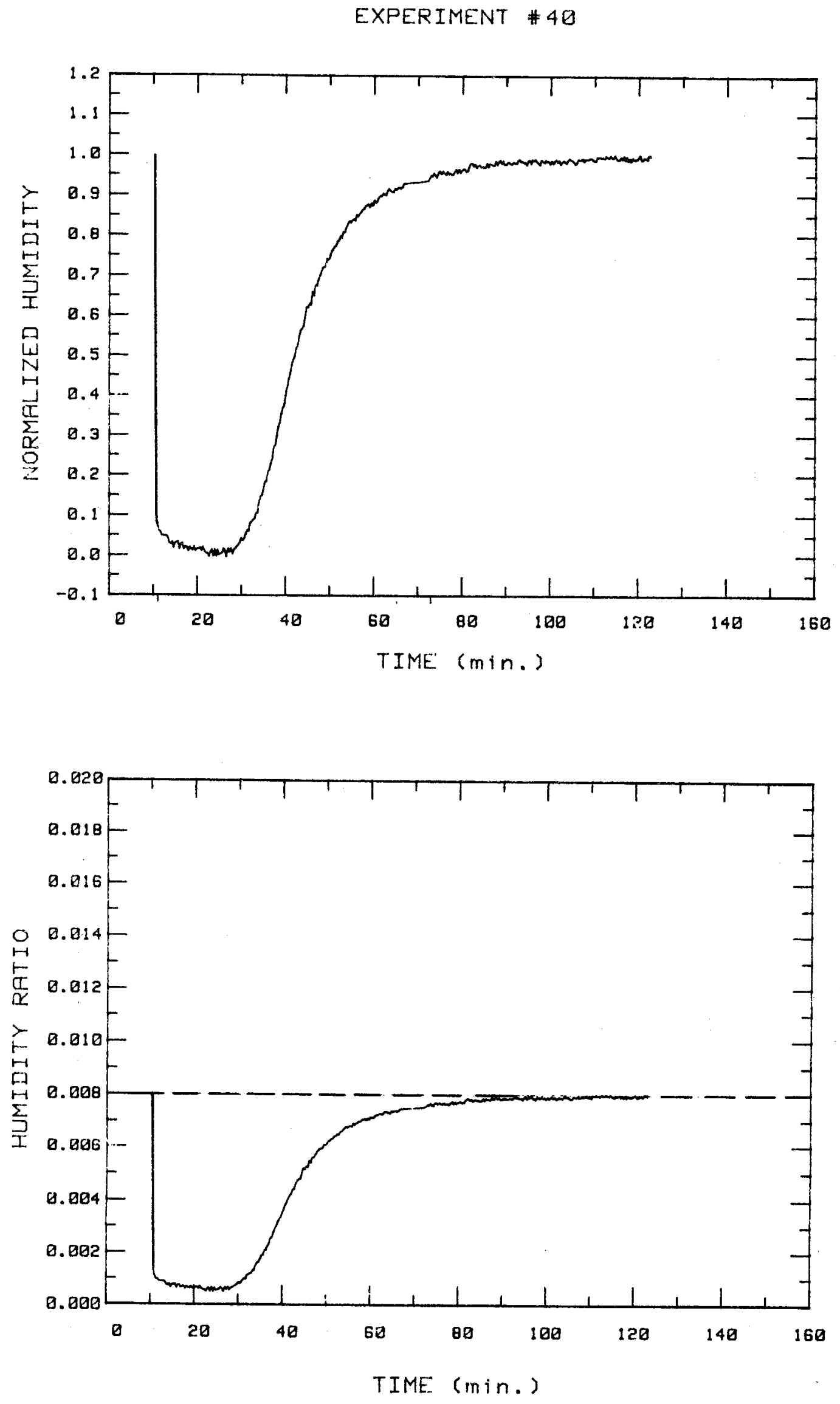


\section{EXPERIMENT \#41}
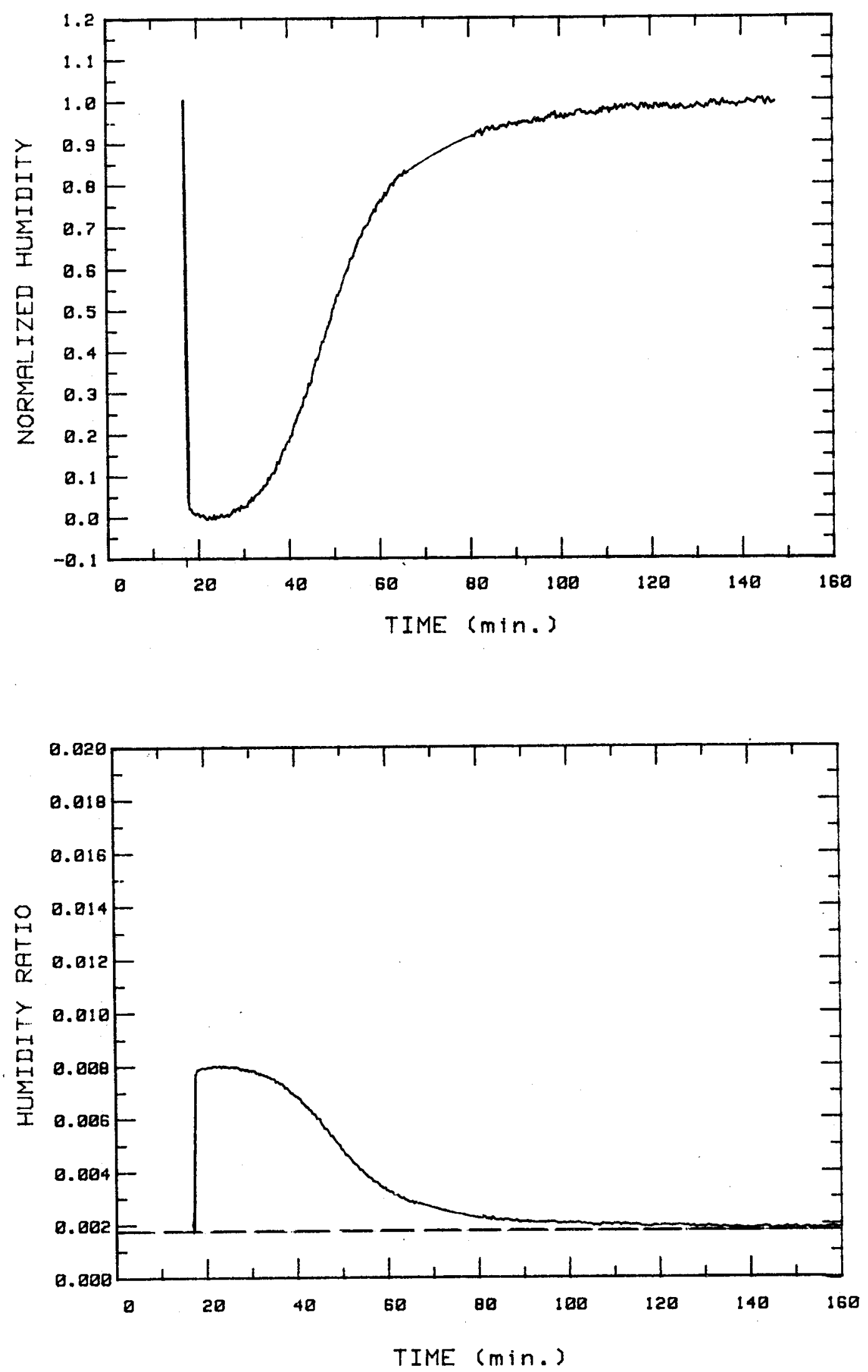


\section{EXPERTMENT \#42}
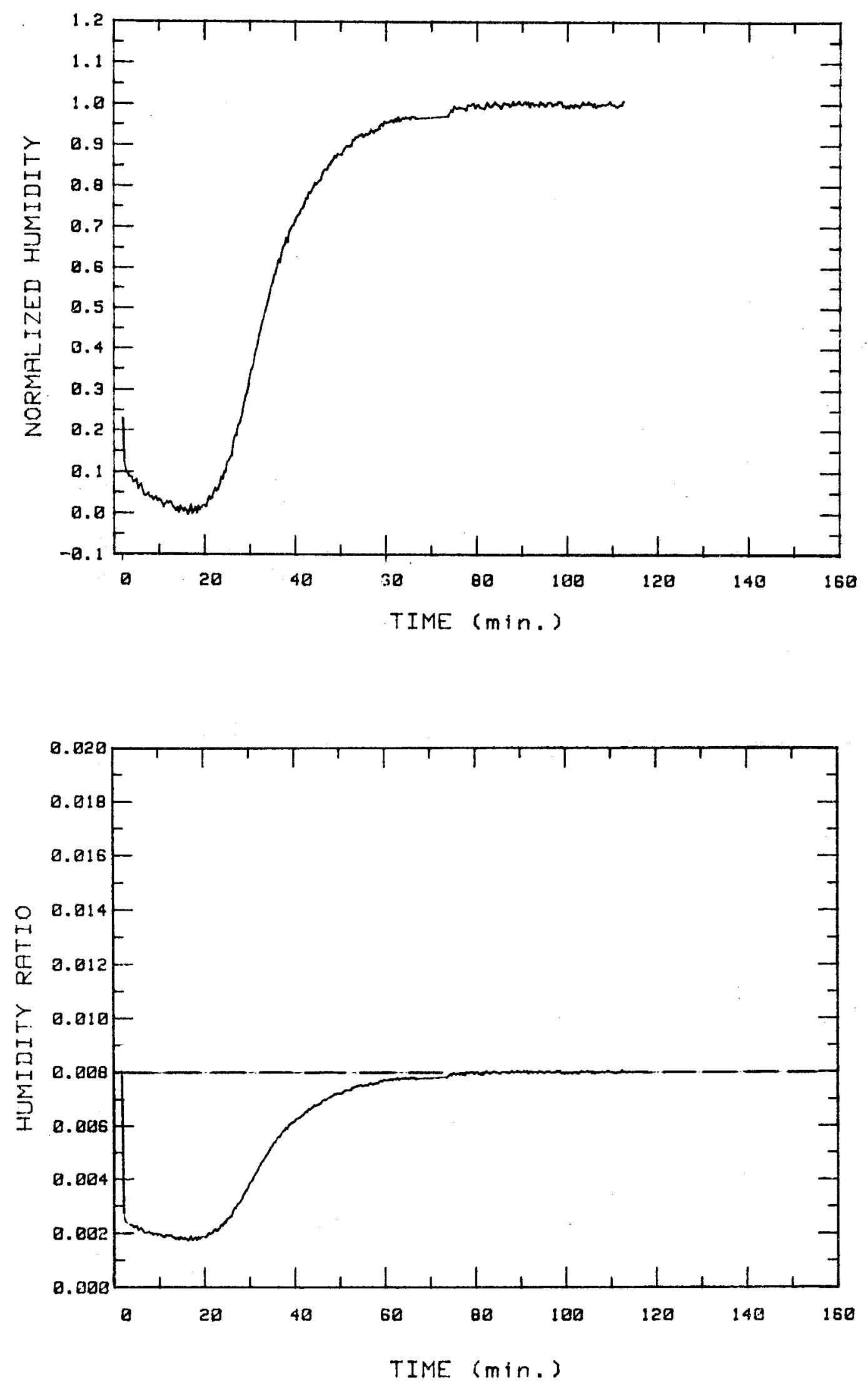


\section{EXPERIMENT \#43}
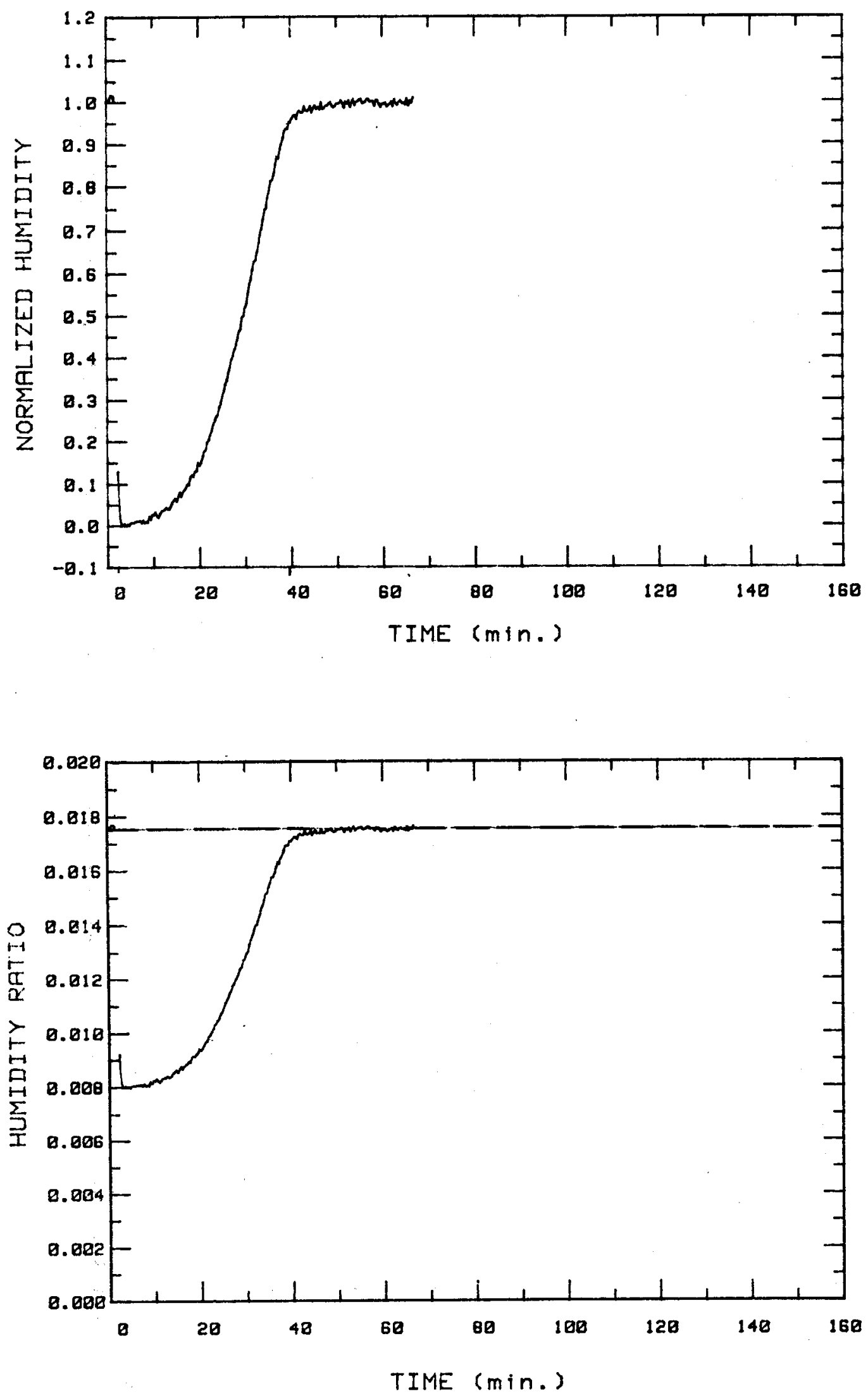


\section{EXPERIMENT \#44}
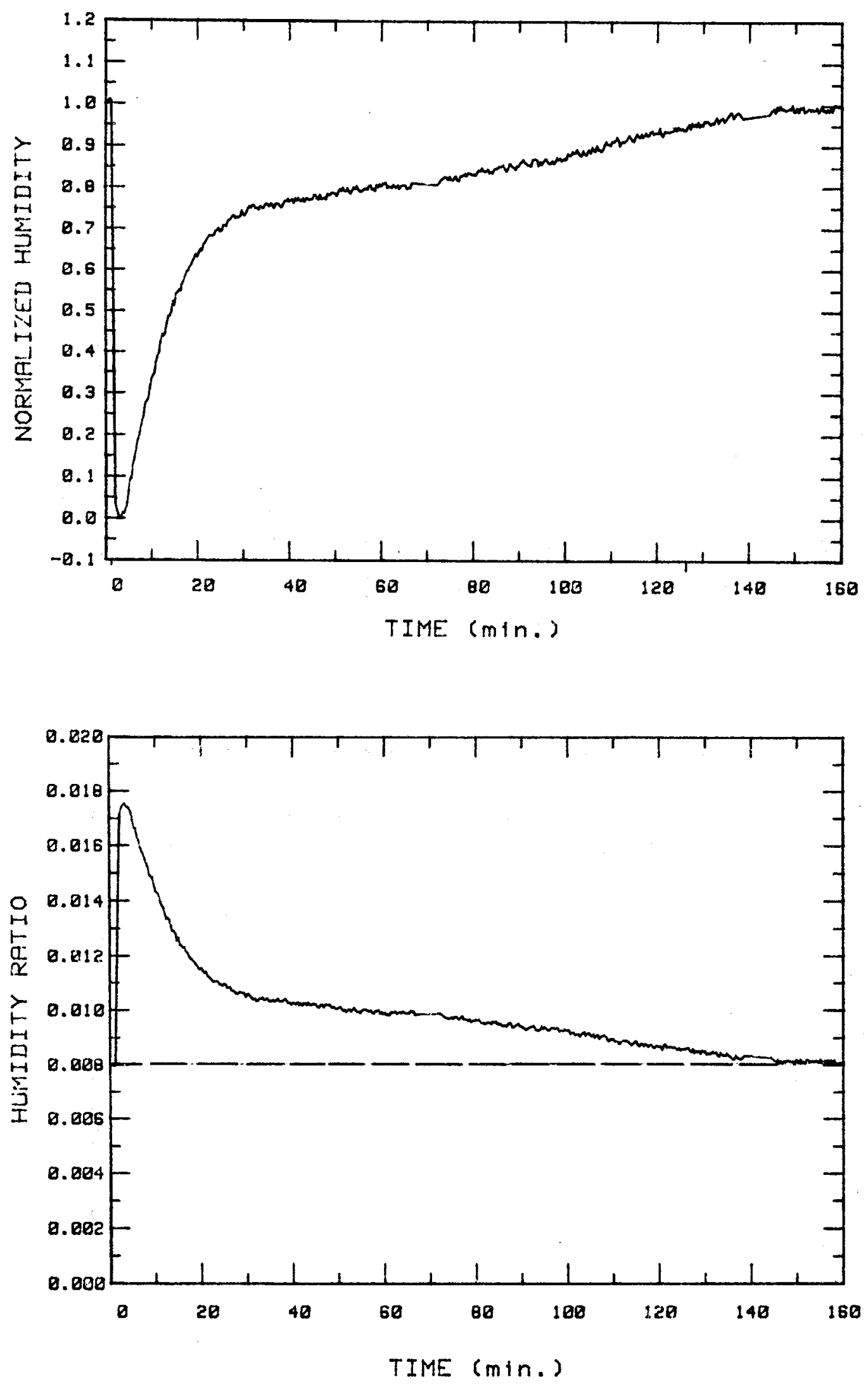
EXPERIMENT * 49
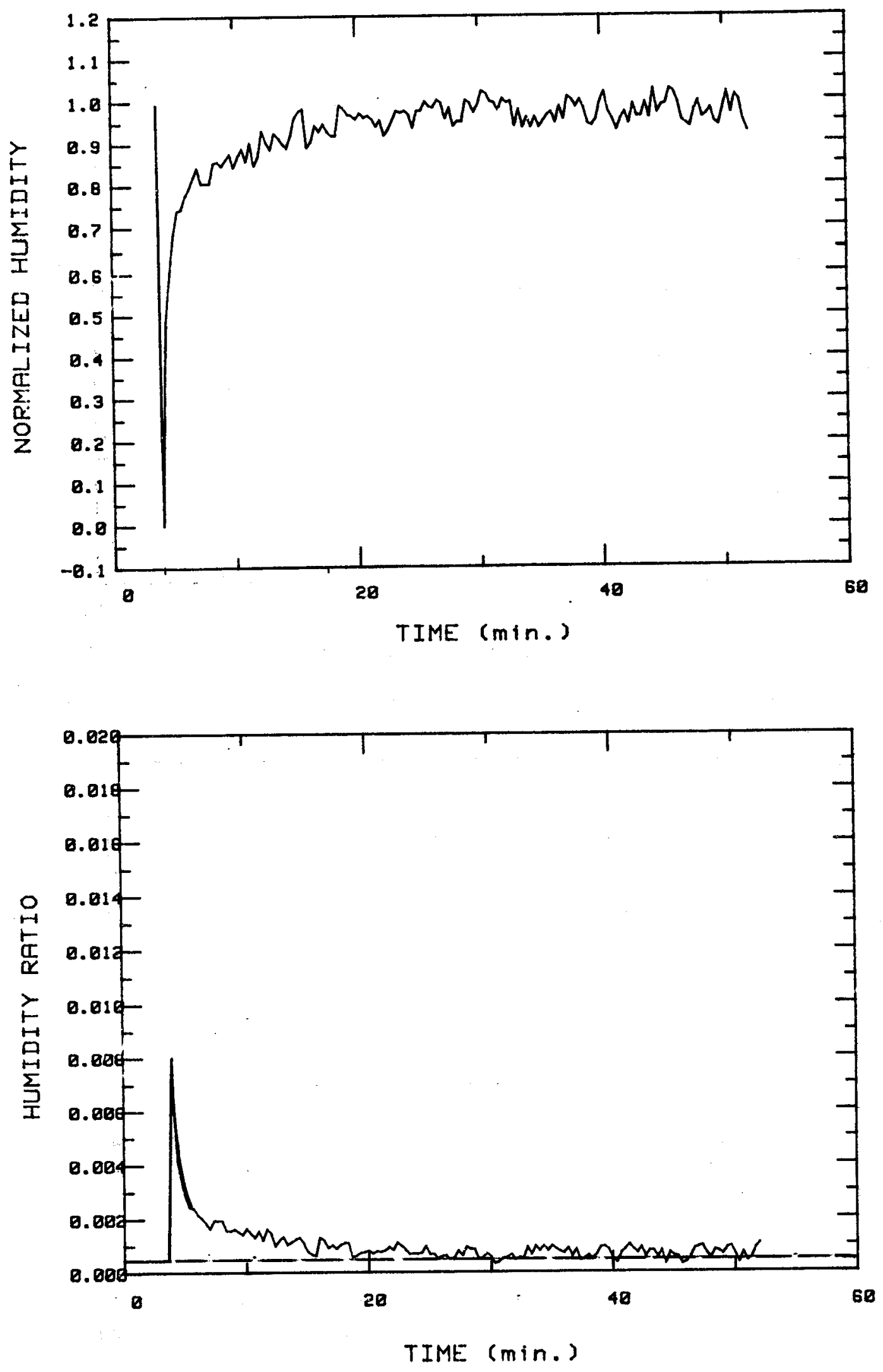
EXPERIMENT * 50
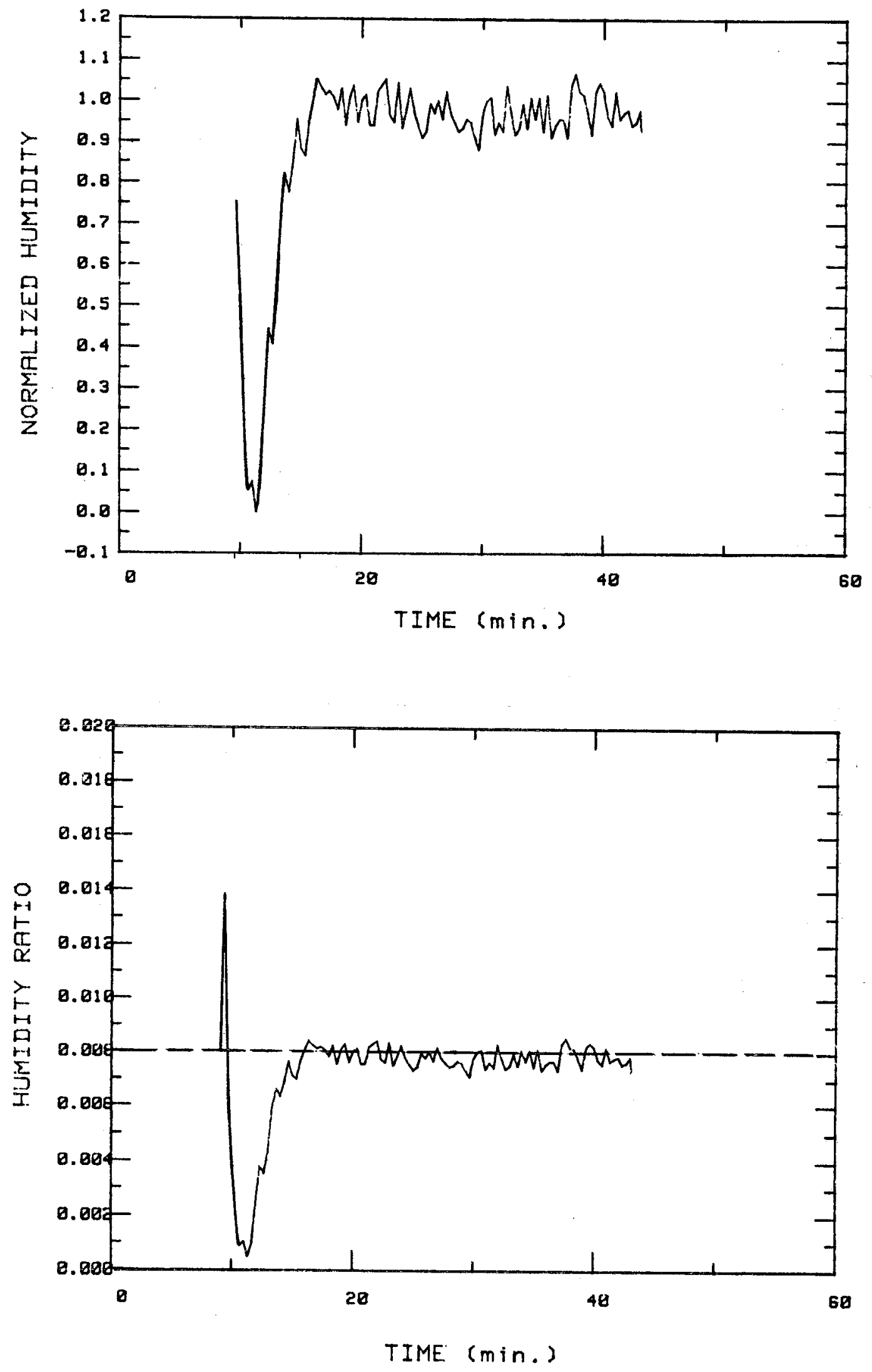
EXPERIMENT * 51
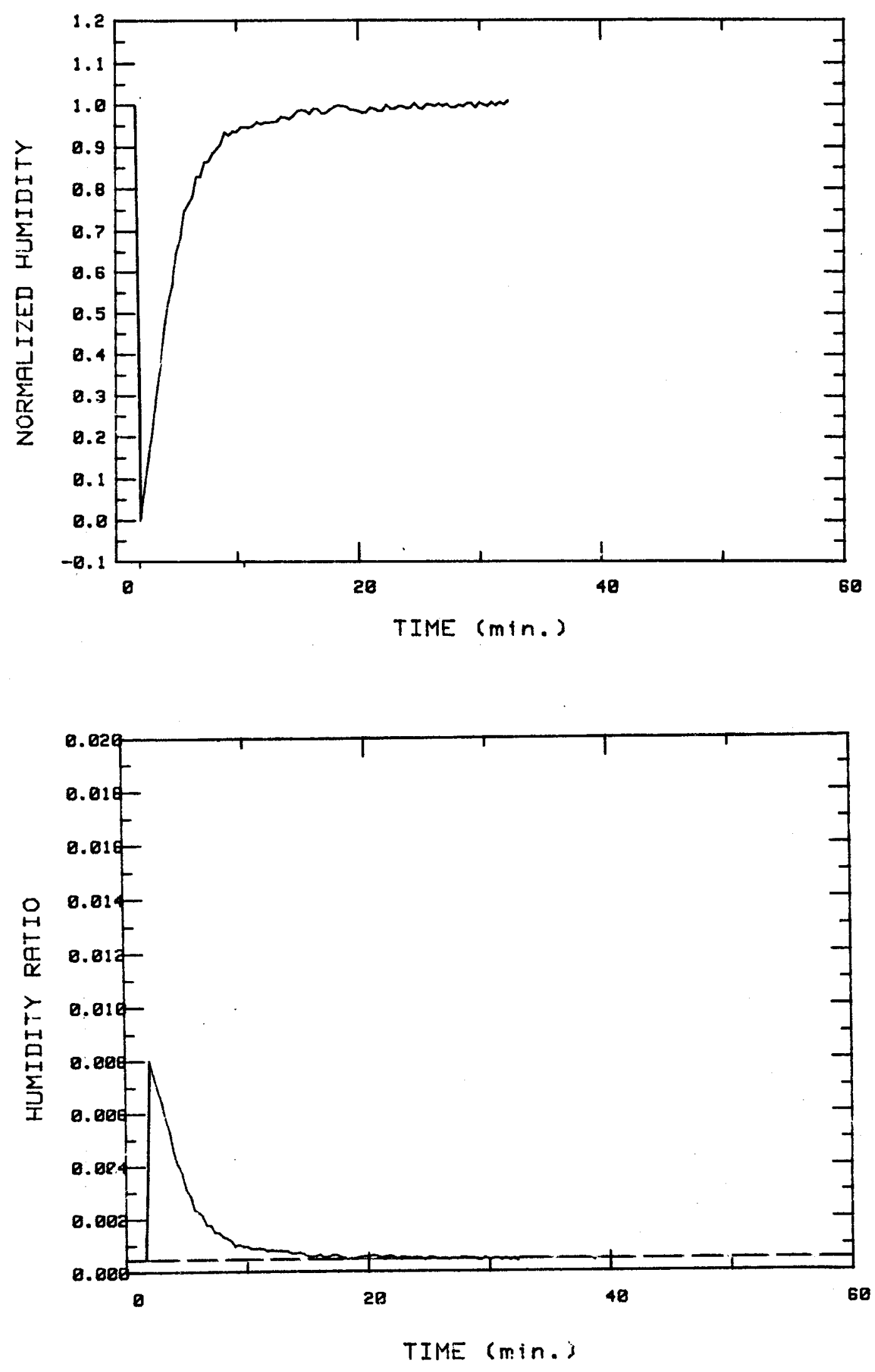
EXPERIMENT * 52
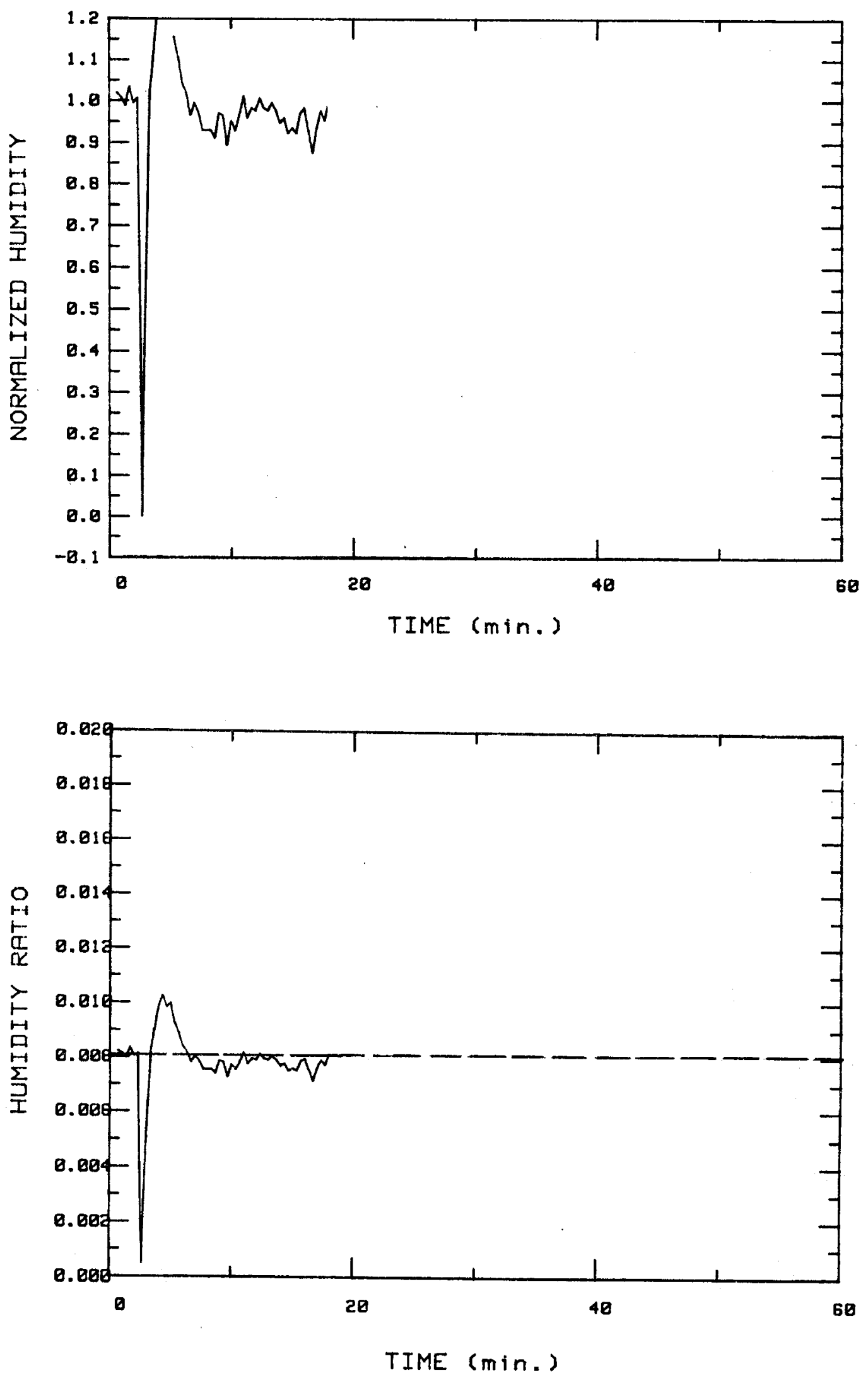


\section{EXPERIMENT * 53}
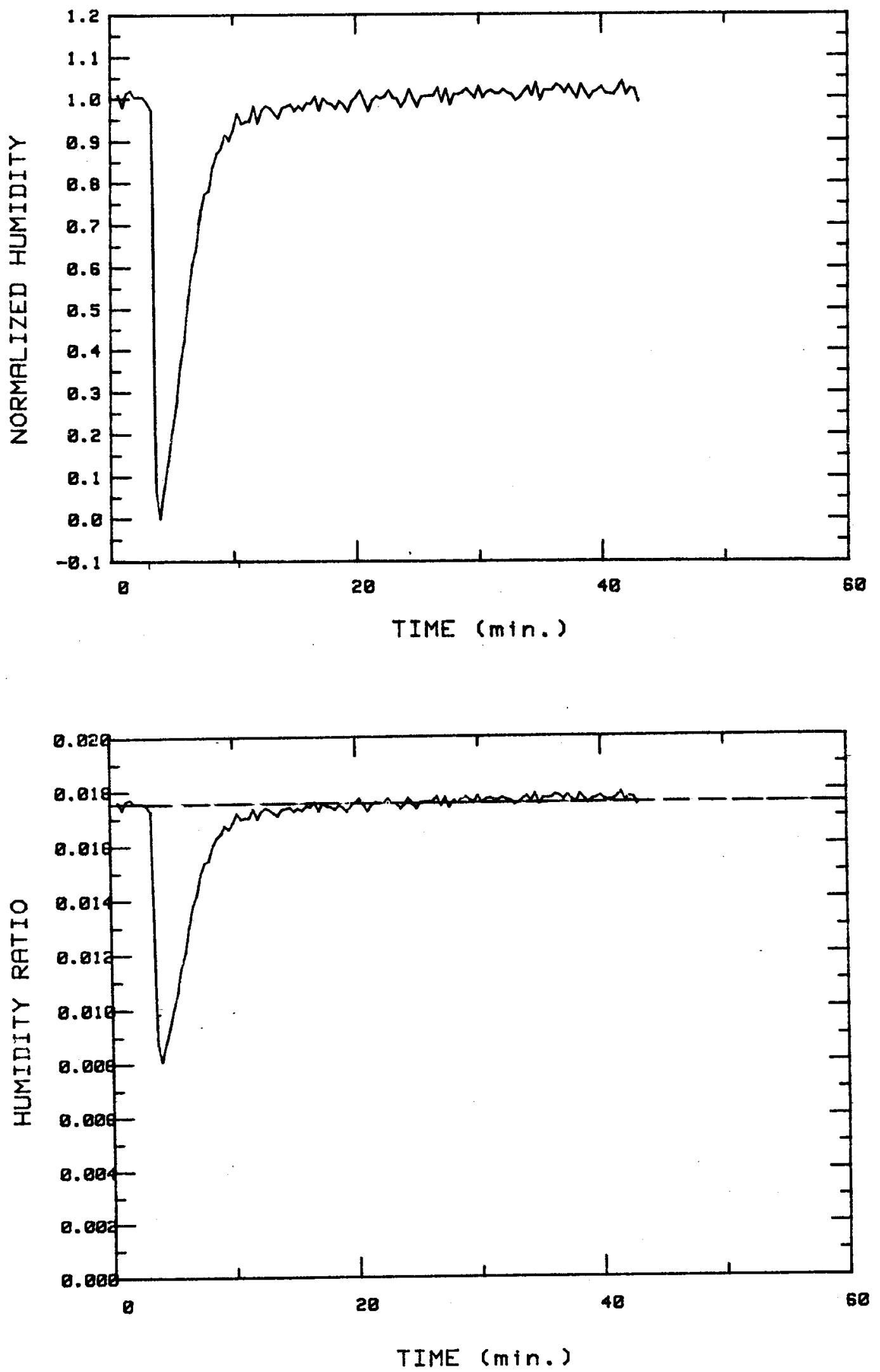

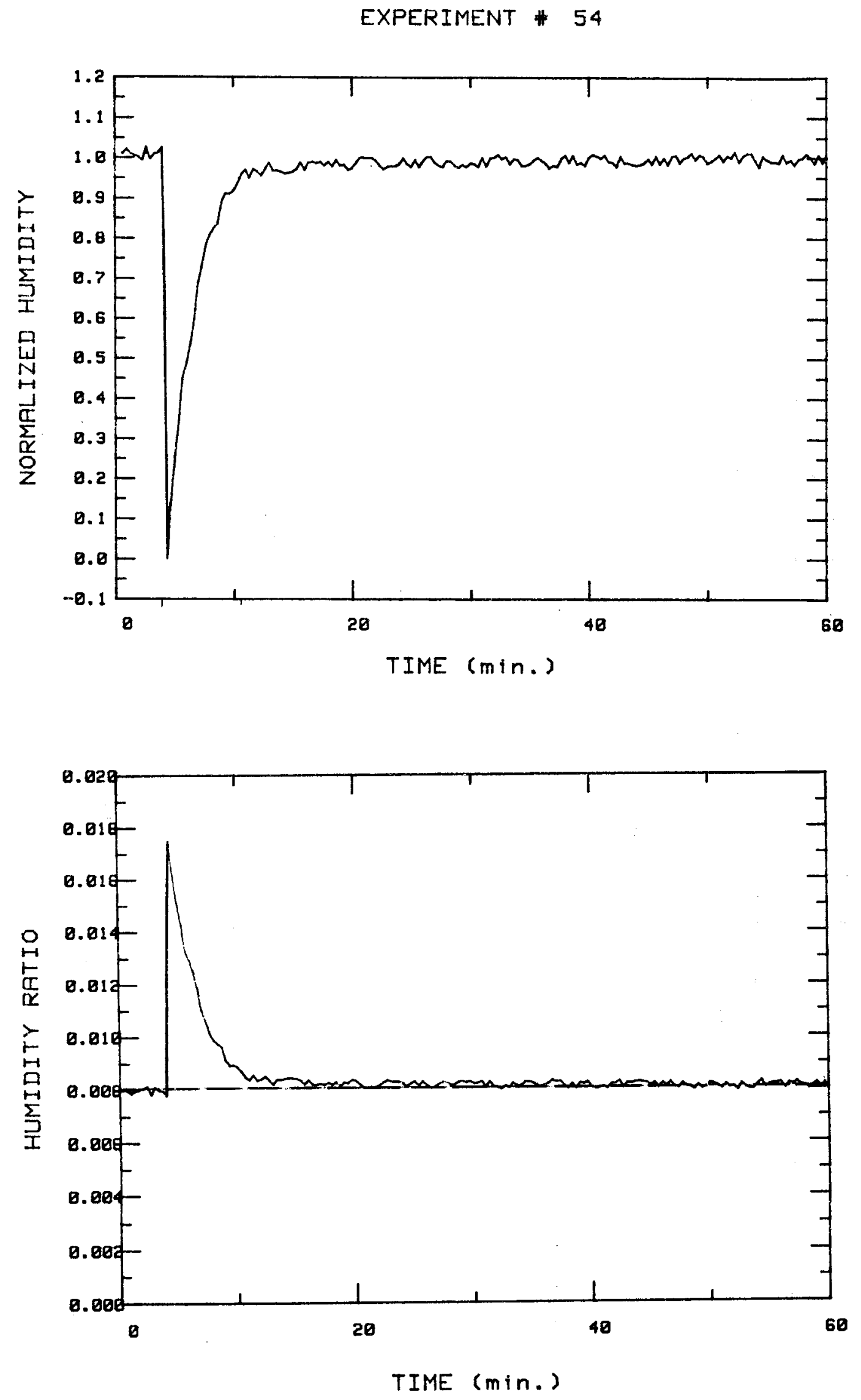

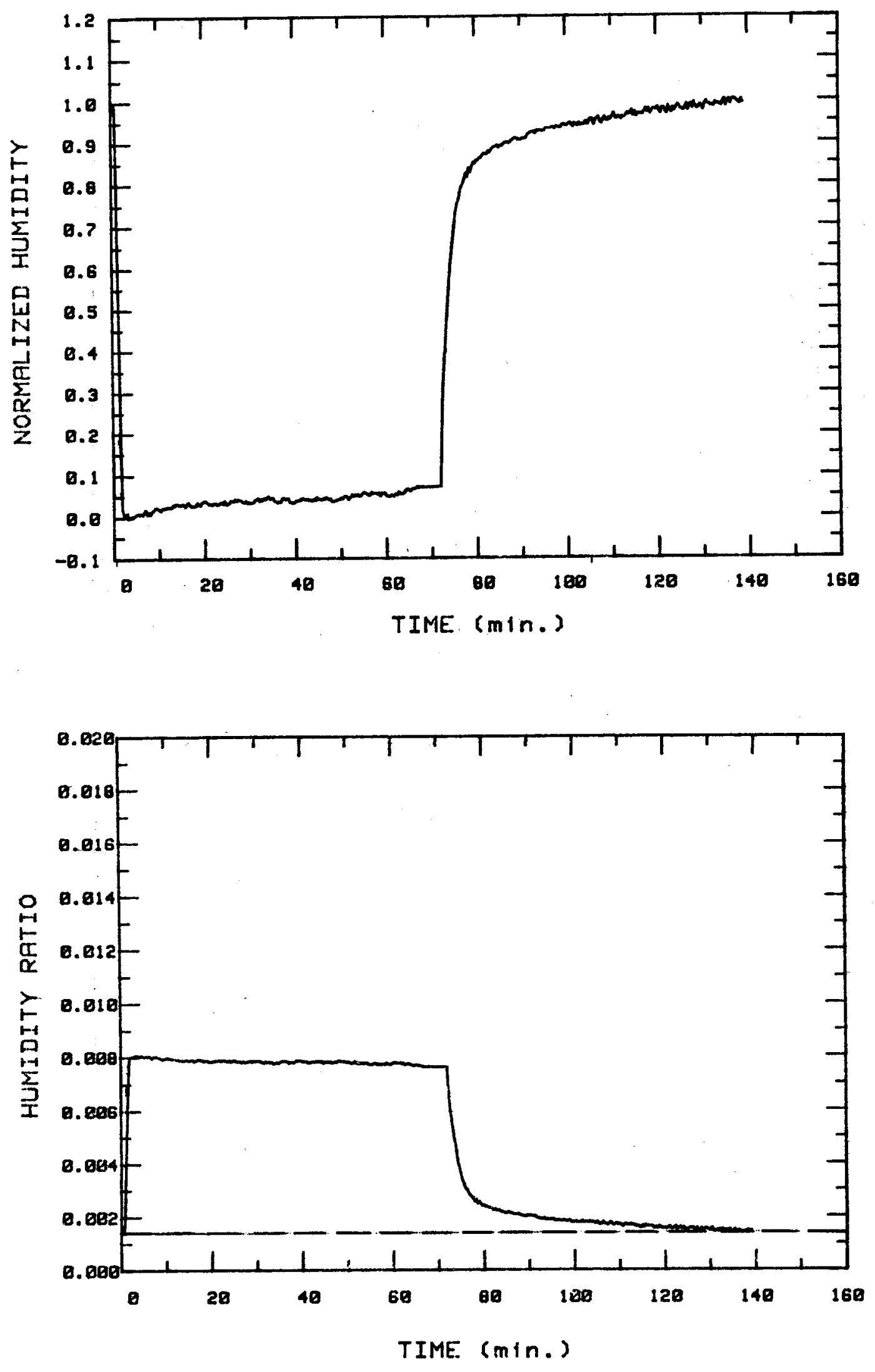


\section{EXPERIMENT * 56}
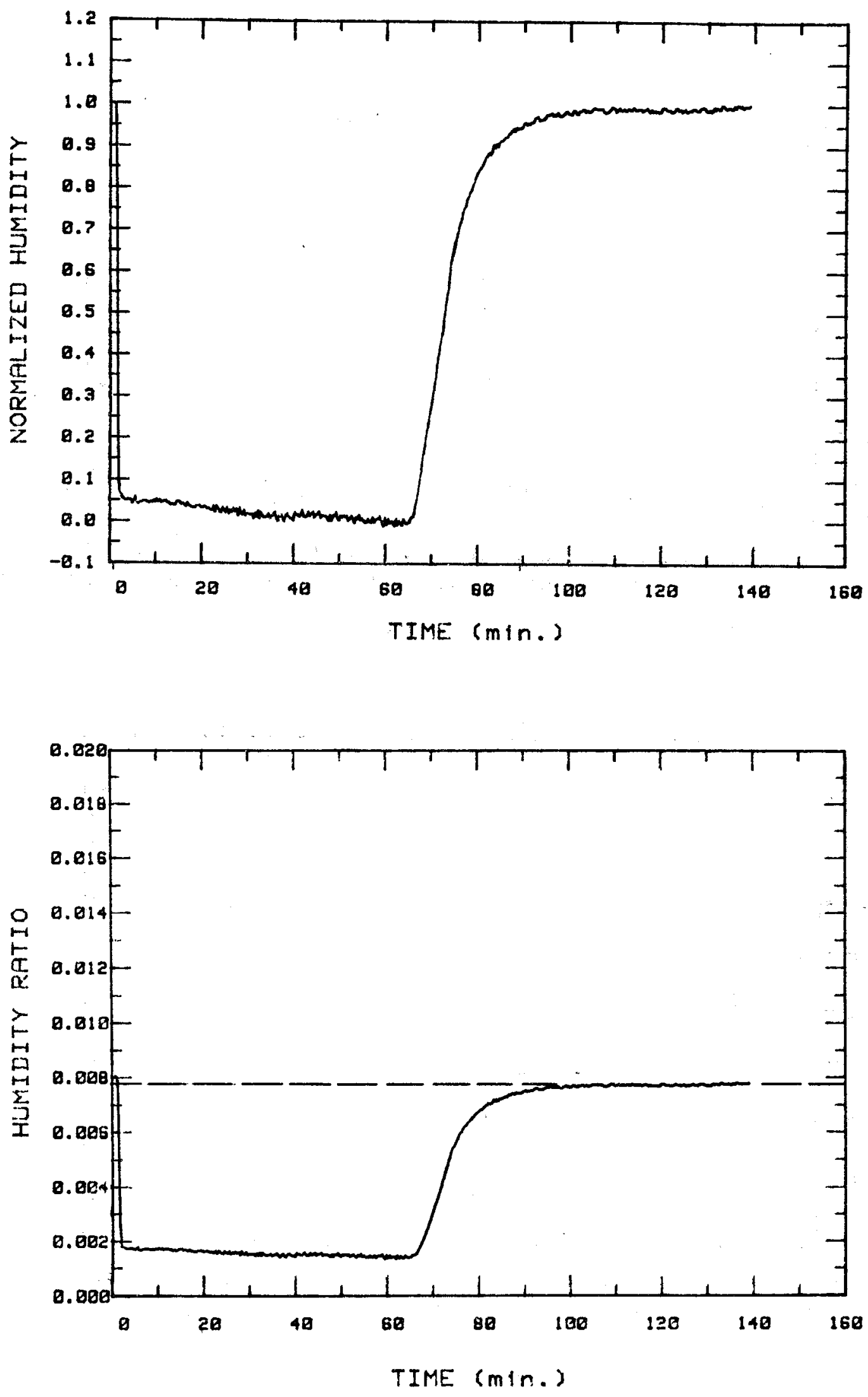


\section{EXPERIMENT * 57}
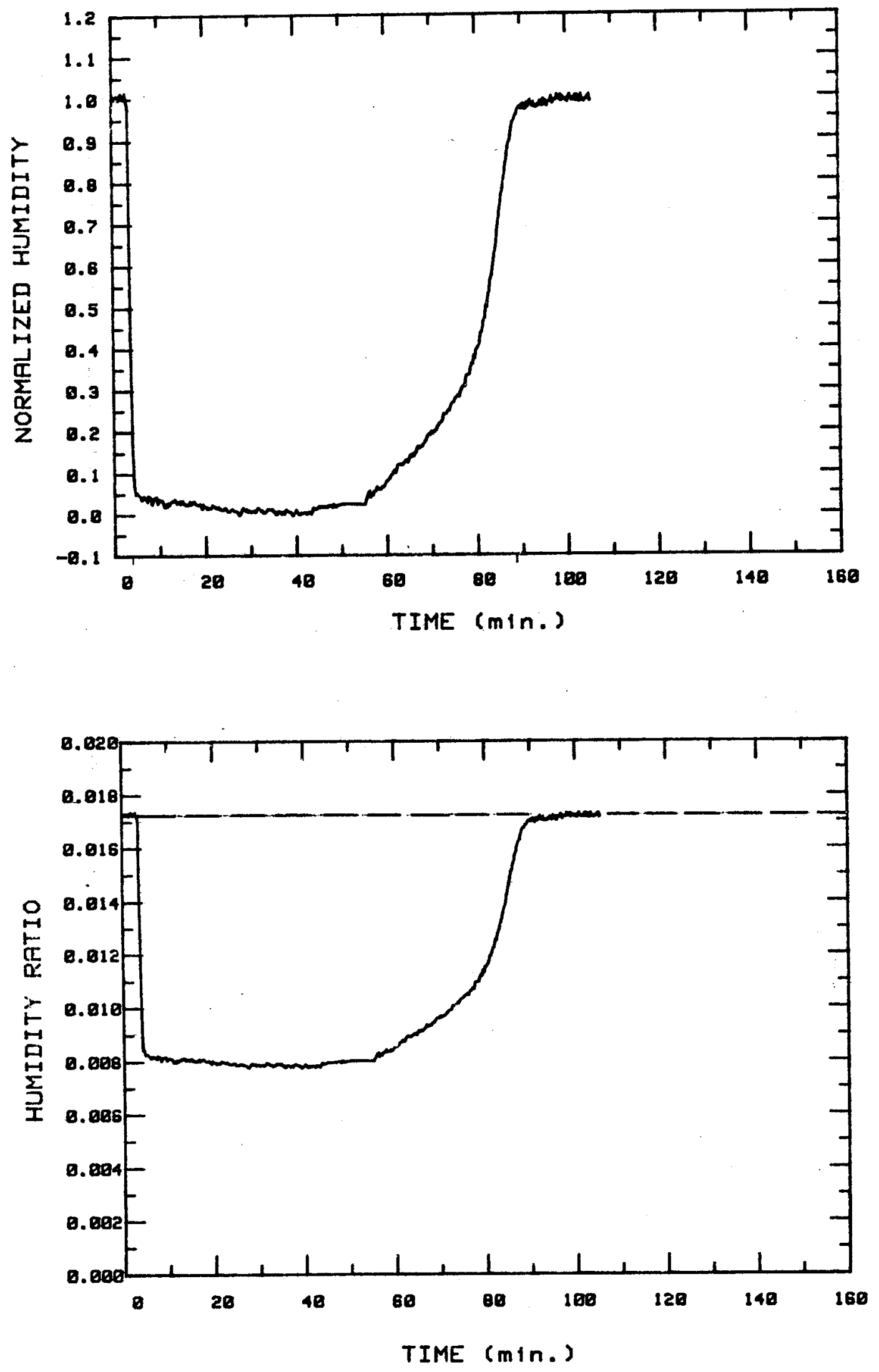

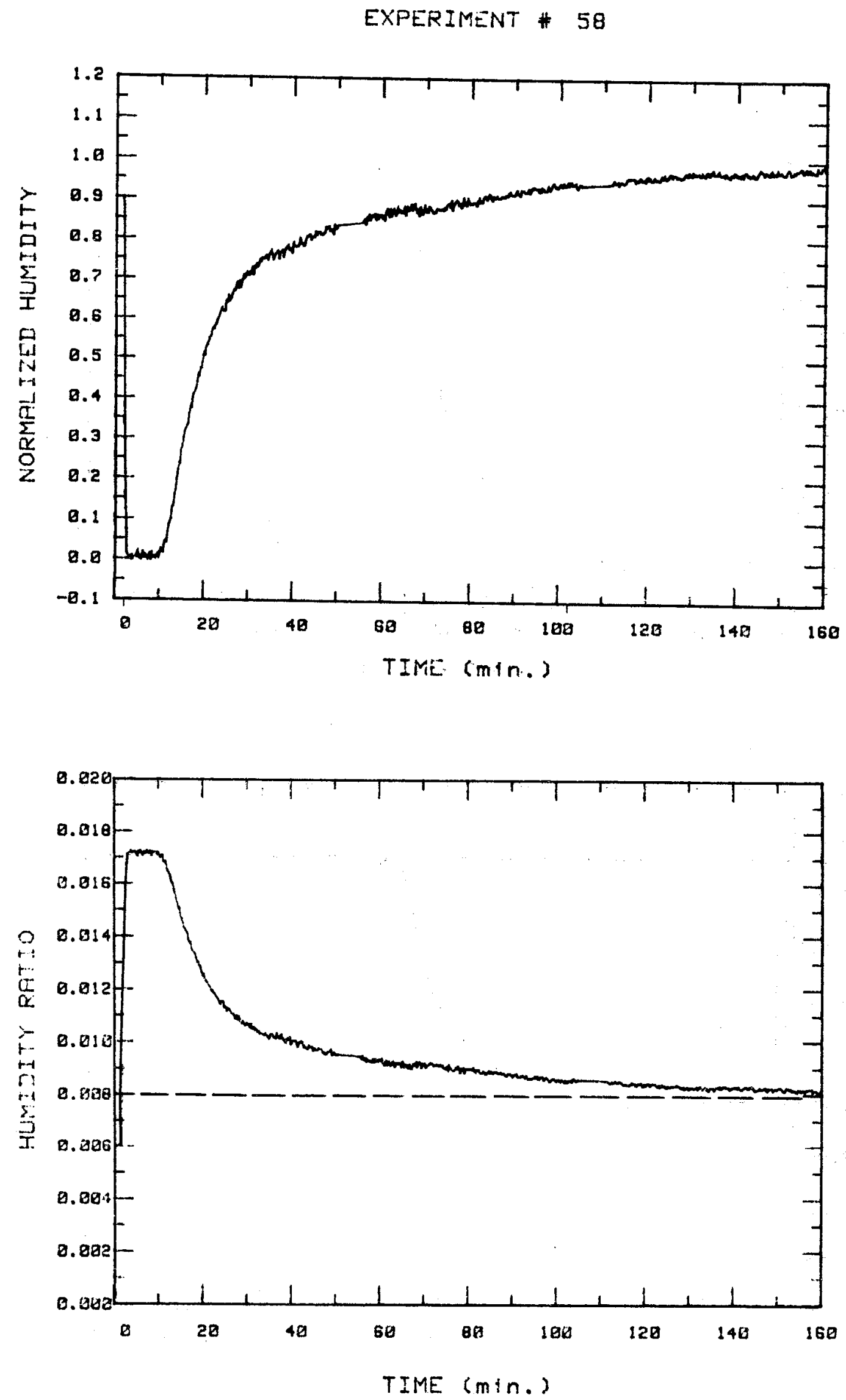
FXPERIMENT \# 59
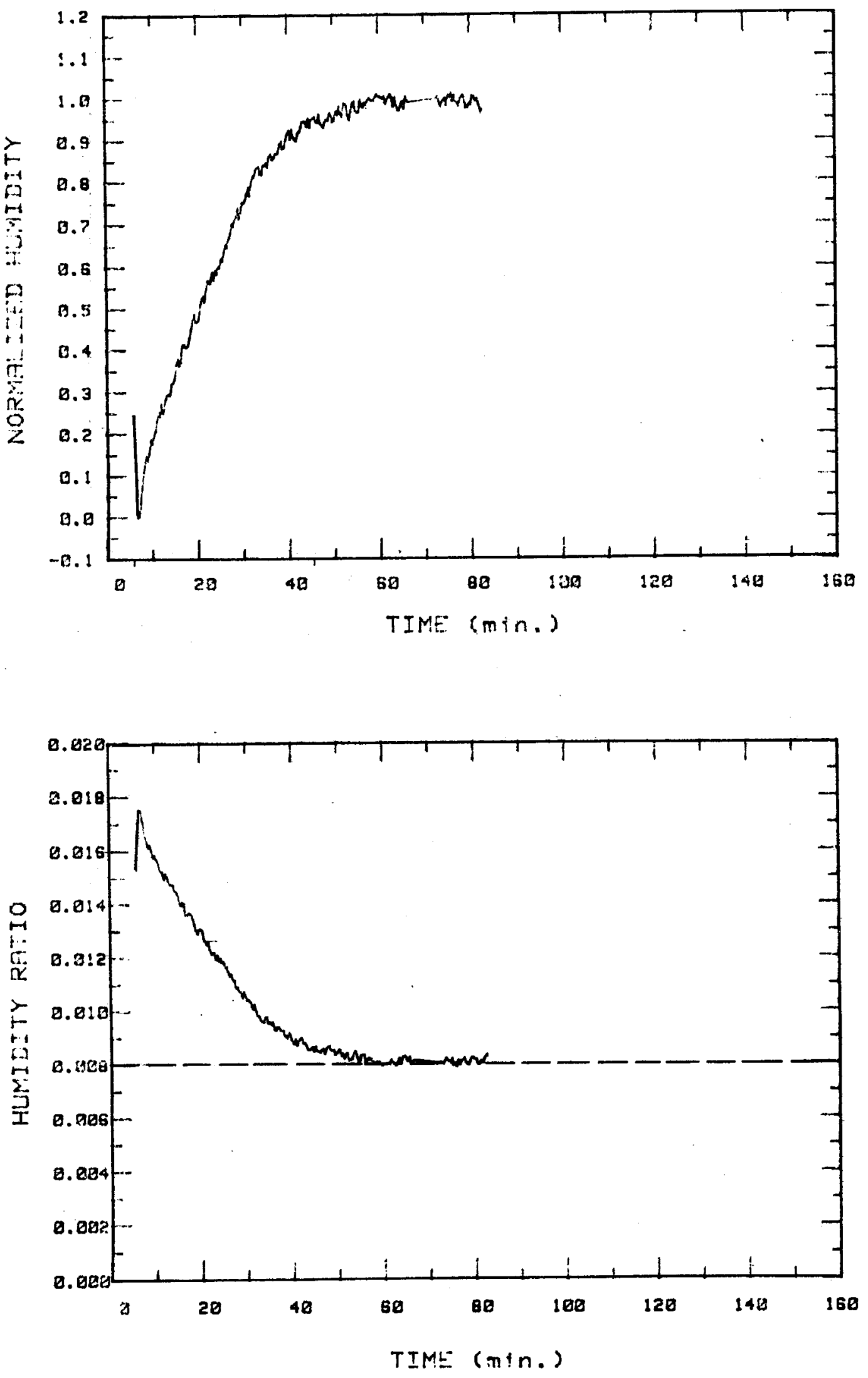

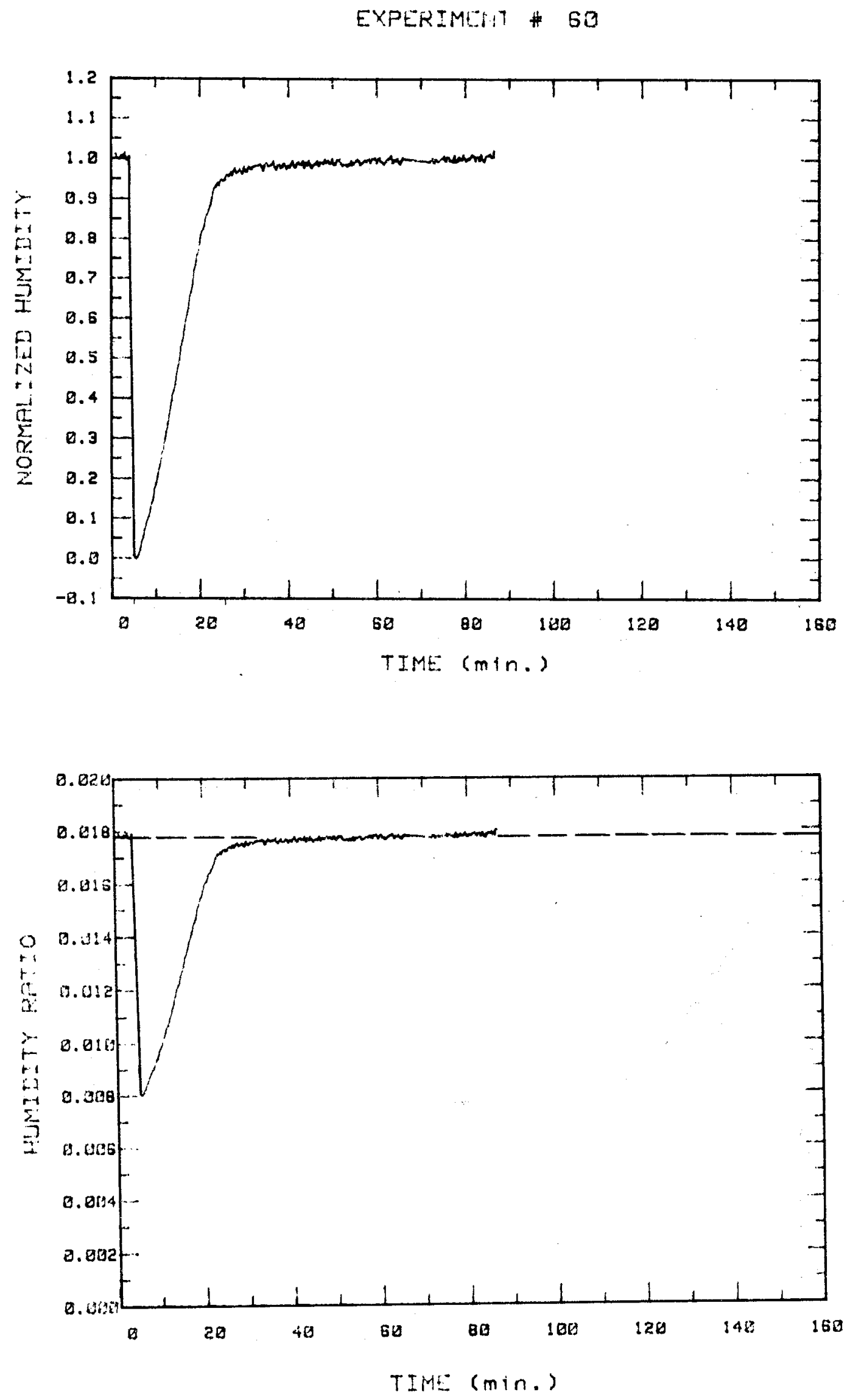

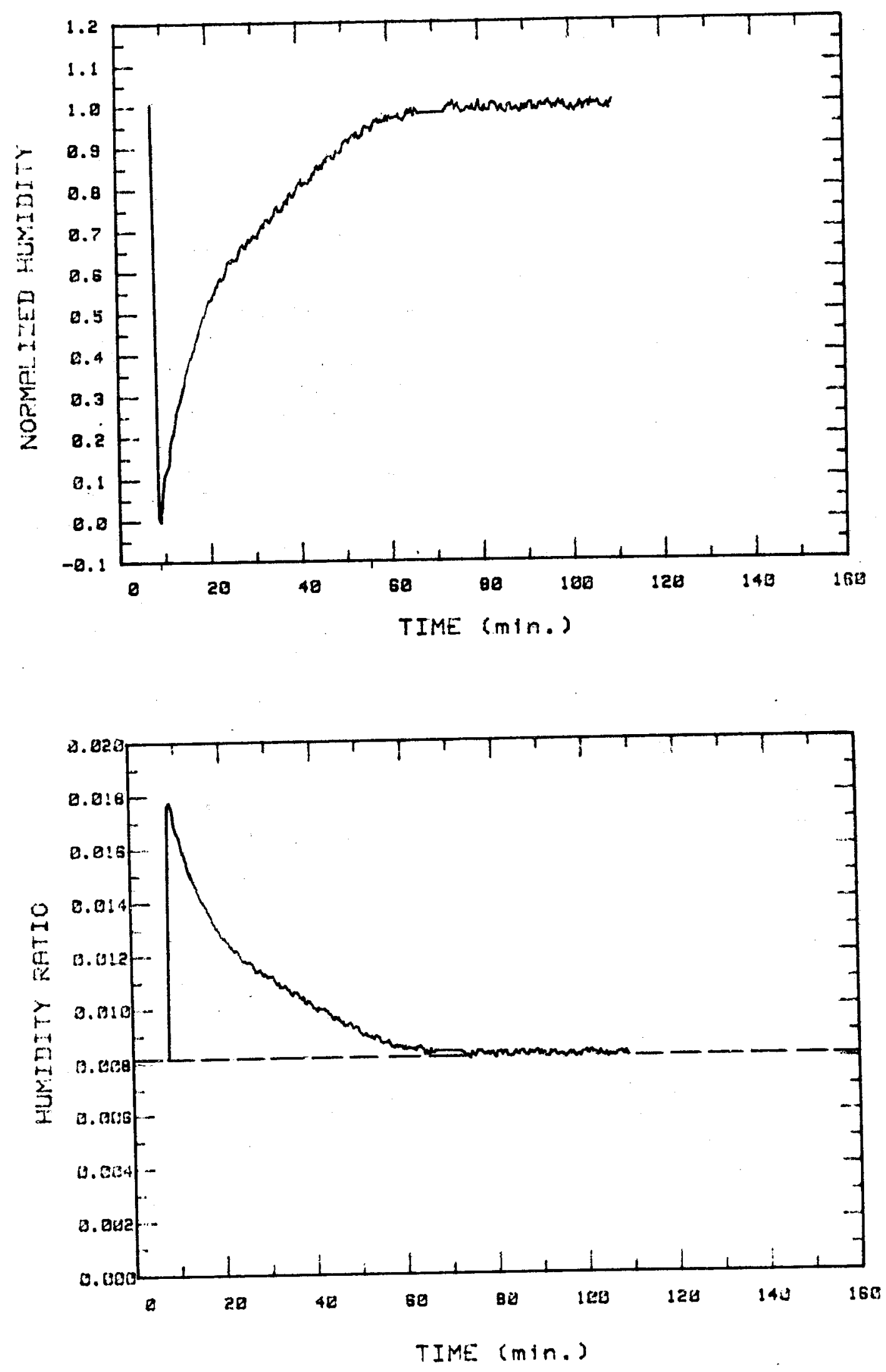


\section{DISTRIBUTION LIST}

Mr. Kirk Collier

Collier Engineering

Route 2, Box 240

Cave Creek, AZ 85331

Mr. Keith Davidson

Gas Research Institute

8600 West Bryn Mawr Avenue

Chicago, IL 60631

Mr. Robert Dikkers

National Bureau of Standards

Technology B-148

Washington, D.C. 20585

Mr. Anthony Fraioli

Argonne National Laboratory

9700 South Cass Avenue

Argonne, IL 60439

Mr. John Goldsmith

Route CE-311, Room 5H065

U.S. Department of Energy

1000 Independence Ave., S.W.

Washington, D.C. 20585

R. Harkins

ASES

2030 17th St.

Boulder, CO 80302

Ralph Johnson

NAHB Research Foundation, Inc.

3720 T St., N.W.

Washington, D.C. 20007

Robert Jones

Los Alamos National Lab

P.O. Box 1663

Mail Stop $\mathrm{H} 577$

Los Alamos, NM 87545

Dr. Susumi Karaki

Colorado State University

Fort Collins, Co 80523

K. LaForta

SEIA

1156 15th St., N.W., Suite 520

Washington, D.C. 20005
Mr. Zalman Lavan

Illinois Institute of Technology

Department of Mechanical Engineering

I11inois Institute of Technology

Center

Chicago, IL 60616

Bob LeChevalier

U.S. Department of Energy

San Francisco Operations office

1333 Broadway

Oakland, CA 94612

Mr. Ian Maclaine-Cross

University of New South Wales

School of Mechanical and Industrial

Engineering

P.0. Box 1

Kensington, NSW 2033 Australia

Dr. John Mitchell

University of Wisconsin-Madison

Engineering Research Building

1500 Johnson Drive

Madison, WI 53706

Mr. Jeff Morehouse

Science Applications, Inc.

8400 Westpark Drive

McLean, VA 22101

Dr. Frederick Morse

U.S. Department of Energy

Route CE-31, Room 5H-095

1000 Independence Ave., S.W.

Washington, D.C. 20585

Mr. John Schuler

Route CE-311, Room 5H065

U.S. Department of Energy

1000 Independence Ave., S.W.

Washington, D.C. 20585

Bi11 Seaton

ASHRAE

1791 Tullie Circle, NE

Atlanta, GA 30329 
Dr. William Shertz

Argonne National Laboratory

9700 South Cass Avenue

Argonne, IL 60439

Mr. Morris Skalka

Route CE-311, Room 5H065

U.S. Department of Energy

1000 Independence Ave., S.W.

Washington, D.C. 20585

Dr. M. Wahlig

Lawrence Berkeley Laboratories

University of California

Berkeley, CA 94720

Mr. Alex Willman

ACEC Resource and Management

Foundation

1015 15th Street, N.W.

Washington, D.C. 20005

M. Yarosh

Florida Solar Energy Center

300 State Road, 401

Cape Canaveral, FL 32920 


\begin{tabular}{|c|c|c|c|}
\hline $\begin{array}{l}\text { Document Control } \\
\text { Page }\end{array}$ & $\begin{array}{l}\text { 1. SERI Report No. } \\
\text { SERI/TR-252-2382 }\end{array}$ & 2. NTIS Accession No. & 3. Recipient's Accession No. \\
\hline \multirow{2}{*}{\multicolumn{3}{|c|}{$\begin{array}{l}\text { 4. Title and Subtitle } \\
\text { Experiments on Sorption Hysteresis of Desiccant } \\
\text { Materials }\end{array}$}} & $\begin{array}{l}\text { 5. Publication Date } \\
\text { August } 1984\end{array}$ \\
\hline & & & 6. \\
\hline \multicolumn{3}{|c|}{$\begin{array}{l}\text { 7. Author(s) } \\
\text { A. Pesaran. F Zanarando }\end{array}$} & 8. Performing Organization Rept. No. \\
\hline \multicolumn{3}{|c|}{ 9. Performing Organization Name and Address } & 10. Project/Task/Work Unit No. \\
\hline \multicolumn{3}{|c|}{$\begin{array}{l}\text { Solar Energy Research Institute } \\
1617 \text { Cole Boulevard } \\
\text { Golden, Colorado } 80401\end{array}$} & $\begin{array}{l}\text { 11. Contract (C) or Grant (G) No. } \\
\text { (C) } \\
\text { (G) }\end{array}$ \\
\hline \multirow{2}{*}{\multicolumn{3}{|c|}{ 12. Sponsoring Organization Name and Address }} & $\begin{array}{l}\text { 13. Type of Report \& Period Covered } \\
\text { Technical Report }\end{array}$ \\
\hline & & & 14. \\
\hline \multicolumn{4}{|l|}{ 15. Supplementary Notes } \\
\hline \multicolumn{4}{|c|}{$\begin{array}{l}\text { 16. Abstract (Limit: 200 words) Solid desiccant cooling systems take advantage of solar energy } \\
\text { for air conditioning. The process involves passing air through a desiccant bed for } \\
\text { drying and subsequent evaporative cooling to provide the air conditioning. The } \\
\text { desiccant is then regenerated with hot air provided by a gas burner or solar col- } \\
\text { lectors. This performance is limited by the capacity of the desiccant, its sorption } \\
\text { properties, and the long-term stability of the desiccant material under cyclic } \\
\text { operation conditions. Therefore, we have developed a versatile test facility to } \\
\text { measure the sorption properties of candidate solid desiccant materials under dynamid } \\
\text { conditions, under different geometrical configurations, and under a broad range of } \\
\text { process air stream conditions, characteristic of desiccant dehumidifier operation. } \\
\text { We identified a dependence of the sorption processes on air velocity and the test } \\
\text { cell aspect ratio and the dynamic hysteresis between adsorption and desorption pro- } \\
\text { cesses. These experiments were geared to provide data on the dynamic performance } \\
\text { of silica gel in a parallel-passage configuration to prepare for tests with a } \\
\text { rotary dehumidifier that will be conducted at SERI in late Fy 1984. We also recom- } \\
\text { mend improving the accuracy of the isotopic perturbatian technique. }\end{array}$} \\
\hline \multirow{2}{*}{\multicolumn{4}{|c|}{ ants ; Gas Chromatography ; Silica Gel ; }} \\
\hline & & & \\
\hline \multicolumn{4}{|l|}{ c. UC Categories } \\
\hline \multicolumn{4}{|l|}{59} \\
\hline \multirow{2}{*}{\multicolumn{3}{|c|}{$\begin{array}{l}\text { 18. Availability Statement } \\
\text { National Technical Information Service } \\
\text { U.S. Department of Commerce } \\
5285 \text { Port Royal Road } \\
\text { Springfield, Virginia } 22161\end{array}$}} & $\begin{array}{c}\text { 19. No. of Pages } \\
130\end{array}$ \\
\hline & & & $\begin{array}{l}\text { 20. Price } \\
\text { A07 }\end{array}$ \\
\hline
\end{tabular}

